\title{
Diverse Policy Committees Can Reach Underrepresented Groups
}

Francesco D'Acunto | Andreas Fuster | Michael Weber 
WORKING PAPER · NO. 2021-95

\section{Diverse Policy Committees Can Reach Underrepresented Groups}

Francesco D'Acunto, Andreas Fuster, and Michael Weber

AUGUST 2021 


\title{
Diverse Policy Committees Can Reach Underrepresented Groups*
}

\author{
Francesco D’Acunto ${ }^{\dagger}$ Andreas Fuster; and Michael Weber ${ }^{\S}$
}

This version: August 2021

\begin{abstract}
Increasing the diversity of policy committees has taken center stage worldwide, but whether and why diverse committees are more effective is still unclear. In a randomized control trial that varies the salience of female and minority representation on the Federal Reserve's monetary policy committee, the FOMC, we test whether diversity affects how Fed information influences consumers' subjective beliefs. Women and Black respondents form unemployment expectations more in line with FOMC forecasts and trust the Fed more after this intervention. Women are also more likely to acquire Fed-related information when associated with a female official. White men, who are overrepresented on the FOMC, do not react negatively. Heterogeneous taste for diversity can explain these patterns better than homophily. Our results suggest more diverse policy committees are better able to reach underrepresented groups without inducing negative reactions by others, thereby enhancing the effectiveness of policy communication and public trust in the institution.
\end{abstract}

${ }^{*}$ We thank Carola Binder, Lisa Cook, Michael Ehrmann, Luigi Guiso, Anne Hannusch, Andrei Shleifer, Stefanie Stantcheva, Jeremy Stein, and seminar and conference participants at the University of Chicago, University of Mannheim, the Center for the Foundations of Law and Finance at Goethe-Universität Frankfurt, Toulouse School of Economics, Bank of Italy, the Monetary Meeting of the Verein für Socialpolitik, Econometric Society Winter Meetings, the Federal Reserve Bank of Cleveland, the Bundesbank International Conference on Household Finance, JILAEE seminar, the Ifo Conference on Macro and Survey Data, the Bank of Ukraine Research Conference, the CEBI Workshop on Subjective Beliefs in Macroeconomics and Household Finance, and the MiSoC Workshop on Subjective Expectations. Weber gratefully acknowledges financial support from the Fama Research Fund at the University of Chicago Booth School of Business and the Fama-Miller Center.

${ }^{\dagger}$ Carroll School of Management, Boston College, Chestnut Hill, MA, USA. Email: dacuntof@bc.edu

${ }^{\ddagger}$ Swiss Finance Institute @ EPFL, Lausanne, Switzerland, and CEPR. Email: andreas.fuster@epfl.ch.

$\S$ Booth School of Business, University of Chicago, Chicago, IL, USA, CEPR, and NBER. Email: michael.weber@chicagobooth.edu. 
"We should mirror the society we serve."

ECB President Christine Lagarde, 2020.

"[D]iversity is a hallmark of successful organizations because diverse organizations draw from a richer pool of experience and reflect more points of view - they often make better decisions. Diverse organizations are also better able to relate to and talk to many different communities."

Federal Reserve Chair Jerome Powell, 2018.

\section{Introduction}

Over the last few years, the lack of demographic diversity in the composition of important policy committees such as the Federal Open Market Committee (FOMC) at the US Federal Reserve or the European Central Bank's Governing Council has climbed to the top of the agenda of policymakers and public debates around the world. Advocates of higher diversity argue unequal representation of different groups (e.g., based on race or gender) is a form of discrimination and may undermine equity and fairness in the policy process. Advocates also argue more diverse committees reflect more viewpoints and experiences, which may lead to better decisions. ${ }^{1}$

Whereas ethical motives are important, they are hard to quantify. Economists can instead test empirically for the channels through which higher diversity might increase the effectiveness of policymaking bodies. For instance, when a primary channel of monetary policy transmission is the management of households' expectations (Coibion et al., 2020b; D'Acunto et al., 2021b), diverse committees might be better able to relate to and be trusted by more communities and hence be able to influence their expectations.

Testing this hypothesis faces two major challenges. First, the composition of existing committees such as the FOMC cannot be modified at random. Second, if we compared consumers' reactions across times in which committee diversity varied, we could not disentangle the effect of changing diversity from other time-varying shocks that led the committee and consumers to behave differently.

\footnotetext{
${ }^{1}$ For a discussion of these points, see, for example, the Center for American Progress article, "We Need to Increase Diversity in Policymaking," available here, or the discussion in the New York Times on "Jerome Powell advocates greater diversity at the Federal Reserve," available here.
} 
To overcome these hurdles, we build on a large body of research in social psychology and cultural economics and design an information-treatment randomized control trial (RCT) on a representative survey population of more than 9,000 US consumers (see Haaland, Roth, and Wohlfart, 2021, for an overview of information-treatment experiments in economics). In our RCT, subjects read the FOMC's medium-term macroeoconomic forecasts for unemployment or inflation, but face contexts in which the salience of the FOMC's demographic diversity varies randomly. We create this variation by including with the FOMC forecasts one of three pictures of same-rank FOMC members at random: Thomas Barkin (White man), Raphael Bostic (Black man), and Mary Daly (White woman). ${ }^{2}$ In a separate survey, we verify the effectiveness of this experimental intervention, in that exposure to the Black or female committee member induces subjects of all demographics, on average, to perceive a higher presence of these traditionally underrepresented groups on the FOMC.

Our main test compares the subjective macroeconomic expectations of consumers who belong to the same demographic group and see the same forecast but for whom FOMC diversity salience varies. We also elicit trust in the Federal Reserve and proxies for the attention subjects pay to the survey information to test for possible economic channels driving our results.

We approach this RCT with a pre-registered two-sided hypothesis, and our findings, whatever their sign, should be assessed against the ethical value of more equal representation. If higher committee diversity led female and non-White respondents - the groups that have been underrepresented on the FOMC and most other policy committees - to update their beliefs more in line with those of policymakers, our results would provide an economic argument for increasing committee diversity above and beyond the ethical debate, which is based on non-quantifiable and possibly incompatible views of the world. If, instead, diversity awareness did not help influence underrepresented groups' beliefs and affected overrepresented groups negatively, our paper would help quantify potential costs of reducing unequal

\footnotetext{
${ }^{2}$ All three are presidents of regional Federal Reserve Banks and were non-voting members at the June 2020 FOMC meeting, from which we draw the forecasts. Non-voting (or alternate) FOMC members participate in discussions and also contribute their forecasts to the Survey of Economic Projections, which is the information source we present to subjects. As we discuss in more detail below, our design also includes a control group that did not receive any macroeconomic forecasts and did not see the pictures of any FOMC members.
} 
representation in policy committees.

We find consumers belonging to underrepresented groups who are randomly exposed to a female or Black FOMC member on average form macroeconomic expectations, especially on unemployment, closer to the FOMC forecasts. For example, 52\%-56\% of our White female subjects form expectations within the range of the FOMC's unemployment forecasts if the presence of a White woman or a Black man on the FOMC are salient, relative to $48 \%$ if the presence of a White man is salient, and $32 \%$ when they do not receive any forecast. Effects are even stronger for Black women. For Black men, effects are smaller but indicate a stronger reaction when Raphael Bostic's presence on the FOMC is salient. The expectations of Hispanic respondents - who are not represented on the FOMC - and White men do not respond differentially to the three committee members. ${ }^{3}$ White men's non-reaction implies increasing diversity representation does not move the expectations of the overrepresented group away from the FOMC forecast.

For inflation expectations, the FOMC inflation forecasts affect all subjects' beliefs, and the differential effects based on exposure to diversity are weaker. Our analysis cannot disentangle if this homogeneous reaction is due to a lack of statistical power or to differences in the ways subjects relate the concepts of unemployment and inflation to diversity. For instance, if underrepresented consumers thought unemployment rates vary more than inflation across demographic groups, knowing underrepresented points of view contributed to form FOMC unemployment forecasts might increase their credibility, whereas the inflation forecasts would be deemed credible even if a committee of White men produced them. ${ }^{4}$

In the second part of the paper, we assess a set of non-mutually-exclusive channels through which higher FOMC diversity salience affects subjective beliefs. We start with trust in the FOMC, because earlier literature emphasized the role of consumers' trust in central

\footnotetext{
${ }^{3}$ As explained later, our survey sample included roughly 50\% non-Hispanic White, $30 \%$ Black, and $20 \%$ Hispanic respondents, with equal male/female shares. To maximize statistical power, we did not include other groups (e.g., Asian-Americans).

${ }^{4}$ Ample evidence exists for differential labor-force attachment across demographic groups; see, for instance, Bergman et al. (2020). Instead, whereas realized inflation at the household level also varies substantially in the cross section (Kaplan and Schulhofer-Wohl, 2017), little evidence exists on a systematic relationship between observables and realized inflation. For example, Argente and Lee (2021) find only a weak unconditional relationship between realized inflation and income at the household level, with differences in realized inflation between high- and low-income households of 0.02 percentage points, on average, between 2014-2016.
} 
banks when forming and updating their subjective expectations (e.g., Ehrmann et al., 2013; Christelis et al., 2020). Policymakers also stress the importance of agents' trust in the central bank for an effective transmission of monetary policy (e.g., Schnabel, 2020), and public trust is a necessary condition for central banks' independence. We asked subjects to report their trust (on a 7-point Likert scale) in the Fed's ability to adequately manage inflation and unemployment, and their trust that the Fed acts in the interest of all Americans, including people like themselves. Both forms of trust correlate significantly with subjects' propensity to form expectations in line with the FOMC's forecasts. Furthermore, underrepresented subjects are substantially more distrustful of the Fed in the control treatment that did not receive any forecast and did not see the picture of any policymaker. By contrast, female and Black subjects become significantly less distrustful when the presence of Mary Daly or Raphael Bostic on the FOMC is salient. Again, no offsetting negative effect on the trust of White male subjects exists, so that overall trust in the Fed increases in these treatments.

We then assess whether diversity salience makes underrepresented groups pay more attention to Fed-related information. In our main experiment, underrepresented subjects did spend more time on the information screen and were more likely to state that the survey was interesting when they saw a diverse policymaker, but these effects are only marginally significant. To study endogenous information acquisition, we designed a second survey for which we were able to recontact about one third of the original subjects. Respondents chose between reading one of two articles featuring a statement about the US economy from a high-ranked policymaker, either from the Congressional Budget Office (CBO) or the Federal Reserve. Subjects were randomized into three groups. In the first group, the policymakers were not named (only their institutions were provided). In the second group, both (named) policymakers were men. The third group, instead, had the choice between the same CBO male and a Fed female policymaker. ${ }^{5}$ We find female subjects in the third group are significantly more likely to choose the article about the Fed than female subjects in the other two groups, whereas male subjects choose similarly across treatments. Higher policy committee diversity might thus increase underrepresented groups' willingness to acquire information

\footnotetext{
${ }^{5}$ The policymakers are Phillip Swagel (CBO), Richard Clarida (Fed official in group 2), and Michelle Bowman (Fed official in group 3). The policymakers were referred to as "Mr" or "Ms" so no ambiguity about their gender existed, but we did not show any pictures.
} 
provided by the committee members.

We finally investigate two potential underlying drivers of our results: homophily — whereby agents react more if a member of their same demographic group is on the FOMC - and "taste for diversity" - whereby all agents with such a taste react to the presence of any underrepresented group on the FOMC. Even though we do not completely dismiss either driver, taste for diversity appears more consistent with our results, because female and Black subjects react similarly to Mary Daly and Raphael Bostic, whereas homophily predicts White women should react less to Mr. Bostic than to Thomas Barkin (because the latter shares their race) and Black men react less to Ms. Daly than to Mr. Barkin (because the latter shares their gender). Furthermore, White men's expectations do not react differently across treatments, which is not consistent with homophily.

For more direct evidence of a taste for diversity, we elicit respondents' support for quotas in organizations like the Fed, and document that women and minorities are much more in favor of such quotas. Furthermore, within the group of White men, we study how reactions to minority policymakers vary depending on a respondent's views about the Black Lives Matter (BLM) movement and discrimination against women in the US. ${ }^{6}$ In these tests, homophily cannot play any role by construction. We find more "progressive" White men adjust their expectations more strongly and trust the Fed more when the presence of a diverse FOMC member is salient, which is consistent with a taste for diversity.

Collectively, our results suggest higher committee diversity makes underrepresented consumers form macroeconomic beliefs that are more aligned with the FOMC forecasts, while it does not affect the expectations of the overrepresented group. Higher diversity might thus increase the ability of FOMC communication to influence consumers' expectations and lead to more trust in the Fed, especially on the part of underrepresented consumers, who are often part of the most vulnerable communities.

One might worry that White men do not react, on average, because even when exposed to FOMC diversity they believe the majority of the committee consists of White men, who ultimately make the decisions. This possibility is barely consistent with our results because,

\footnotetext{
${ }^{6}$ We elicited these dimensions after the treatments and the outcomes of interest to avoid priming.
} 
based on this reasoning, female and Black subjects should not react to diversity salience either because they would think a White male majority drives the decisions. Second, many treated White men in our manipulation check report a perceived FOMC demographic composition in which White men are not the absolute majority.

Note that our analysis, which only varies diversity salience, cannot provide guidance on the optimal degree of diversity in terms of maximizing the effectiveness of policy communication. The inability to test for the salience of minorities that are not represented on the FOMC is another limitation of our approach. For instance, we could not use our setting to test for the effects of the salience of a Hispanic policymaker, because no FOMC members were Hispanic when we ran our experiment.

\section{$1.1 \quad$ Related Literature}

Our paper builds on several strands of research in economics, social psychology, and sociology. First, we relate to the literature on the effects of social identity on beliefs and decision-making (see, for instance, Akerlof and Kranton, 2000; Benjamin et al., 2010; Fehr and Hoff, 2011; D'Acunto, 2020). We contribute by studying the effects of perceptions of diversity on the effectiveness of economic policy (see Shayo, 2020, for a recent survey). Specifically, our paper relates to research on the effects of gender, racial, and ethnic diversity in professional advising roles on agents' willingness to follow advice. For instance, recent work has documented homophily in patients' willingness to follow medical (Greenwood et al., 2018; Alsan et al., 2019) and financial advice (Stolper and Walter, 2019).

Our study is novel in that all agents, regardless of their demographics and identity, are exposed to macroeconomic information from the same "advisory body" - the FOMC. For this reason, if the homophily channel documented in other settings was the only relevant channel, the overrepresented group of White men would align its subjective beliefs less with the FOMC's forecasts once diversity was salient, thus potentially reducing rather than improving the effectiveness of monetary policy communication. By contrast, we find an asymmetric effect - underrepresented individuals react positively to diversity salience and White men do not react on average. The lack of any personal interactions between the 
advisor and the advisee in our setting might help explain this asymmetric effect.

Methodologically, our paper builds on a large literature in social psychology and marketing, starting with Steele and Aronson (1995), that primes the salience of demographic attributes to gauge the causal effect of social identity on perceptions and decision-making (see Cohn and Maréchal, 2016, for a recent overview). We display to each subject the picture of one policymaker whose gender and race are clear. The picture may prime respondents' own identity, but, unlike the literature on priming, we study subjects' beliefs about macroeconomic variables whose realizations are the same for everybody rather than beliefs about own personal outcomes that depend on views of the self and own effort. Our between-subjects design, whereby subjects observe only one picture, reduces the concern of demand effects, which are low in contexts like ours in which subjects do not have repeated interactions with the experimenter (see De Quidt et al., 2018).

Moreover, our paper belongs to the recent literature that studies consumers' subjective economic beliefs. We combine an information-provision survey experiment with belief elicitation building on recent work in this area such as Armantier et al. (2016), Cavallo et al. (2017), Binder and Rodrigue (2018), Coibion et al. (2019), Armona et al. (2019), Binder (2020), Roth and Wohlfart (2020), Coibion et al. (2020a), and Coibion et al. (2021). ${ }^{7}$ The information-selection part of our follow-up survey is related to recent work by Fuster et al. (2020) and Roth et al. (2021). The existing literature has focused on how different pieces of information affect beliefs; we instead focus on how the same information affects beliefs differently depending on who communicates it. In this realm, we contribute to recent attempts to understand the effects of monetary policy communication on households' beliefs (see, for instance, Blinder et al., 2008; Haldane and McMahon, 2018; D'Acunto et al., 2020; D'Acunto et al., 2021b) as well as the heterogeneous effects of monetary policy across racial groups (see, for instance, Bartscher et al., 2021; Bergman et al., 2020; Gerardi et al., 2020).

Finally, our paper relates to the literature on the roles of policy-making committees

\footnotetext{
${ }^{7}$ See also the literature surveyed in Haaland, Roth, and Wohlfart (2021). Studies on the formation of subjective macroeconomic and financial expectations using micro data further include Bachmann et al. (2015), Malmendier and Nagel (2016), Kuchler and Zafar (2019), Das et al. (2020), D'Acunto et al. (2021a), D'Acunto et al. (2021c), and Giglio et al. (2021).
} 
(Blinder, 2007; Blinder et al., 2008; Riboni and Ruge-Murcia, 2010). We contribute by showing committee composition matters for the ability to reach different communities.

\section{Experimental Design and Data}

In this section, we discuss the composition of our sample, the experimental design, and some descriptive statistics of our subject pool.

\subsection{Experimental Procedure and Manipulation Checks}

To administer our survey experiment, we paired up with a leading US surveying company, Qualtrics, which recruited the subjects based on a set of quotas we agreed upon before the sampling started. The quotas were designed to obtain a generally representative sample of the US population in terms of gender, age, education levels, and regional distribution, but with a slight oversampling of Black respondents. We oversampled Blacks - the smallest group whose reactions we wanted to study - to reduce concerns about the possible lack of statistical power if we found no effects of minority salience on Black subjects' expectations. ${ }^{8}$

The experimental design, content of the survey experiment, and sampling choices were approved by the Boston College IRB in March 2020 (20.218.01e). We fielded the experiment after the pre-registration in the AEA RCT Registry in July 2020. All the information we reported in the survey was up to date as of June 2020, two months before the survey was fielded. The survey experiment was administered electronically.

The consent form made subjects aware that they would be exposed to information about the economy during the experiment and that they would be asked about their opinions. The form emphasized that no right or wrong answers existed, but we were interested in subjects' own opinions and not in the opinions of others, and for this reason, subjects should have responded without seeking advice or looking up any information on the internet. The recruiting material did not refer in any way to issues related to gender, ethnicity, or discrimination to avoid the possibility of subjects selecting into the experiment based on their views about

\footnotetext{
${ }^{8}$ Also due to a concern for statistical power, our sampling included Black, Hispanic, and White nonHispanic subjects, but not other minority groups (e.g., American Indian and Alaska Native, Asian, or Native Hawaiian and Other Pacific Islander).
} 
these topics and to reduce concerns of demand effects.

In terms of experimental procedure, after consenting to participate, subjects started the survey, which consisted of five sections: an introductory section, a pre-treatment expectationselicitation section, the experimental treatments, a post-treatment expectations-elicitation section, and a concluding section. ${ }^{9}$ In the pre-treatment section, after answering three basic demographic questions (age, education level, and state of residence), we assessed subjects' awareness and perceptions of macroeconomic and own economic conditions. These questions included asking subjects about the sources they used to gather information about the economy, assessing whether they knew the FOMC and its role, and asking them whether their household income had changed during the COVID-19 pandemic. For the pre-treatment expectations-elicitation questions, we asked subjects for point estimates of the US unemployment and inflation rates, their forecasts for the unemployment and inflation rates 12 months later, and the confidence they had in their forecasts on a scale from 1 to 7 . In the first section, we also implemented two attention filters to screen bots and low-attention participants.

We then administered the experimental treatments, which we randomized across subjects. The experiment included seven arms. The control group read a short paragraph (four sentences) about the Federal Reserve System and about the FOMC and its composition in terms of members of the Fed Board of Governors and regional Fed Presidents. The paragraph was accompanied by a picture of the seal of the Federal Reserve. We did not provide any information about the demographic composition of the FOMC or any economic forecasts to control subjects. Each of the six treatment groups, instead, read a text of similar length to the one the control group read, but reporting the macroeconomic forecasts of FOMC meeting participants from the Summary of Economic Projections that were published after the June 2020 FOMC meeting. Three groups received the median unemployment rate forecasts for 2020 and 2021, and three groups received the inflation rate forecasts for 2020 and 2021. We used the median forecasts from the FOMC Survey of Economic Projections for the unemployment rate and PCE inflation (https://www.federalreserve.gov/monetarypolicy/fomcprojtabl20200610.htm). ${ }^{10}$

\footnotetext{
${ }^{9}$ Online Appendix B contains the survey questions.

${ }^{10}$ Proposing two forecasts rather than one allows us to reduce concerns that subjects merely report the
} 
Moreover, each forecast was accompanied by one of three pictures, names, and titles of alternate members of the FOMC who belong to different demographic groups: Thomas Barkin, the president of the Richmond Fed (White man); Raphael Bostic, the president of the Atlanta Fed (Black man); and Mary Daly, the president of the San Francisco Fed (White woman). For each member, we emphasized that they had taken part in the June 2020 FOMC meeting. We selected Raphael Bostic because he was the only Black member of the FOMC at the June 2020 meeting. We selected Thomas Barkin and Mary Daly, among other potential choices with similar demographics, because they were both regional Fed Presidents and both sat on the FOMC as alternate members at the time of our experiment. In sum, all subjects who were not assigned to the control group read either the FOMC unemployment or inflation forecasts. These subjects were also randomly exposed to the picture, name, and title of one of the three alternate members of the FOMC.

The aim of this experimental manipulation was to vary the perceived diversity representation on the FOMC. We verified the manipulation was effective in an auxiliary analysis that we ran on a different sample to avoid making the aims of our study clear to the subjects of the main experiment. After exposing auxiliary subjects to the pictures and titles of $\mathrm{Mr}$. Barkin, Mr. Bostic, and Ms. Daly, we asked them how many of the 11 FOMC members they thought were women and how many were Black or Hispanic. In Figure A.1 in the Online Appendix, we show subjects exposed to Mary Daly tend to perceive a higher number of female members on the FOMC relative to subjects in other treatment arms. Subjects exposed to Raphael Bostic tend to perceive a higher number of racial-minority members. ${ }^{11}$ Unreported results (available upon request) show this effect was similar across subjects by gender and ethnicity, which supports the effectiveness of our procedure in increasing diversity salience for all subjects.

To further assess the validity of our procedure, we also verify in the same auxiliary analysis that committee members' recognizability was similar across demographic groups. Otherwise,

same number they read in the experimental text when asked about their expectations.

${ }^{11}$ Relative to the control group and the Thomas Barkin treatment, the $25^{\text {th }}, 50^{\text {th }}$ and $75^{\text {th }}$ percentile of perceived number of female members (Black or Hispanic members) are shifted by one unit in the Daly (Bostic) treatment. The median perceived numbers in the control and Barkin treatments are three female FOMC members and two Black or Hispanic members. 
exposure to diverse members might confound the role of higher perceived diversity on the FOMC with a different response to familiar names and portraits (for instance, see Cook, Logan, and Parman, 2014). We find few subjects recognize the three committee member names (see Panel A of Figure A.2 in the Online Appendix). White women are slightly more likely to report that they recognize Mary Daly's name, but once we add unsure respondents we detect no differences across genders, and almost $80 \%$ of White women state that they definitely do not recognize Ms. Daly's name. The results are similar for portrait recognition (Panel B). The share of respondents of any demographic groups who claim recognizing any of the members' portraits is systematically below $10 \% .^{12}$

Going back to the experimental procedure, after the manipulation stage, subjects moved on to the post-treatment expectations-elicitation questions. First, we asked the extent to which subjects trusted the Fed (i) to adequately manage inflation and unemployment, and (ii) to care about the economic well-being of "all Americans, including people like yourself" (in both cases, on a 1-7 scale). Then, we elicited probability distributions for the one-yearahead unemployment and inflation rate following the wording in the New York Fed Survey of Consumer Expectations (see, e.g., Armantier et al., 2017; Crump et al., 2018). ${ }^{13}$ We elicited probability distributions instead of point estimates to avoid asking the same question twice, and hence reduce the concerns of demand effects and survey fatigue.

We focus on expectations about unemployment and inflation because they are the two pillars of the Fed's mandate, and because a change in these expectations should affect individual behavior. Lower unemployment expectations should induce people to spend more, because their perceived need for precautionary savings decreases. Empirically, Roth and Wohlfart (2020) document that indeed, people's macroeconomic outlook has a causal effect on their consumption plans and stock purchases. A change in inflation expectations similarly should induce a change in spending via intertemporal substitution and affect asset allocation; for evidence on these points, see, for instance, D'Acunto et al. (2021b) and Coibion et al.

\footnotetext{
${ }^{12}$ One exception is non-White men for the case of Raphael Bostic. Once we assess if reported recognition coincides with actual recognition based on whether respondents select the correct occupation of each committee member, though, we find that the share of non-White men who actually plausibly recognize Mr. Bostic and know what he does is below $5 \%$, in line with the recognition levels by other subjects.

${ }^{13}$ Compared to the Survey of Consumer Expectations, we slightly reduced the number of intervals for possible values in order to reduce the cognitive burden from answering these questions.
} 
(2019).

The final section of the survey elicited subjects' gender and race/ethnicity, as well as marital status, political views, household income, wealth components, two financial literacy questions, and the extent to which subjects supported the BLM movement and thought women in the US were discriminated against (on a 1-7 scale). We asked these questions at the end to avoid priming subjects, and hence reduce the concerns of demand effects. Finally, we asked subjects a multiple-choice question about the picture related to the Federal Reserve that we had shown them to see whether they could recall its content. After completion, subjects were asked how interesting they found the survey and had a chance to leave comments.

Starting four weeks after completion of the first survey wave, we fielded a second survey to the same participants. In a first part, among other questions, we re-elicited participants' inflation and unemployment expectations and their trust in the Fed, using the same questions (but in different order) as in the the main survey. The purpose of this part was to test whether the information we had provided in the first wave had persistent effects. We then administered an information-selection experiment within the survey, which we describe in detail in section 4.2. In the last part of the survey, we elicited agreement with six statements related to diversity and policy making. We describe these statement in section 4.3.

\subsection{Sample Composition and Summary Statistics}

Our experimental protocol was pre-registered in the American Economic Association (AEA) RCT Registry. ${ }^{14}$ We targeted a minimum of 8,750 valid answers for the first wave, with the possibility of obtaining more answers. ${ }^{15}$ The survey was launched on August 10, 2020, after the July FOMC meeting and the release of the most recent unemployment numbers on August 7, 2020. The survey was continuously available to subjects until completion of the data collection on September 11, 2020, even though the vast majority of answers

\footnotetext{
${ }^{14}$ The RCT ID is AEARCTR-0006174 and the title is "Does Policy Committee Diversity Affect Public Trust and Expectations?"

${ }^{15}$ Note that on an online platform such as Qualtrics, subjects self-select into the experiment by clicking on a survey link and are not physically admitted one by one by a laboratory official. Because we had defined quotas by race and gender, which were only elicited in the last part of the survey, we ended up with more than the targeted number of responses.
} 
(88\%) were recorded by August 26, 2020, and hence before the Economic Policy Symposium in Jackson Hole, during which the Federal Reserve announced changes to its policy framework (e.g., a move to average inflation targeting).

We targeted an equal number of men and women, ${ }^{16}$ whereas we oversampled underrepresented groups in terms of race and ethnicity relative to their share in the general population (50\% White subjects, 30\% Black subjects, and 20\% Hispanic subjects). We oversampled minority groups to avoid the possibility that our within-group analyses across experimental manipulations would lack statistical power. The sample was targeted to be representative of the broader population in terms of other demographics we could observe in the selection stage - age categories, education levels, and geographic regions within the US.

Table 1 reports a set of summary statistics for the sample on which we run our empirical analyses. The sample size is 9,140, which exceeds the minimum number of answers we had targeted. ${ }^{17}$ The top panel considers a set of demographic characteristics. As intended, respondents are equally split between men and women, and the shares of Blacks (30\%) and Hispanics (19\%) are close to their targets. The median age is 45, 55\% of respondents are married, and $41 \%$ have a bachelor's degree or higher level of education. In terms of employment, $55 \%$ have full-time or part-time employment, $19 \%$ are retired, and $12 \%$ are unemployed. ${ }^{18}$

As far as household finances are concerned, 40\% report a household income over the past 12 months above $\$ 75,000$, and $43 \%$ report having experienced some income reduction during the pandemic period. Fourteen percent say they would currently be unable to pay for a $\$ 400$ emergency expense, $59 \%$ are homeowners, $41 \%$ hold stocks directly and 55\% have a 401(k) retirement account. Just under half of respondents make all the financial decisions in their household. Overall, relative to the US population, our subject pool is slightly younger

\footnotetext{
${ }^{16}$ Gender identities other than male or female did not have enough observations within the platform population to allow for their sampling.

${ }^{17}$ The total number of valid answers was 9,224 . We remove 84 respondents who did not identify as White, Black, or Hispanic. Note that the panel provider only invited participants from one of the three targeted groups, based on available information from previous surveys.

${ }^{18}$ We identify respondents as unemployed if they selected "Not working, but would like to work." This definition does not exactly correspond to the official definition of unemployment, which requires one to actively look for work. The official US unemployment rate in August 2020 was 8.4\%.
} 
and more educated. Income values and homeownership are slightly lower than in the overall population, but the differences are small.

The bottom part of Table 1 reports statistics for the main outcome variables in the analysis. The average priors for the 12-month-ahead unemployment and inflation rates are high $-21.3 \%$ and $10.3 \%$ - largely due to some very high forecasts, given that the median values are $12 \%$ and $4 \%$, respectively. The posteriors are lower, on average, as expected due to the provision of the June 2020 FOMC forecasts to treated groups, as well as the different elicitation methods for priors and posteriors. ${ }^{19}$

We also consider respondents' trust in the Federal Reserve, measured along two dimensions on a 1-7 Likert scale. The median level of trust is 4 out of 7 . Below, we define a dummy for distrust in the Fed if the subject reported a level of 3 or lower. Based on this dummy, 35\% of respondents distrust the Fed's ability to adequately manage unemployment and inflation and $44 \%$ do not trust that the Fed cares about the well-being of all Americans. ${ }^{20}$

In the follow-up survey, we obtained 2,933 respondents between September 26 and October 21, 2020. The median number of days between completion of the two survey waves was 41 (with 10th and 90th percentile at 37 and 50 days, respectively). Summary statistics for the follow-up sample are in Online Appendix Table A.1. For the most part, average characteristics are close to those in the main sample, but repeat respondents tend to be somewhat older and more educated.

\section{The Effect of FOMC Diversity Salience on Expectations}

In this section, we discuss the effects of diversity salience on how much individuals belonging to different demographic groups incorporate Fed information into their subjective macroeconomic expectations.

\footnotetext{
${ }^{19}$ In the prior stage, we simply elicit the point forecast, whereas in the posterior stage, we provide different possible bins to respondents and ask them to allocate probabilities to the different bins. For instance, the highest bin for unemployment was " $17 \%$ or higher," and for calculating the implied subjective mean, we impute a value of $18.5 \%$ for this bin (because all other bins had a width of 3 percentage points). The differential mode of elicitation is immaterial in our experiment because we have a control group.

${ }^{20}$ The two forms of distrust are correlated: among the 4,434 respondents (48.5\% of the total) who express distrust on at least one dimension, 2,771 (or $62.5 \%$ ) do so on both dimensions.
} 
For both unemployment and inflation expectations, the main measure we consider is whether the mode of a subject's posterior expectations is consistent with the FOMC's macroeconomic projections. If so, we denote the expectation as "anchored." For unemployment, this rule requires the mode of the posterior distribution to be either $5 \%-8 \%$ or 8\%-11\%, given that the FOMC forecasts we presented were 9.3\% for 2020 and $6.5 \%$ for $2021 .^{21}$ For inflation, the mode has to be $0 \%-2 \%$, given the FOMC forecasts of $0.8 \%$ and $1.6 \%$. We focus on the mode rather than the mean of the posterior distribution because it does not require us to make assumptions about the values in the highest/lowest bins. Nevertheless, because the effect on the mean expectation is also of interest, we use it as a secondary outcome below.

We first consider the share of subjects in the control condition reporting anchored posterior expectations across demographic groups. Because the control condition did not receive any FOMC forecast, it captures baseline differences in expectations across groups as well as any potential systematic effects of asking subjects for their economic expectations twice and of eliciting expectations through a probability distribution. Figure 1 shows White men have the highest share of anchored expectations, followed by Hispanic men. Without seeing any forecasts, women and Black respondents tend to have the lowest shares of anchored expectations. These baseline differences in the share of anchored expectations suggest a scope for influencing the economic expectations of underrepresented groups.

Next, in Figure 2, we plot the estimated treatment effects across demographic groups. We compute these effects relative to the control group based on whether respondents read the FOMC's unemployment forecasts (Panel A) or inflation forecasts (Panel B). Below, we assess the statistical significance of these effects.

A few patterns stand out. First, the FOMC's forecasts affects the expectations of all groups irrespective of diversity salience - the estimated treatment effects are positive in all cases, meaning a larger share of respondents have anchored expectations compared to the control group after seeing the FOMC forecasts. Second, for the overrepresented group

\footnotetext{
${ }^{21}$ Recall that we elicit posterior expectations via a distribution question with pre-specified bins and individuals have to allocate mass adding to 100 to the different bins. Hence, the mode of the subjective distribution corresponds to the bin the subject assigns the most mass to.
} 
(White men, dark gray bars in the leftmost panels), the salience of FOMC diversity does not mediate the positive treatment effect of the FOMC forecasts, because the reactions are virtually identical across treatment conditions. Third, and in stark contrast, underrepresented groups' expectations react to reading the FOMC forecasts differently depending on which policymaker is shown, especially in the unemployment domain. The share of White women with anchored unemployment forecasts is 8 and 4 percentage points higher when the FOMC forecast is presented alongside the portraits of Mr. Bostic and Ms. Daly. The effect of the FOMC forecast is thus $50 \%$ and $25 \%$ larger than its effect when FOMC diversity is not salient (16 percentage points). The effects are even stronger for Black women (light-grey bars in the middle plot of Panel A) - FOMC diversity salience increases their treatment effect by 6 and 11 percentage points relative to a baseline effect of 4 percentage points.

For non-White men, the univariate results are more mixed. Black men react more strongly to Mr. Barkin and Mr. Bostic and to a lesser extent to Ms. Daly. Hispanic men react most to Mr. Barkin. For inflation expectations (Panel B), we find large but more homogeneous treatment effects of policymaker salience across different subpopulations. We discuss possible reasons for the homogeneous treatment effects below.

Table 2 quantifies the effects on unemployment expectations in a multivariate regression framework that controls for subject-level characteristics. ${ }^{22}$ We pool the information types and estimate the regressions separately across groups; the omitted categories are the control group (for the information type) and the group that saw the picture of Mr. Barkin.

Panel A of Table 2 shows White and Black women are significantly more likely to have anchored unemployment expectations if they see Mr. Bostic or Ms. Daly alongside the forecast. Effects are particularly large for Black women, who respond most strongly to Ms. Daly. Black men exhibit a slightly stronger degree of anchoring when seeing Mr. Bostic, but

\footnotetext{
${ }^{22}$ Controls include functions of the subject's point forecast before the experimental treatment (prior beliefs), the date the survey was taken, and dummies for the following characteristics (with number of distinct values in parentheses): geographic region (4), income category (11), education category (6), age category (6), employment status (7), marital status (2), political leaning (4), financial literacy score (3), whether they lost their job (2) or faced reduced income since March 2020 (2), whether they state that they could not pay for a $\$ 400$ emergency expense (2), whether they own their primary residence, and if so, have a mortgage (3), hold stock (2), have a $401(\mathrm{k})$ or similar (2), whether they are the main grocery shoppers (3), whether they make financial decisions in their household (3; D'Acunto et al., 2021c; D'Acunto et al., 2021d), and whether the survey was taken on a mobile device (2).
} 
the effect is statistically insignificant. We detect no significant effects on White men and Hispanics. In the last two columns, we pool all respondents and either equal-weight them (column 7) or apply Census-based population weights to make the sample representative for the six groups we consider (column 8). ${ }^{23}$ We find positive coefficients for both the Bostic and Daly treatments, but statistical significance is limited (which is not very surprising, given that White male and Hispanic respondents account for a substantial part of the survey population).

Panel B of Table 2 focuses on a continuous measure of expectations - the imputed expected unemployment rate. This dependent variable captures respondents' entire subjective distribution, but requires us to make assumptions regarding the values we assign to the different bins. ${ }^{24}$ The results confirm those based on the anchoring indicator: being exposed to the Bostic or Daly portraits lowers the unemployment expectations of White women and Black subjects, thereby bringing underrepresented groups closer to the Fed forecast, and in the pooled sample overall. In contrast to Panel A, the effect of the Bostic treatment on Black male respondents is now statistically significant. Still no effect in the opposite direction for White men exists.

Table 2 also illustrates that providing information in itself moves underrepresented groups by more, especially when focusing on the continuous outcome (Panel B): the effect of seeing the FOMC unemployment forecast is insignificant for White men but large for the other groups. In Table A.2 in the Online Appendix, we repeat the analysis for inflation expectations. Seeing the inflation forecast has rather large effects on anchoring for all groups (last row of Panel A), and mean expectations in the pooled sample are directionally lower in the Bostic and Daly treatments (Panel B), but we detect no statistical significance. This null effect could be due to limited statistical power: given the large treatment effects of the inflation forecast, effects across experimental arms might be smaller and hence harder to

\footnotetext{
${ }^{23}$ Data source: U.S. Census Bureau (2020); the population numbers are for 2019. Because we oversampled minority respondents, especially Black respondents, they are assigned lower weights in column (8) than in column (7), whereas White respondents are assigned higher weights.

${ }^{24}$ These assumptions may play a role especially for respondents who put non-zero weight on the extreme bins, which are as follows, along with the assigned values in the analysis in parentheses: (i) for unemployment, " $17 \%$ or higher" (18.5\%) and " $5 \%$ or lower" (3.5\%); (ii) for inflation, "8\% or more" (10\%) and "deflation of $8 \%$ or more" $(-10 \%)$.
} 
differentiate from zero. Alternatively, as discussed above, diverse points of view about unemployment, which varies systematically across demographic groups, might be deemed more important than diverse points of view about inflation, whose realizations underrepresented consumers might perceive as more similar across groups.

Overall, FOMC diversity salience appears to move the subjective expectations of underrepresented groups - especially White women and Blacks - closer to the Fed's forecast, at least in the case of unemployment expectations. At the same time, it does not reduce the ability of FOMC forecasts to anchor the expectations of the overrepresented group.

\section{Economic Channels: Why Does Diversity Facilitate Expecta- tions Management?}

In this section, we aim to dissect a set of non-mutually-exclusive potential channels that might mediate the effects of diversity salience on the expectation formation of underrepresented and overrepresented groups.

\subsection{Trust in the Policy Committee}

The first channel we consider is agents' trust in the policy committee, because if agents did not trust the committee, they might find its forecasts non-credible and irrelevant to their decision-making. ${ }^{25}$ Moreover, public trust and credibility are the key pillars based on which central banks justify their independence and legitimacy.

In the experiment, we elicited two forms of trust in the Federal Reserve on a 7-point Likert scale - first, trust in the Fed's ability to adequately manage inflation and unemployment, and second, trust in the Fed to care about the economic well-being of all Americans, "including people like yourself."

Trust can only have a scope to explain our results if, absent any experimental interventions, subjects in underrepresented groups were less trustful of the FOMC than others, ceteris paribus. Figure 3 supports this condition. It displays the distribution of control sub-

\footnotetext{
${ }^{25}$ Distrustful agents might even disagree with a policy committee's attempt to manage their macroeconomic expectations, and, in the extreme, react in the opposite direction.
} 
jects by trust levels for White men (gray histograms) and others (red histograms). The left panel refers to trust in the Fed's ability to manage inflation and unemployment. White men's modal value is 5 , and almost $60 \%$ report a value of 5 or higher. For others, instead, the modal value is 4 and only a third report a value of 5 or higher. The whole distribution is shifted to the left for underrepresented groups relative to White men. The right panel displays similar patterns for trust that the Fed acts to foster the well-being of all Americans. ${ }^{26}$

We confirm these raw-data patterns in a multivariate analysis. In Table 3, we use either the 1-7 rating as in the histograms or a simpler $0 / 1$ indicator for whether a respondent indicated distrust (defined as a trust value $\leq 3$ out of 7 ). Even after controlling for a broad range of additional characteristics (even columns), the differences in trust between White men and other groups point in the same direction as the raw data (odd columns). In particular, women remain substantially less likely to trust the Fed. For instance, White women are 18 percentage points more likely to express distrust in the Fed's management of inflation and unemployment (column 4), which is a large effect given that, in the sample, $34 \%$ express distrust. ${ }^{27}$

We then move on to ask whether diversity salience increases the degree of trust by underrepresented groups. ${ }^{28}$ In Figure 4, we report the share of subjects who distrust the Fed across groups. Panel A focuses on distrust in the Fed's ability to reach its objectives. FOMC diversity salience reduces White women's distrust but has no effect on White men (leftmost figure in Panel A). The effect, although large, does not eliminate the gender gap in trust levels. Among Blacks, women also tend to distrust the Fed more than men, but the extent of distrust drops for both men and women exposed to Mr. Bostic or Ms. Daly rather than Mr. Barkin. For Hispanic respondents, whose ethnic group was not represented on the FOMC at the time of our experiment, we detect different patterns: Hispanic men tend to be more distrustful when exposed to a female or non-White FOMC member.

\footnotetext{
${ }^{26}$ Note also that both subsamples have lower trust in the Fed caring for all than in the Fed's ability to manage inflation and unemployment.

${ }^{27}$ The finding that women exhibit less trust in central banks and its policies also appears in studies by Ehrmann et al. (2013) and Christelis et al. (2020) for the ECB and Jost (2017) for the Bank of England, although such demographic differences are not the main focus of these authors.

${ }^{28}$ Because we asked the questions on trust only after the experimental manipulations, we assess the reaction in a between-subjects design after manipulating diversity salience.
} 
Panel B of Figure 4 focuses on the level of trust that the Fed acts to foster the well-being of all Americans. The patterns are qualitatively similar. White women's distrust is lower if FOMC diversity is salient, whereas White men are unaffected. Blacks are also less distrustful when exposed to FOMC diversity, although the differences are smaller than those in Panel A. For Hispanic subjects, the differences across treatments are small, although this time directionally aligned with the other underrepresented groups.

We confirm the robustness and statistical significance of these raw-data patterns in Table 4, where each specification includes the same set of individual-level controls as in the expectations analysis. White women and Blacks are less distrustful of the Fed when FOMC diversity is salient. The estimated effects correspond to 10\%-20\% of the average distrust share (reported in the bottom parts of each panel), and are in most cases statistically significant. By contrast, we find no significant effects on White men. ${ }^{29}$

The last two columns in each panel assess whether the average distrust toward the Fed declines with diversity salience in the pooled sample. In column (7), respondents are equally weighted, whereas in column (8), we apply US-population-weights for the six groups. We find the Daly and Bostic pictures reduce the level of distrust in an economically and statistically significant way in Panel B. Effects are qualitatively similar in Panel A, but we find statistically significant effects only for the Bostic treatment in the equal-weighted version.

In a final step, we ask if subjects' trust in the Fed is linked to expectations anchoring. Otherwise, we could not argue that higher trust in the Fed increases its effectiveness. Table 5 supports this link: subjects who express distrust in the Fed are less likely to express posterior expectations in line with the FOMC forecasts, for both types of trust and controlling for all other characteristics. For unemployment expectations, this finding holds in the control group as well; for inflation expectations, only when we look at the groups that see a Fed forecast. Furthermore, subjects who express distrust in the Fed to adequately manage inflation and unemployment are less receptive to the provided forecast (columns 3 and 6 of Panel A).

Overall, diversity salience increases underrepresented groups' trust in the policy com-

\footnotetext{
${ }^{29}$ Hispanic men express more distrust in the Fed's management of inflation and unemployment when exposed to the Bostic or (especially) Daly picture, but we do not find this effect for distrust regarding the Fed caring for all.
} 
mittee, which is a plausible channel driving the effects of diversity salience on expectations discussed above.

\subsection{Paying Attention to Fed Communication and Information Acquisition}

The second channel we consider involves consumers' attention allocation and information acquisition regarding the economy, which in turn might feed into their expectations. Once underrepresented consumers realize the FOMC has a diverse demographic composition, their interest in this committee's views of the economy, including their macroeconomic forecasts, might increase.

Similar to the trust channel, an attention channel is more plausible if, absent any interventions, underrepresented subjects are less informed about monetary policy and the macroeconomy. Figure 5 supports this condition. ${ }^{30}$ Panel A shows the share of subjects who answer a question about the role of the FOMC correctly before the experimental intervention is higher for White men than other groups. Panel B shows the same patterns for the share of subjects who know the Fed's target for inflation $(2 \%$, black bars) or at least report values between $1 \%$ and $3 \%$ (gray bars). We confirm these raw-data patterns in multivariate analysis - see Table 6. We regress dummy variables for whether the subject knows the role of the FOMC (columns 1-2) and the Fed's inflation target (columns 3-6) on group membership dummies (with White men as the omitted category) and, in even columns, our rich set of individual controls. ${ }^{31}$ The negative associations between belonging to an underrepresented group and the level of informedness decline once we control for other characteristics, but for the most part they remain economically and statistically significant. ${ }^{32}$

To investigate the attention channel, we first study a few proxies for attention within our main experiment: (i) the (log) amount of time a respondent spends on the treatment

\footnotetext{
${ }^{30}$ In this case, we consider subjects in all experimental arms, because in the survey, we asked the information question before we administered the experimental manipulations.

${ }^{31}$ These regressions are arguably overcontrolling, because they include variables such as the financial literacy score that capture an understanding of concepts such as interest rates and inflation.

${ }^{32}$ In Online Appendix Table A.3, we further study a potential underlying driver for these differences, namely, variation in the number and type of sources of news about the economy and business that the different groups consume. In short, female and Black respondents are more likely to say they do not consult any sources; furthermore, they are less likely to rely on "traditional" sources but more likely to rely on social media and (for White females) their friends.
} 
screen, ${ }^{33}$ (ii) whether they are able to correctly recall which Fed-related picture they saw in the experiment, and (iii) their stated interest at the end of the experiment. Table 7 reports the results. We combine the Bostic and Daly treatments and check whether they differentially affected attention among White female and Black respondents, for whom we detected effects on expectations. Columns (1) and (2) show these groups spent approximately $4 \%$ more time on the forecast screen in the Bostic and Daly treatments. By contrast, in columns (3) and (4), we detect no differential ability of these respondents to recall the name of the policymaker they were shown when this policymaker was not a white male. ${ }^{34}$ Finally, White female and Black respondents were more likely to state at the end that the survey was interesting after being exposed to the Bostic or Daly pictures, although this effect loses statistical significance when we add control variables (columns 5 and 6 ).

For a direct test of whether diversity salience affects underrepresented groups' willingness to gather information about the Fed, we turn to our second survey. ${ }^{35}$ Subjects could choose between reading one of two articles on the future of the US economy. They were randomly sorted into one of three groups. The first group (control) chose between an article featuring an unnamed policymaker from the US Congressional Budget Office (CBO) or from the Federal Reserve (Fed). ${ }^{36}$ In the other two groups, the policymakers were named. In group 2, both articles featured White men-CBO Director Philipp Swagel or Fed Governor Richard Clarida. In group 3, subjects chose between CBO's Swagel or Fed Governor Michelle Bowman - a female policymaker. ${ }^{37}$ All pieces were recent news articles. We edited them slightly to keep a consistent length of about 150 words, and we did not display media sources. We focused exclusively on gender in the design of the second survey because (i)

\footnotetext{
${ }^{33}$ Due to outliers, this variable is winsorized at the $2.5 \%$ tails.

${ }^{34}$ All groups were more likely to correctly recall Mary Daly ( $81 \%$ correct recall overall) than either Thomas Barkin $(68 \%)$ or Raphael Bostic $(67 \%)$, which is likely driven by the fact that among our multiple-choice options, she was the only woman. We also added one multiple-choice option of a Regional Fed president who was not shown to anybody (Neel Kashkari). Only $2.6 \%$ of respondents picked this option.

${ }^{35}$ The second wave of the survey also includes an assessment of whether the first-wave treatment effects are persistent, as well as the elicitation of subjects' support for policies that grant explicit quotas to underrepresented groups in committees. We discuss these results below.

${ }^{36}$ If choosing the Fed, subjects were then assigned with equal probability an article featuring Richard Clarida or Michelle Bowman.

${ }^{37}$ In the second and third groups, in which policymaker names were featured, the gender titles were provided as well-for example, "Mr. Philipp Swagel" and "Ms. Michelle Bowman" (see Online Appendix B for the exact wording).
} 
the manipulation did not feature pictures, so race/ethnicity could not be salient, and (ii) the smaller sample size in the follow-up survey would make detecting differences across more granular groups difficult.

Our hypothesis is that female subjects might be more likely to pick the Fed article if it features a woman (in group 3) as opposed to a man (group 2) or an unnamed policymaker (group 1). ${ }^{38}$ Figure 6 shows strong support for this hypothesis: women are 13 percentage points $(20 \%)$ more likely to choose the Fed-related article over the CBO article if the article features Ms. Bowman rather than Mr. Clarida. If anything, men also display a slight preference for the Fed article when Ms. Bowman is featured, but the difference is only about 3 percentage points relative to Clarida. In an auxiliary analysis that we ran separately to avoid demand effects, respondents were slightly more likely to report that they recognized Ms. Bowman's name than that they recognized Mr. Swagel and Mr. Clarida's names. However, differences in perceived recognition of these policymakers barely vary across genders and ethnicities (see Figure A.3 in the Online Appendix). Recognizability might thus, at most, explain why men also prefer the Fed article featuring Ms. Bowman, but cannot explain the differential effects across genders.

Table 8 shows these results are robust to controlling for demographic characteristics. Odd columns correspond to the bar charts just discussed (the control group with unnamed policymakers is the omitted category). The p-values in the bottom part of columns (1)(4) indicate that for male respondents, the differences between the Bowman and Clarida treatments are not statistically significant, ${ }^{39}$ whereas for female respondents, the difference is highly statistically significant $(p<0.001)$. The p-values in the bottom part of columns (5) and (6) indicate that for female respondents, the difference in the probability of choosing the Fed article between the Bowman and Clarida treatments is differentially larger than for male respondents at $p=0.06$.

After reading the article, subjects answered a set of opinion questions about the article on

\footnotetext{
${ }^{38}$ We are also interested in a potential offsetting negative effect on male respondents' interest in the Fed when a female Fed policymaker is featured.

${ }^{39}$ Note that in both treatments, men are more likely to select the Fed article than in the control treatment without names.
} 
a 1-7 Likert scale: (i) whether they found the article interesting, (ii) whether they trusted the cited policymaker's competence in understanding the economy and proposing effective policy measures to counteract the COVID-19 crisis, and (iii) whether they thought policymakers like the one featured in the article were effective at helping the economy in the current situation. We are interested in whether female respondents are more likely to give positive ratings to the article featuring Michelle Bowman than the article featuring Richard Clarida. Because in groups 2 and 3, articles (and the gender of policymakers) were selected endogenously, for this test, we restrict the analysis to respondents in the control treatment who selected the Fed article and were randomly assigned either the Bowman or the Clarida article. A caveat with this test is that the article content varied, as did the gender of the policymaker (see Online Appendix B.2). Thus, any differences in the ratings across respondent groups could be driven either by the identity of the policymaker or the article content. Regression results, reported in Online Appendix Table A.4, do not indicate any systematic gender differences in the ratings of the articles, although, directionally, women rate the article featuring Michelle Bowman as relatively more interesting. ${ }^{40}$

In sum, women are more willing to select Fed-related information when it features a female policymaker, with no offsetting effect on the likelihood of men choosing the Fed article; if anything, the opposite occurs. Policy statements by female policymakers might thus reach a larger share of the overall population and increase the level of informedness about the macroeconomy through an extensive margin of information acquisition.

\subsection{Homophily and/or Taste for Diversity?}

We now assess the relative importance of two non-mutually exclusive potential drivers behind the channels we have considered so far: homophily and taste for diversity. Homophily is a tendency of humans to relate more to those who are similar along personal characteristics, such as gender or ethnicity/race. In our setting, a policymaker with the same gender and/or race might be seen as an "in-group" member, whereas a policymaker not sharing either of

\footnotetext{
${ }^{40}$ We note that female respondents give lower ratings to both articles along all three dimensions, even conditional on all observable characteristics, again suggesting a gender difference in the levels of interest and trust in central banks.
} 
these characteristics is from the "out-group." Under a taste-for-diversity channel, instead, some subjects might relate more to diverse policymakers irrespective of whether they share the same personal characteristics.

In our context, homophily predicts each group will react more strongly when exposed to an in-group policymaker. White women, for instance, should react more to Mr. Barkin than to Mr. Bostic, because Mr. Barkin shares at least their race. And Black men should react more to Mr. Barkin than to Ms. Daly, due to being of the same gender. Homophily also predicts White men should react less when facing a policymaker other than Mr. Barkin. None of these predictions is borne out in our results.

If, instead, subjects from underrepresented groups have a higher taste for diversity, homophily predicts they should react to the salience of any diverse demographic representation on the FOMC. For instance, White women and Blacks should react similarly to both Ms. Daly and Mr. Bostic and less to Mr. Barkin, which is consistent with our baseline evidence. At the same time, we find White men do not react, on average. For this reason, taste for diversity can only explain our results if it is heterogeneous across demographic groups.

To assess the possibility of systematic heterogeneity in taste for diversity across demographic groups, in the follow-up survey, we asked for respondents' agreement with the statement that "Public organizations such as the Federal Reserve should be required by law to have at least the same share of women and minorities in their top management as in the population overall" - that is, whether they support quotas. We also showed five statements related to diversity from policymakers, journalists, and academics, and elicited subjects' agreement. $^{41}$

In terms of support of quotas, the differences between White men and other groups are stark (see Figure 7): the histograms of the two groups are almost inverted. The first two columns of Table 9 show differences in means across individual groups (relative to White men), with and without additional controls. Within each ethnic/racial group, women express

\footnotetext{
${ }^{41}$ Four of these statements, by Claudia Sahm, Pedro Nicolaci da Costa, and Jerome Powell $(\times 2)$, implied more diversity was desirable; one statement, by Anthony Kronman, suggested costs of diversity. These statements were shown in randomized order and before we asked about the support for quotas; see Online Appendix B for details.
} 
stronger support for quotas. However, the coefficients for Black and Hispanic men are also significant and positive. Column (3) shows that two proxies for taste for diversity we elicited in the main survey-BLM support and considering discrimination against women an important problem - are strongly correlated with the support for quotas of the same respondents, even within group. We return to these proxies below.

We also take the first principal component of respondents' agreement levels to the five statements about diversity discussed above and standardize it to have mean zero and standard deviation of one. We call this variable the "diversity support score." Columns (4) and (5) of Table 9 show that Black respondents in particular express a strong taste for diversity. White women are, on average, 0.2 standard deviations more supportive than White men, whereas for Hispanic respondents, the difference is smaller (once we control for other characteristics). Again, our proxies from the main survey are strongly correlated with this outcome in column (6).

A heterogeneous taste for diversity across demographic groups would be consistent with most of our results, but other unobserved differences across groups might be driving the results, too. To further pin down the role of heterogeneous taste for diversity, we go back to our main experiment and consider four proxies for heterogeneous taste for diversity within the overrepresented group-White men. The four proxies we use are as follows: (i) respondents' support for the BLM movement; (ii) their agreement with the statement that discrimination against women is an important problem in the US; (iii) age, because younger respondents might be more used or sensitive to diverse representation; and (iv) political views, because recent proposals for increasing minority representation in public committees have come primarily from the Democratic party.

We consider the two key outcome variables for which we documented significant effects earlier - anchored unemployment expectations and distrust in the Fed's ability to manage inflation and unemployment. ${ }^{42}$ Given that the Bostic and Daly treatments produced effects of similar magnitude, we pool them and compare them with the Barkin treatment (the omitted category in the regression). Table 10 displays the results. Across all proxies, White

\footnotetext{
${ }^{42}$ Results are similar with the other type of distrust.
} 
men with a higher taste for diversity react more strongly to diverse policymakers, although the effect is not statistically significant for all proxies. When we enter all four interaction terms jointly (in columns 5 and 10), at least one of the interaction terms remains statistically significant. ${ }^{43}$ These results suggest that even among White men, those with a likely taste for diversity do incorporate FOMC forecasts more and trust the Fed more when diversity is more salient. ${ }^{44}$

Overall, we conclude a heterogeneous taste for diversity seems a more promising explanation for our results than homophily. Taste for diversity is heterogeneous across and within demographic groups and relates to subjects' response to FOMC diversity salience.

\subsection{Demand Effects and Persistence}

Within-subject experimental designs like ours raise the concern of demand effects, whereby subjects might guess the experimental hypotheses and align their behavior to please the experimenter or because they would like these hypotheses to be found correct in academic research that might inform policy and practice. ${ }^{45}$ In settings like ours, which study a general population that is uninformed about the researchers' hypotheses and receives fixed monetary payments for participation, the scope for demand effects has been shown to be minimal (see, e.g., De Quidt et al., 2018). Moreover, our discussion of the experimental procedure has emphasized several design features of the experiment that were purposefully implemented to reduce concerns of demand effects.

To further assess concerns about demand effects, we check if the effects detected in the main experiment at least partially persist several weeks later, when a subset of respondents took our follow-up survey - see Table A.7 in the Online Appendix. The effects on the an-

\footnotetext{
${ }^{43}$ Reduced significance of the individual interaction terms is not surprising, given the positive correlations among these four variables. An F-test for joint significance of the four interaction terms yields $p<0.03$ in both columns (5) and (10).

${ }^{44}$ Online Appendix Tables A.5 and A.6 show that the differential effects of exposure to Mr. Bostic or Ms. Daly for White female and Black respondents are robust to controlling for the same interaction effects as in this section.

${ }^{45}$ Note that the issue of demand effects was first discussed in social-psychology experiments in which students, who might have been informed about the psychological theories their instructors wanted to test, received class credits from participating in experiments. In that case, both pre-experimental knowledge and the structure of incentives might have induced subjects to align their behavior with the hypotheses to be tested.
} 
choring of unemployment expectations persist directionally, even if they are not statistically significant. This lack of statistical significance likely is due to a lack of statistical power, because the effects in the main experiment would also not be significant if we restricted the sample to respondents who took the follow-up survey. Similar results obtain for the other outcome variables we studied.

\section{Conclusions}

In a large-scale information experiment, we test whether the salience of a demographically diverse composition of the FOMC makes policy communication more effective in anchoring the subjective expectations of underrepresented groups and/or affects the expectations of other groups. Diversity salience appears to increase the effectiveness of communication in terms of influencing White female and Black individuals' macroeconomic expectations, especially for the unemployment rate. At the same time - and crucially to assess the aggregate effects of diversity salience-White men, the overrepresented group, do not react negatively.

In terms of channels, direct tests suggest diversity salience increases underrepresented groups' trust in the FOMC as well as their interest in gathering Fed-related information. Various patterns in the data are consistent with a heterogeneous taste for diversity (rather than simple homophily) as a driver of these effects.

Future research should study the differential effectiveness of policy communications to reach demographic groups based on the content of communication. The information-selection experiment in our follow-up survey suggests diversity itself can spark interest in policy communications, but the wording of messages and the way they are disseminated may have larger effects. Moreover, the nature of our experimental setting hinders us from being able to quantify the aggregate effects of increasing diversity on the FOMC (or other policy committees) on the effects of policy actions. Future research using field settings should be devoted to this fundamental question. 


\section{Bibliography}

Akerlof, G. A. And R. E. Kranton (2000): "Economics and identity," Quarterly Journal of Economics, 115, 715-753.

Alsan, M., O. Garrick, and G. Graziani (2019): "Does diversity matter for health? Experimental evidence from Oakland," American Economic Review, 109, 4071-4111.

Argente, D. And M. Lee (2021): "Cost of living inequality during the great recession," Journal of the European Economic Association, 19, 913-952.

Armantier, O., S. Nelson, G. Topa, W. Van der Klaauw, and B. Zafar (2016): "The Price is Right: Updating Inflation Expectations in a Randomized Price Information Experiment," Review of Economics and Statistics, 98, 503-523.

Armantier, O., G. Topa, W. van der Klaauw, and B. Zafar (2017): "An Overview of the Survey of Consumer Expectations," Federal Reserve Bank of New York Economic Policy Review, 23, 51-72.

Armona, L., A. Fuster, And B. Zafar (2019): "Home price expectations and behaviour: Evidence from a randomized information experiment," The Review of Economic Studies, 86, 1371-1410.

Bachmann, R., T. O. Berg, and E. R. Sims (2015): "Inflation expectations and readiness to spend: Cross-sectional evidence," American Economic Journal: Economic Policy, $7,1-35$.

Bartscher, A., M. Kuhn, M. Schularick, And P. Wachtel (2021): "Monetary policy and racial inequality," Discussion Paper 15734, CEPR.

Benjamin, D. J., J. J. Choi, And A. J. Strickland (2010): "Social identity and preferences," American Economic Review, 100, 1913-28.

Bergman, N., D. A. Matsa, And M. Weber (2020): "Heterogeneous Labor Market Effects of Monetary Policy," Research Paper 21-02, Chicago Booth.

Binder, C. (2020): "Coronavirus fears and macroeconomic expectations," Review of Economics and Statistics, 102, 721-730.

Binder, C. AND A. Rodrigue (2018): "Household informedness and long-run inflation expectations: Experimental evidence," Southern Economic Journal, 85, 580-598.

Blinder, A. S. (2007): "Monetary policy by committee: Why and how?" European Journal of Political Economy, 23, 106-123.

Blinder, A. S., M. Ehrmann, M. Fratzscher, J. De HaAn, and D.-J. Jansen (2008): "Central bank communication and monetary policy: A survey of theory and evidence," Journal of Economic Literature, 46, 910-45.

Cavallo, A., G. Cruces, and R. Perez-Truglia (2017): "Inflation expectations, learning, and supermarket prices: Evidence from survey experiments," American Economic Journal: Macroeconomics, 9, 1-35. 
Christelis, D., D. Georgarakos, T. Jappelli, and M. Van Rooij (2020): "Trust in the Central Bank and Inflation Expectations," International Journal of Central Banking, $16,1-37$.

Cohn, A. And M. A. Maréchal (2016): "Priming in economics," Current Opinion in Psychology, 12, 17-21.

Coibion, O., D. Georgarakos, Y. Gorodnichenko, G. Kenny, and M. Weber (2021): "The Effect of Macroeconomic Uncertainty on Household Spending," Tech. rep., National Bureau of Economic Research.

Coibion, O., D. Georgarakos, Y. Gorodnichenko, and M. Weber (2020a): "Forward guidance and household expectations," Tech. rep., National Bureau of Economic Research.

Coibion, O., Y. Gorodnichenko, S. Kumar, and M. Pedemonte (2020b): "Inflation expectations as a policy tool?" Journal of International Economics, 124, 103297.

Coibion, O., Y. Gorodnichenko, And M. Weber (2019): "Monetary Policy Communications and their Effects on Household Inflation Expectations," Working Paper.

Cook, L. D., T. D. Logan, And J. M. PArman (2014): "Distinctively black names in the American past," Explorations in Economic History, 53, 64-82.

Crump, R. K., S. Eusepi, A. Tambalotti, and G. Topa (2018): "Subjective intertemporal substitution," Staff Report 734, FRB of New York.

D'Acunto, F. (2020): "Identity and Choice Under Risk," Available at SSRN 2641182.

D’Acunto, F., D. Hoang, M. Palovitta, And M. Weber (2020): "Effective Policy Communication: Targets versus Instruments," Working paper, Chicago Booth.

(2021a): "IQ, Expectations, and Choice," Review of Economic Studies (forthcoming).

D'Acunto, F., D. Hoang, And M. Weber (2021b): "Managing Households' Expectations with Unconventional Policies," Review of Financial Studies (forthcoming).

D'Acunto, F., U. Malmendier, J. Ospina, And M. Weber (2021c): "Exposure to Grocery Prices and Inflation Expectations," Journal of Political Economy (forthcoming).

D'Acunto, F., U. Malmendier, and M. Weber (2021d): "Gender Roles and the Gender Expectations Gap," Proceedings of the National Academy of Sciences (forthcoming).

Das, S., C. M. Kuhnen, And S. NAGEl (2020): "Socioeconomic status and macroeconomic expectations," The Review of Financial Studies, 33, 395-432.

De Quidt, J., J. Haushofer, And C. Roth (2018): "Measuring and bounding experimenter demand," American Economic Review, 108, 3266-3302.

Ehrmann, M., M. Soudan, And L. Stracca (2013): "Explaining European Union citizens' trust in the European Central Bank in normal and crisis times," The Scandinavian Journal of Economics, 115, 781-807. 
FeHR, E. AND K. Hoff (2011): "Introduction: Tastes, castes and culture: The influence of society on preferences," The Economic Journal, 121, F396-F412.

Fuster, A., R. Perez-Truglia, M. Wiederholt, and B. Zafar (2020): "Expectations with Endogenous Information Acquisition: An Experimental Investigation," Review of Economics and Statistics, forthcoming.

Gerardi, K., P. Willen, And D. H. Zhang (2020): "Mortgage Prepayment, Race, and Monetary Policy," Working Paper No. 20-7, Federal Reserve Bank of Boston.

Giglio, S., M. Maggiori, J. Stroebel, And S. Utkus (2021): "Five Facts about Beliefs and Portfolios," American Economic Review, 111, 1481-1522.

Greenwood, B. N., S. Carnahan, and L. Huang (2018): "Patient-physician gender concordance and increased mortality among female heart attack patients," Proceedings of the National Academy of Sciences, 115, 8569-8574.

HaAland, I., C. Roth, And J. Wohlfart (2021): "Designing Information Provision Experiments," Journal of Economic Literature, forthcoming.

Haldane, A. And M. McMahon (2018): "Central bank communications and the general public," in AEA Papers and Proceedings, vol. 108, 578-83.

Jost, A. (2017): "Is Monetary Policy Too Complex for the Public? Evidence from the UK," Working Paper 15/2017, Swiss National Bank.

Kaplan, G. And S. Schulhofer-Wohl (2017): "Inflation at the household level," Journal of Monetary Economics, 91, 19-38.

KuChler, T. AND B. ZAFAR (2019): "Personal experiences and expectations about aggregate outcomes," The Journal of Finance, 74, 2491-2542.

Malmendier, U. AND S. NAGel (2016): "Learning From Inflation Experiences," Quarterly Journal of Economics, 131, 53-87.

Riboni, A. And F. J. Ruge-Murcia (2010): "Monetary policy by committee: consensus, chairman dominance, or simple majority?" Quarterly Journal of Economics, 125, 363-416.

Roth, C., S. Settele, And J. Wohlfart (2021): "Risk Exposure and Acquisition of Macroeconomic Information," American Economic Review: Insights, forthcoming.

Roth, C. And J. Wohlfart (2020): "How do expectations about the macroeconomy affect personal expectations and behavior?" Review of Economics and Statistics, 102, $731-748$.

SCHNABEL, I. (2020): "The importance of trust for the ECB's monetary policy," Speech at the Hamburg Institute for Social Research, available at https: //www.ecb.europa.eu/ press/key/date/2020/html/ecb.sp201216_1 9caf7588cd.en.html.

Shayo, M. (2020): "Social identity and economic policy," Annual Review of Economics.

Steele, C. M. And J. Aronson (1995): "Stereotype threat and the intellectual test performance of African Americans." Journal of Personality and Social Psychology, 69, 797. 
Stolper, O. And A. WAlter (2019): "Birds of a feather: The impact of homophily on the propensity to follow financial advice," The Review of Financial Studies, 32, 524-563.

U.S. Census Bureau (2020): "Annual Estimates of the Resident Population by Sex, Race, and Hispanic Origin for the United States: April 1, 2010 to July 1, 2019 (NC-EST2019SR11H)," Tech. rep., Population Division. 
Figure 1: Share of respondents with anchored expectations: Control Group

A. Unemployment expectations

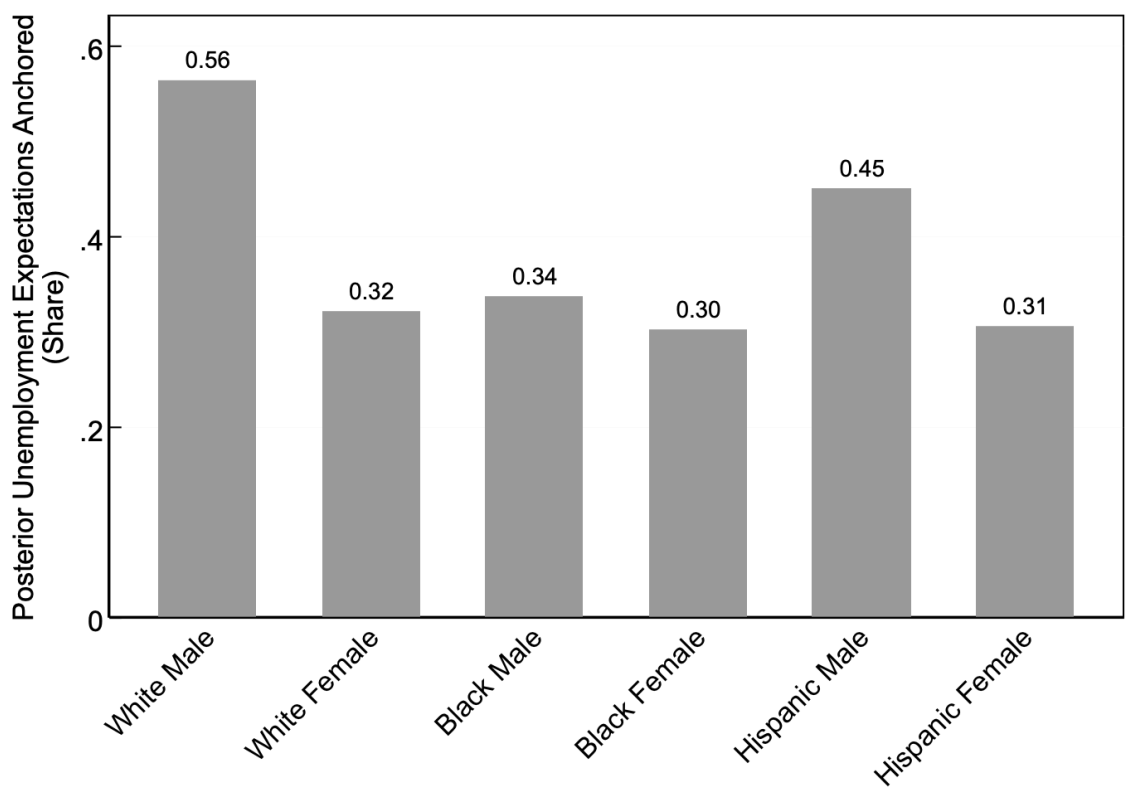

B. Inflation expectations

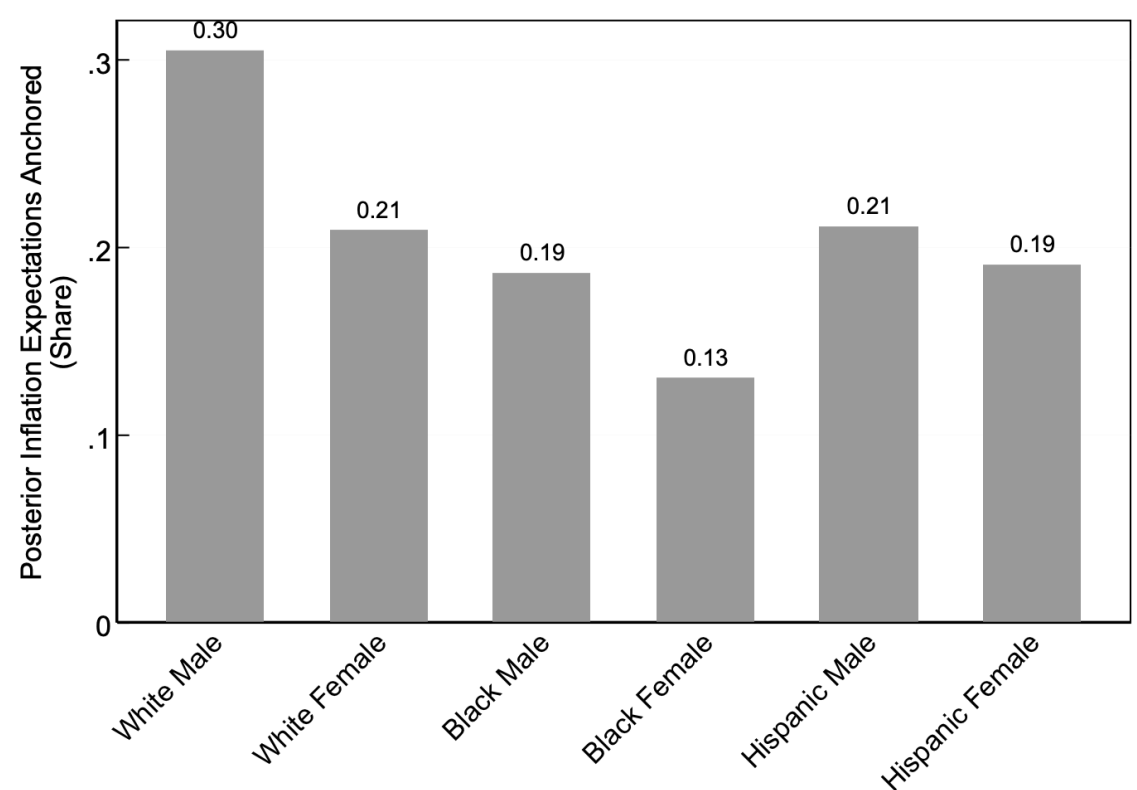

Note: Figure reports the share of control-group subjects, who were not provided any information about FOMC forecasts, that have "anchored" unemployment and inflation expectations, by demographic group. Expectations are considered anchored if the modal bin of the posterior distribution includes at least one of the two June 2020 FOMC forecasts, which are the ones shown to treated subjects. 
Figure 2: Estimated treatment effects on share of respondents with anchored expectations

\section{A. Unemployment expectations}

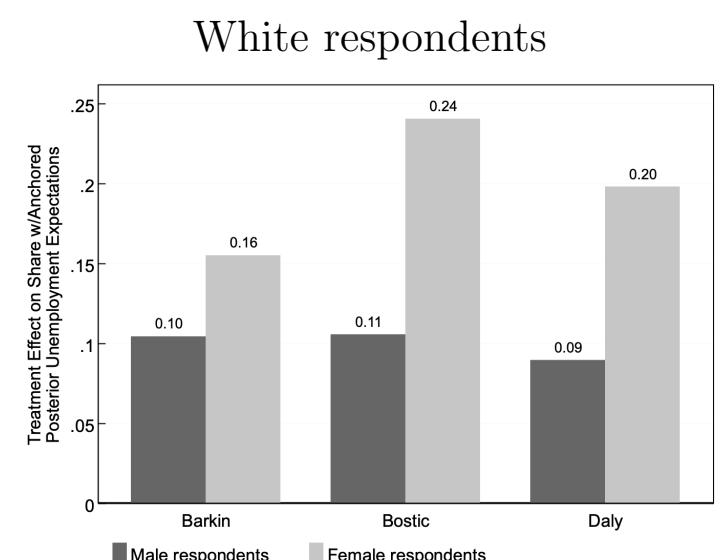

$\stackrel{\oplus}{\perp}$

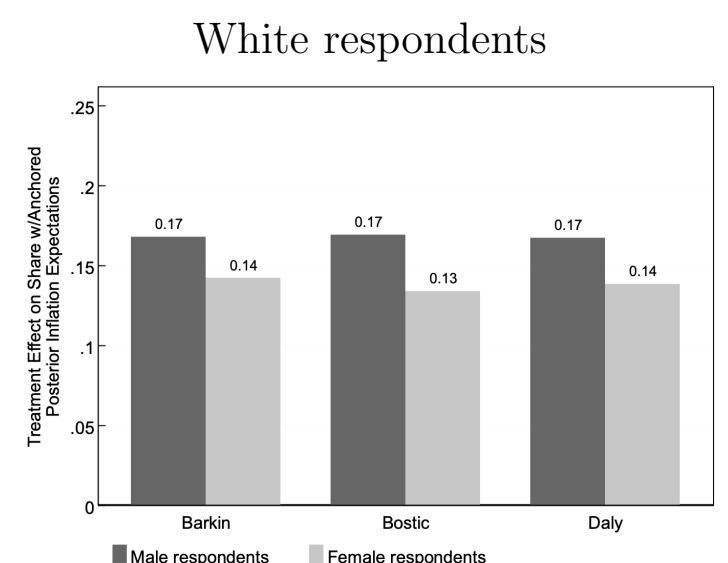

\section{Black respondents}

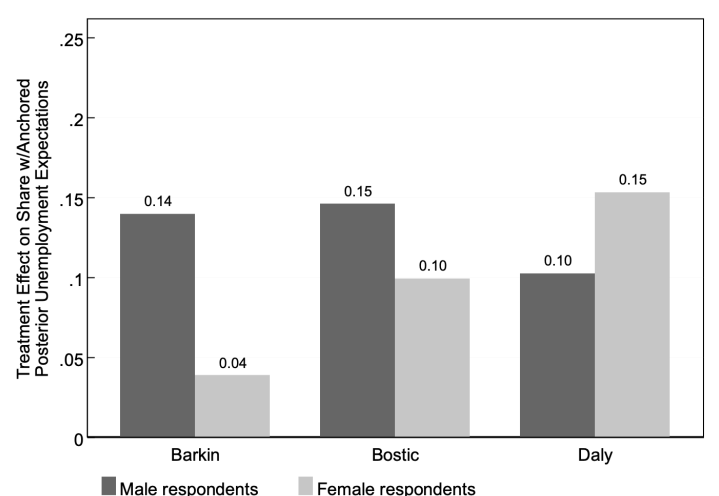

\section{B. Inflation expectations}

Black respondents

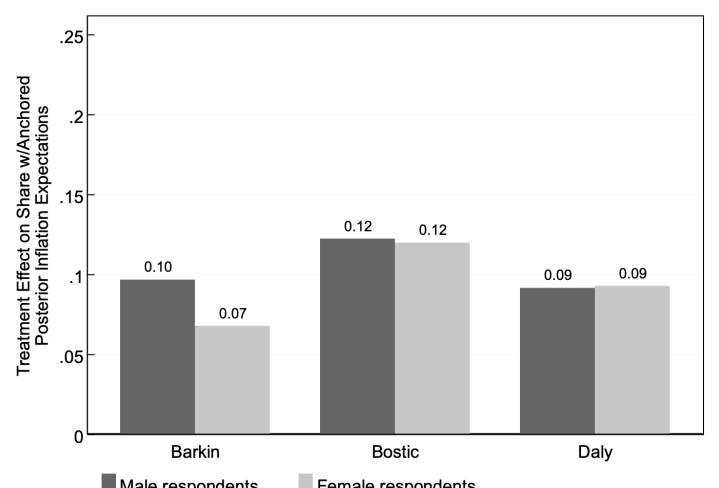

Male respondents Female respondents
Hispanic respondents

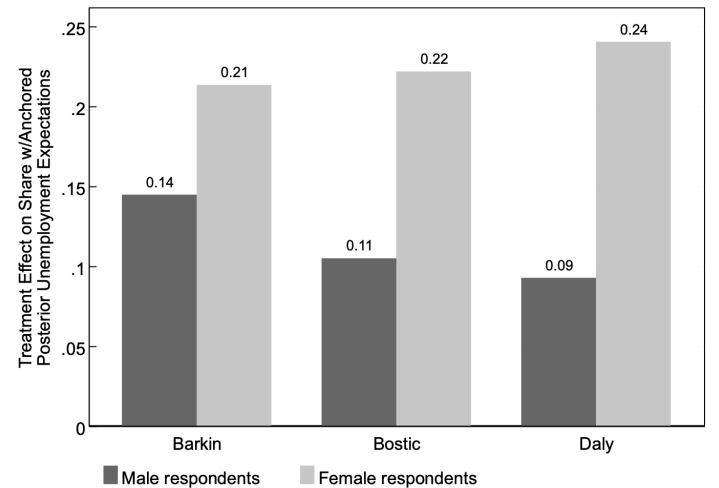

Hispanic respondents

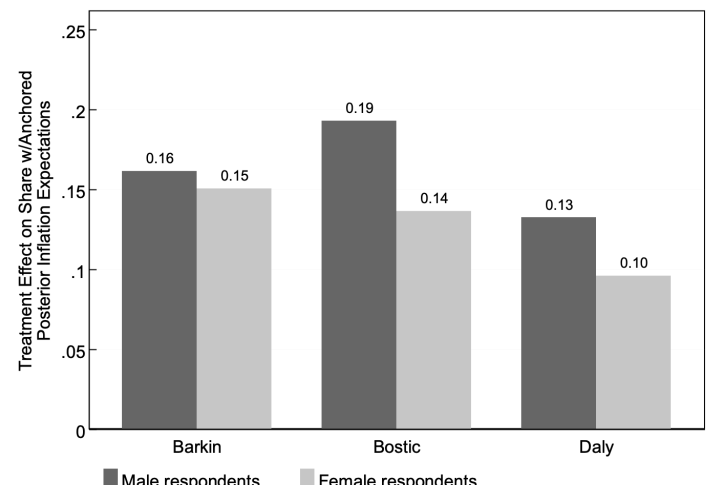

Note: Figure reports the estimated treatment effects of exposure to the June 2020 FOMC forecasts for unemployment (Panel A) or inflation (Panel B) alongside the portrait of the FOMC member reported on the x-axis on the share of subjects with "anchored" expectations across demographic groups, relative to subjects in the control group. Expectations are considered anchored if the modal bin of the posterior distribution includes at least one of the two FOMC forecasts numbers shown. 
Figure 3: Channel 1-Trust in Policy Committees' Action (Absent-Intervention)

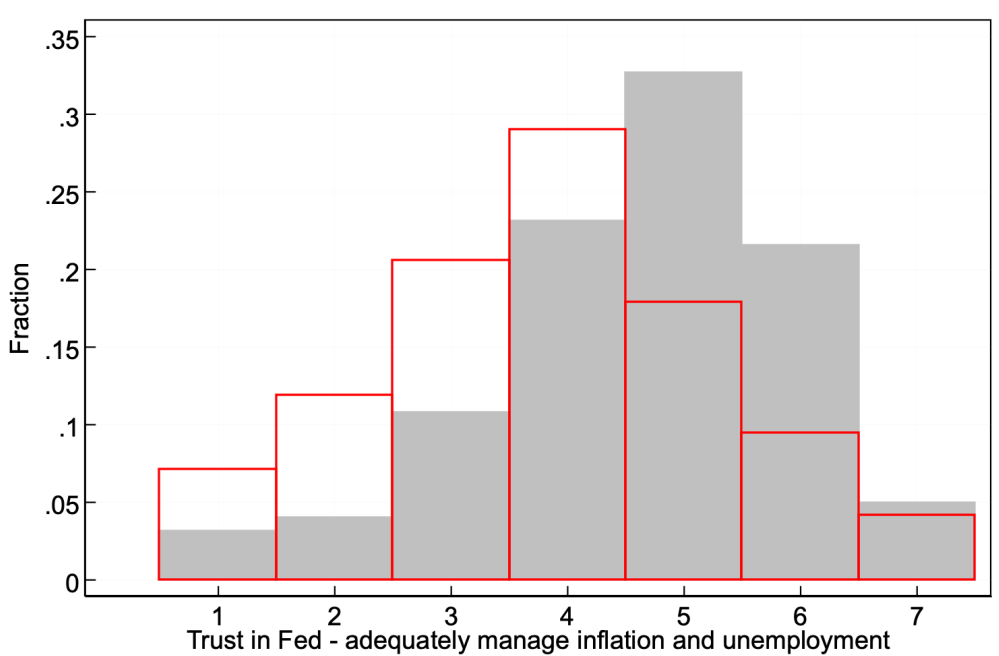

White male respondents $\quad \square$ other respondents

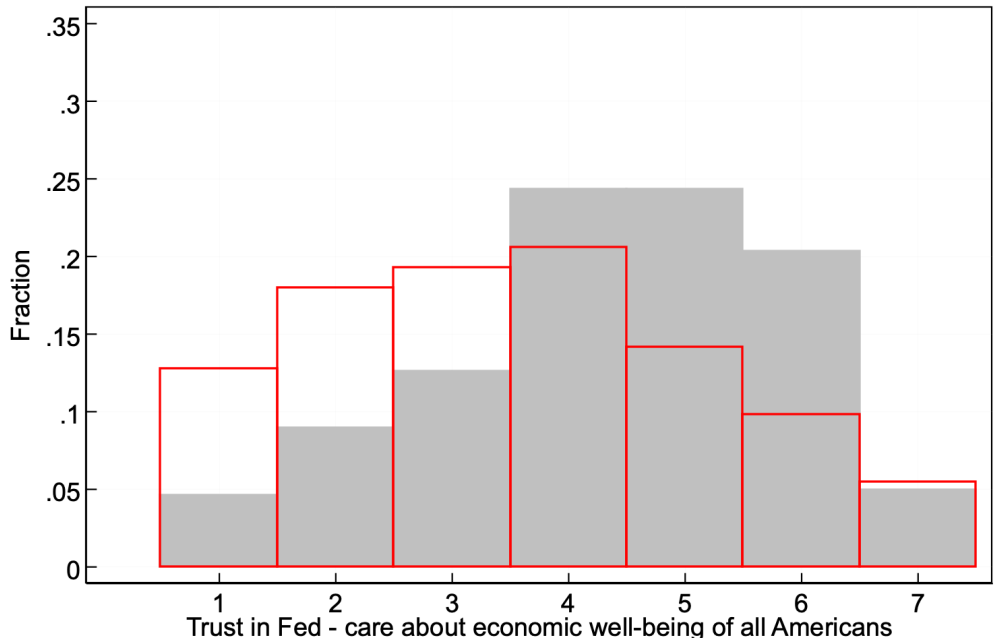

White male respondents $\square$ other respondents

Note: Survey question in left panel was "How much do you trust the Fed to adequately manage inflation and unemployment?"; survey question in right panel was "And how much do you trust the Fed to care about the economic well-being of all Americans, including people like yourself?" In both cases, answers were on 7-point scale from 1 ("no trust at all") to 7 ("complete trust"). In these two histograms, only respondents in the control group are shown $(N=1,294)$. 
Figure 4: Channel 1-Trust in Policy Committees' Action (Control Group)

A. Distrust that Fed adequately manages unemployment and inflation

White respondents

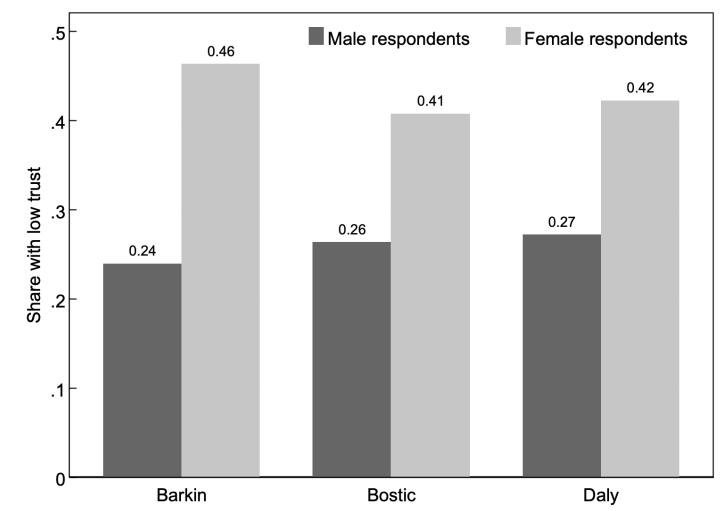

Black respondents

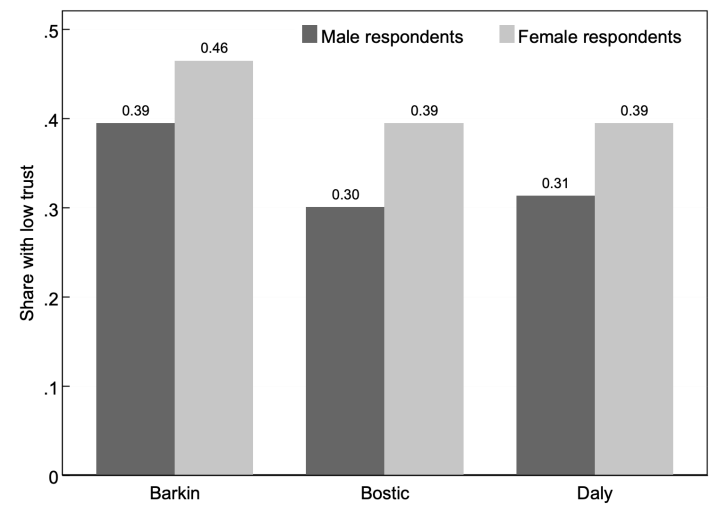

Hispanic respondents

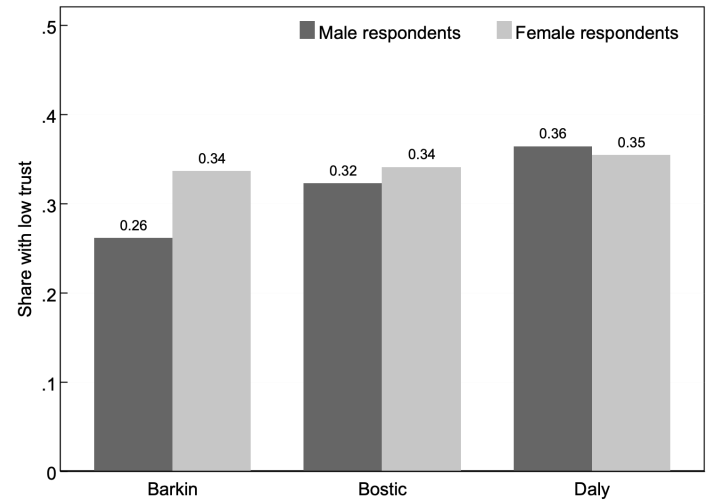

B. Distrust that Fed cares about economic well-being of all Americans

White respondents

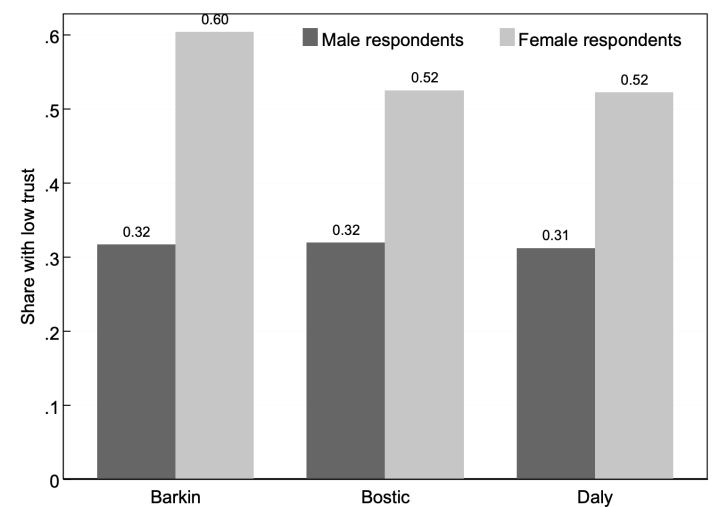

Black respondents

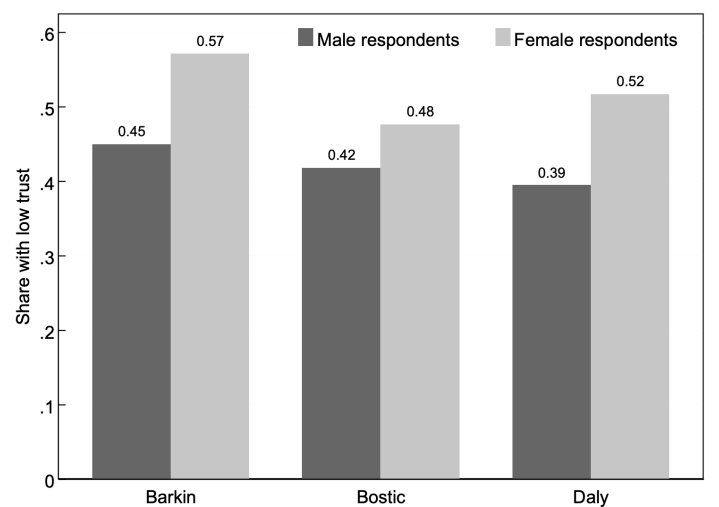

Hispanic respondents

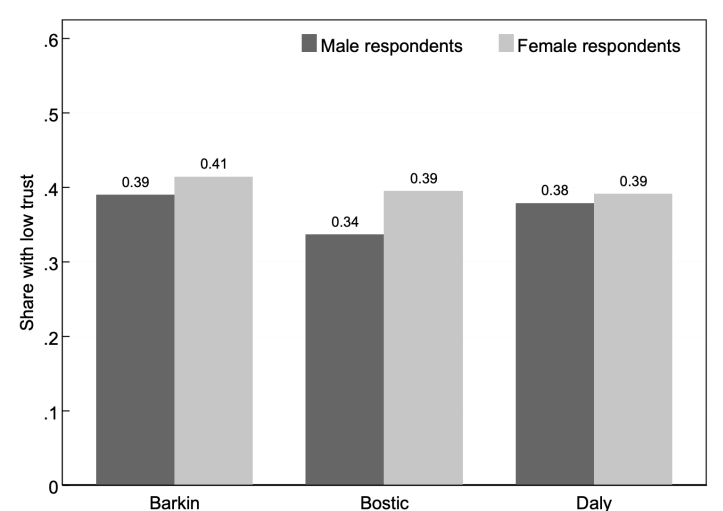

Note: Figure reports the share of respondents that indicated low trust in the Fed $(\leq 3$ out of 7$)$ after seeing the portrait of the FOMC member reported on the $\mathrm{x}$-axis, by demographic group. Survey question in Panel A was "How much do you trust the Fed to adequately manage inflation and unemployment?"; survey question Panel B was "And how much do you trust the Fed to care about the economic well-being of all Americans, including people like yourself?" In both cases, answers were on 7-point scale from 1 ("no trust at all") to 7 ("complete trust"). 
Figure 5: Channel 2-Information and Knowledge about the Fed (PreIntervention)

A. Knows that FOMC sets interest rates

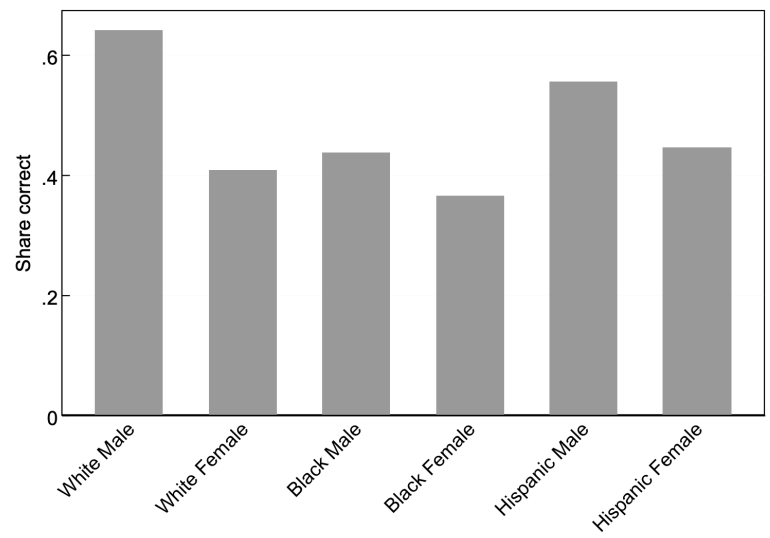

B. Knows Fed's inflation target

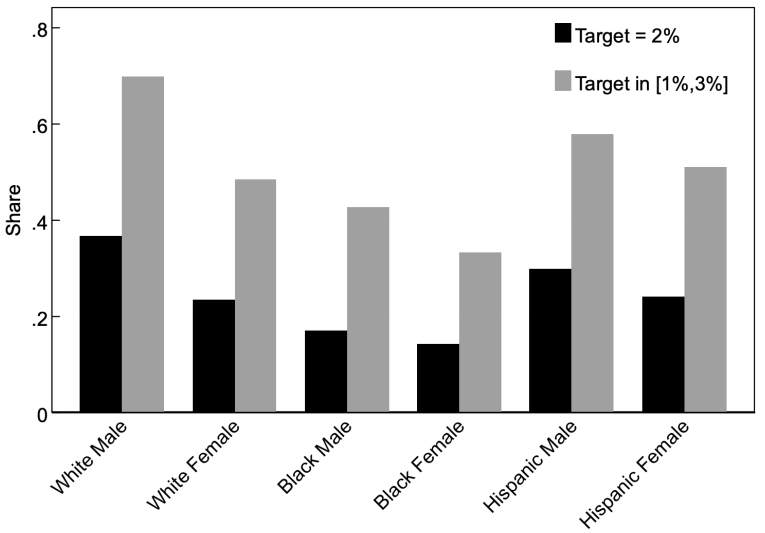

Note: In Panel A, question is "Eight times a year a group of people meets to set the basic interest rate level in the United States. Who do you think comprises this group?" The correct answer, out of 7 multiple choice options, is "The Federal Open Market Committee (part of the Federal Reserve, or Fed)." In the question underlying Panel B, respondents were asked for the annual inflation rate the Federal Reserve tries to achieve (correct answer: $2 \%$ ).

Figure 6: Channel 2-Fed Information Acquisition (Follow-Up Survey)

Male respondents

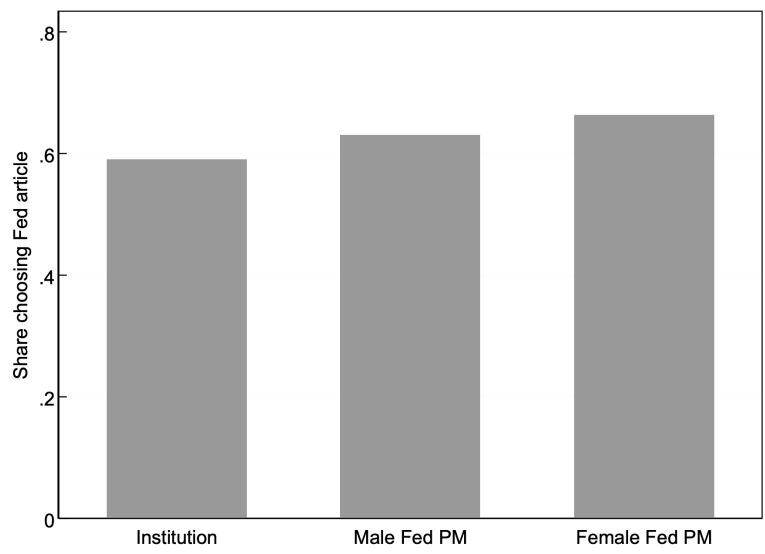

Female respondents

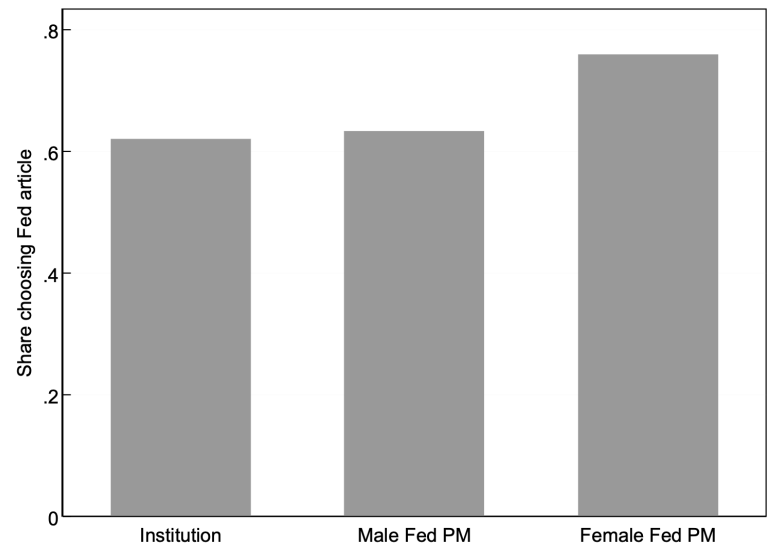

Note: In "Institution" treatment, respondents select between an article featuring an unnamed policymaker from the CBO or the Fed. In "Male Fed PM" treatment, choice is between article featuring Mr. Philipp Swagel, Director of the CBO, or Mr. Richard Clarida, Governor, Federal Reserve Board. In "Female Fed PM" treatment, choice is between article featuring Mr. Philipp Swagel, Director of the CBO, or Ms. Michelle Bowman, Governor, Federal Reserve Board. 
Figure 7: Taste for Diversity—Support for Quotas (Follow-Up Survey)

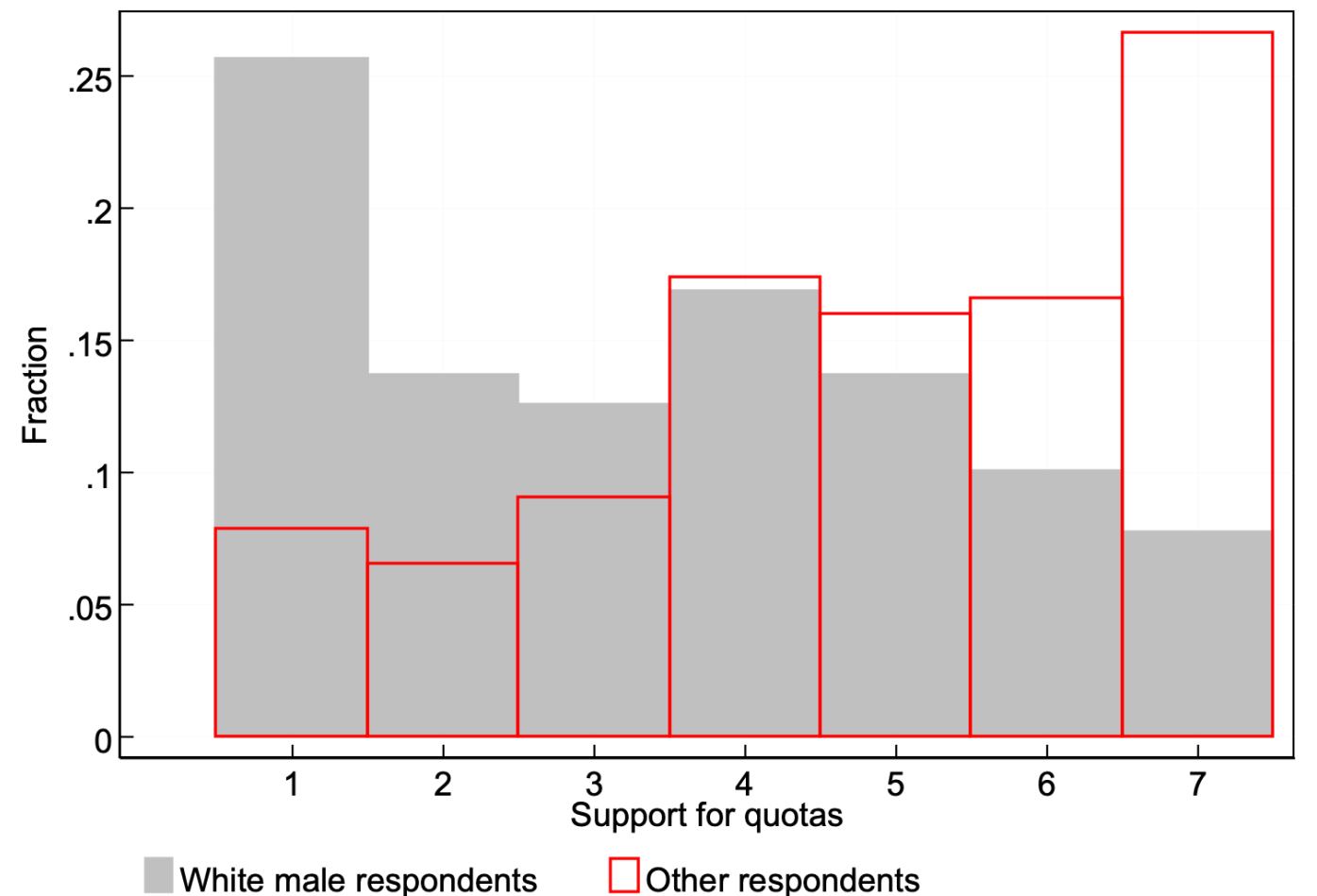

Note: Respondents were asked to indicate their level of agreement with the statement "Public organizations such as the Federal Reserve should be required by law to have at least the same share of women and minorities in their top management as in the population overall" on a 7-point scale from 1 ("completely disagree") to 7 ("completely agree"). 
Table 1: Summary Statistics

\begin{tabular}{|c|c|c|c|}
\hline & Mean & Median & St.Dev. \\
\hline \multicolumn{4}{|l|}{ Demographic Characteristics } \\
\hline Female $(0 / 1)$ & 0.50 & 0.00 & 0.50 \\
\hline Black $(0 / 1)$ & 0.30 & 0.00 & 0.46 \\
\hline Hispanic $(0 / 1)$ & 0.19 & 0.00 & 0.39 \\
\hline Age (years) & 45.75 & 45.00 & 17.04 \\
\hline Married $(0 / 1)$ & 0.55 & 1.00 & 0.50 \\
\hline College $(\mathrm{BA}+)(0 / 1)$ & 0.41 & 0.00 & 0.49 \\
\hline Employed $(0 / 1)$ & 0.55 & 1.00 & 0.50 \\
\hline Retired $(0 / 1)$ & 0.19 & 0.00 & 0.39 \\
\hline Unemployed $(0 / 1)$ & 0.12 & 0.00 & 0.32 \\
\hline Household income $\geq 75 \mathrm{k}(0 / 1)$ & 0.40 & 0.00 & 0.49 \\
\hline Income reduction during pandemic $(0 / 1)$ & 0.43 & 0.00 & 0.50 \\
\hline Can’t pay for $\$ 400$ expense $(0 / 1)$ & 0.14 & 0.00 & 0.34 \\
\hline Homeowner $(0 / 1)$ & 0.59 & 1.00 & 0.49 \\
\hline Holds stock $(0 / 1)$ & 0.41 & 0.00 & 0.49 \\
\hline Has 401k $(0 / 1)$ & 0.55 & 1.00 & 0.50 \\
\hline Democrat $(0 / 1)$ & 0.43 & 0.00 & 0.50 \\
\hline Republican (0/1) & 0.25 & 0.00 & 0.43 \\
\hline Does most of groceries $(0 / 1)$ & 0.71 & 1.00 & 0.45 \\
\hline Makes all financial decisions $(0 / 1)$ & 0.47 & 0.00 & 0.50 \\
\hline Nr. fin. literacy questions correct (0-2) & 0.91 & 1.00 & 0.77 \\
\hline \multicolumn{4}{|l|}{ Perceptions and Expectations } \\
\hline Prior: Unemployment in 12 months (\%) & 21.27 & 12.00 & 20.29 \\
\hline Posterior: E(Unemployment) (mean, \%) & 11.42 & 11.15 & 3.50 \\
\hline Prior: Inflation over 12 months (\%) & 10.29 & 4.00 & 14.61 \\
\hline Posterior: E(Inflation) (mean, \%) & 2.63 & 2.30 & 3.25 \\
\hline Trust in Fed Ability (1-7) & 3.99 & 4.00 & 1.54 \\
\hline Trust in Fed Caring for All (1-7) & 3.73 & 4.00 & 1.71 \\
\hline Obs. & 9140 & & \\
\hline
\end{tabular}

This table reports summary statistics for the demographics as well as economic perceptions and expectations of the sample of subjects in the main survey. Priors for unemployment and inflation are point forecasts, and are winsorized at the 2.5th and 97.5th percentile. Posteriors are imputed means based on the subjective probability distribution over different bins provided by the subjects. "Trust in Fed Ability" refers to reported trust in the Fed to adequately manage inflation and unemployment, and "Trust in Fed Caring for All" to trust in the Fed to care about the economic well-being of all Americans, "including people like yourself." 


\section{Table 2: Effects of Diversity Salience and Information Types on Unemployment Expectations across Groups}

A. Effects on Binary Indicator for Anchored Unemployment Expectations

\begin{tabular}{|c|c|c|c|c|c|c|c|c|}
\hline & \multicolumn{2}{|c|}{ White } & \multicolumn{2}{|c|}{ Black } & \multicolumn{2}{|c|}{ Hispanic } & \multicolumn{2}{|c|}{ All } \\
\hline & M & F & M & F & $\mathrm{M}$ & F & Unw. & Wtd. \\
\hline & (1) & $(2)$ & (3) & (4) & $(5)$ & (6) & (7) & (8) \\
\hline \multirow[t]{2}{*}{ Bostic } & 0.010 & $0.052^{* *}$ & 0.024 & $0.083^{* *}$ & -0.077 & -0.005 & $0.025^{*}$ & $0.023^{*}$ \\
\hline & $(0.025)$ & $(0.024)$ & $(0.033)$ & $(0.034)$ & $(0.047)$ & $(0.044)$ & $(0.013)$ & $(0.013)$ \\
\hline \multirow[t]{2}{*}{ Daly } & -0.029 & $0.047^{*}$ & -0.031 & $0.096^{* * *}$ & -0.003 & -0.022 & 0.013 & 0.012 \\
\hline & $(0.025)$ & $(0.024)$ & $(0.032)$ & $(0.034)$ & $(0.048)$ & $(0.042)$ & $(0.013)$ & $(0.013)$ \\
\hline \multirow[t]{2}{*}{ UR forecast } & $0.094^{* * *}$ & $0.142^{* * *}$ & $0.134^{* * *}$ & 0.020 & $0.160^{* *}$ & $0.209^{* * *}$ & $0.118^{* * *}$ & $0.122^{* * *}$ \\
\hline & $(0.032)$ & $(0.031)$ & $(0.041)$ & $(0.043)$ & $(0.063)$ & $(0.052)$ & $(0.016)$ & $(0.017)$ \\
\hline \multirow[t]{2}{*}{ Infl. forecast } & 0.021 & 0.017 & $0.086^{* *}$ & $-0.077^{*}$ & 0.087 & 0.044 & 0.024 & 0.023 \\
\hline & $(0.033)$ & $(0.031)$ & $(0.041)$ & $(0.043)$ & $(0.062)$ & $(0.051)$ & $(0.016)$ & $(0.017)$ \\
\hline Controls & Yes & Yes & Yes & Yes & Yes & Yes & Yes & Yes \\
\hline Avg. Y & 0.61 & 0.44 & 0.43 & 0.33 & 0.52 & 0.42 & 0.47 & 0.49 \\
\hline Adj. R2 & 0.14 & 0.17 & 0.10 & 0.10 & 0.13 & 0.16 & 0.16 & 0.17 \\
\hline Obs. & 2305 & 2472 & 1540 & 1237 & 731 & 853 & 9140 & 9140 \\
\hline
\end{tabular}

B. Effects on E(unemployment rate)

\begin{tabular}{|c|c|c|c|c|c|c|c|c|}
\hline & \multicolumn{2}{|c|}{ White } & \multicolumn{2}{|c|}{ Black } & \multicolumn{2}{|c|}{ Hispanic } & \multicolumn{2}{|c|}{ All } \\
\hline & M & $\mathrm{F}$ & M & F & $\mathrm{M}$ & F & Unw. & Wtd. \\
\hline & (1) & $(2)$ & (3) & $(4)$ & (5) & (6) & (7) & (8) \\
\hline \multirow[t]{2}{*}{ Bostic } & -0.183 & -0.098 & $-0.359^{*}$ & -0.162 & 0.156 & -0.065 & $-0.156^{* *}$ & $-0.133^{*}$ \\
\hline & $(0.134)$ & $(0.153)$ & $(0.203)$ & $(0.227)$ & $(0.270)$ & $(0.288)$ & $(0.078)$ & $(0.080)$ \\
\hline \multirow[t]{2}{*}{ Daly } & -0.059 & $-0.288^{*}$ & 0.019 & $-0.362^{*}$ & 0.353 & 0.046 & -0.122 & -0.124 \\
\hline & $(0.139)$ & $(0.152)$ & $(0.200)$ & $(0.218)$ & $(0.290)$ & $(0.282)$ & $(0.078)$ & $(0.081)$ \\
\hline \multirow[t]{2}{*}{ UR forecast } & -0.193 & $-0.967^{* * *}$ & $-0.466^{*}$ & $-0.693^{* *}$ & -0.486 & $-0.850^{* *}$ & $-0.594^{* * *}$ & $-0.589^{* * *}$ \\
\hline & $(0.184)$ & $(0.195)$ & $(0.259)$ & $(0.292)$ & $(0.372)$ & $(0.357)$ & $(0.101)$ & $(0.104)$ \\
\hline \multirow[t]{2}{*}{ Infl. forecast } & 0.023 & -0.034 & -0.099 & -0.097 & 0.032 & -0.145 & -0.039 & -0.023 \\
\hline & $(0.189)$ & $(0.194)$ & $(0.262)$ & $(0.301)$ & $(0.378)$ & $(0.358)$ & $(0.102)$ & $(0.105)$ \\
\hline Controls & Yes & Yes & Yes & Yes & Yes & Yes & Yes & Yes \\
\hline Avg. Y & 10.30 & 11.75 & 11.72 & 12.51 & 10.91 & 11.78 & 11.42 & 11.25 \\
\hline Adj. R2 & 0.45 & 0.36 & 0.17 & 0.18 & 0.37 & 0.30 & 0.34 & 0.38 \\
\hline Obs. & 2305 & 2472 & 1540 & 1237 & 731 & 853 & 9140 & 9140 \\
\hline
\end{tabular}

Dependent variable in panel A: indicator $=1$ if modal bin of respondent's posterior contains one of the two FOMC forecast numbers shown for unemployment. Dependent variable in panel B: imputed mean of subjective posterior distribution for unemployment in 12 months. Omitted categories: Barkin (vs. Bostic and Daly), and general Fed info (control treatment). Column (7) pools all respondents and equal-weights them, while column (8) uses US-population-weights for the different groups. Controls include a cubic function of the prior point forecast (unemployment or inflation), quadratic function of survey date, and dummies for: geographic region, income category, education cat., age cat., employment status, marital status, political leaning, financial literacy score, whether lost job or reduced income since March 2020, whether state that could not pay for $\$ 400$ emergency expense, whether own primary residence, hold stock, have 401k or similar, whether do groceries, take financial decisions in household, and whether took survey on a mobile device. In columns (7) and (8) we also control for respondent race/ethnicity and gender. Robust standard errors in parentheses. ${ }^{*} \mathrm{p}<0.1,{ }^{* *} \mathrm{p}<0.05,{ }^{* * *} \mathrm{p}<0.01$. 


\section{Table 3: Channel 1-Trust in Fed (Control Group)}

\begin{tabular}{|c|c|c|c|c|c|c|c|c|}
\hline & \multicolumn{4}{|c|}{$\begin{array}{l}\text { Adequately manages inflation } \\
\text { and unemployment }\end{array}$} & \multicolumn{4}{|c|}{$\begin{array}{c}\text { Cares about economic well-being } \\
\text { of all Americans }\end{array}$} \\
\hline & \multicolumn{2}{|c|}{$\begin{array}{c}\text { Continuous } \\
(1-7) \\
\end{array}$} & \multicolumn{2}{|c|}{$\begin{array}{c}\text { Distrust }(0 / 1) \\
(\text { Trust } \leq 3) \\
\end{array}$} & \multicolumn{2}{|c|}{$\begin{array}{c}\text { Continuous } \\
(1-7)\end{array}$} & \multicolumn{2}{|c|}{$\begin{array}{c}\text { Distrust }(0 / 1) \\
(\text { Trust } \leq 3) \\
\end{array}$} \\
\hline & (1) & $(2)$ & (3) & (4) & (6) & (7) & (8) & (9) \\
\hline White Female & $\begin{array}{c}-0.939^{* * *} \\
(0.106)\end{array}$ & $\begin{array}{c}-0.634^{* * *} \\
(0.116)\end{array}$ & $\begin{array}{c}0.260^{* * *} \\
(0.034)\end{array}$ & $\begin{array}{c}0.182^{* * *} \\
(0.039)\end{array}$ & $\begin{array}{c}-0.995^{* * *} \\
(0.120)\end{array}$ & $\begin{array}{c}-0.614^{* * *} \\
(0.131)\end{array}$ & $\begin{array}{c}0.300^{* * *} \\
(0.036)\end{array}$ & $\begin{array}{c}0.201^{* * *} \\
(0.041)\end{array}$ \\
\hline Black Male & $\begin{array}{c}-0.684^{* * *} \\
(0.132)\end{array}$ & $\begin{array}{l}-0.217 \\
(0.149)\end{array}$ & $\begin{array}{c}0.190^{* * *} \\
(0.039)\end{array}$ & $\begin{array}{l}0.059 \\
(0.045)\end{array}$ & $\begin{array}{c}-0.649^{* * *} \\
(0.146)\end{array}$ & $\begin{array}{l}-0.098 \\
(0.169)\end{array}$ & $\begin{array}{c}0.193^{* * *} \\
(0.042)\end{array}$ & $\begin{array}{c}0.044 \\
(0.048)\end{array}$ \\
\hline Black Female & $\begin{array}{c}-0.903^{* * *} \\
(0.136)\end{array}$ & $\begin{array}{c}-0.526^{* * *} \\
(0.156)\end{array}$ & $\begin{array}{c}0.212^{* * *} \\
(0.043)\end{array}$ & $\begin{array}{l}0.109^{* *} \\
(0.051)\end{array}$ & $\begin{array}{c}-0.940^{* * *} \\
(0.155)\end{array}$ & $\begin{array}{c}-0.441^{* *} \\
(0.178)\end{array}$ & $\begin{array}{c}0.230^{* * *} \\
(0.046)\end{array}$ & $\begin{array}{l}0.093^{*} \\
(0.052)\end{array}$ \\
\hline Hispanic Male & $\begin{array}{c}-0.395^{* *} \\
(0.171)\end{array}$ & $\begin{array}{l}-0.119 \\
(0.217)\end{array}$ & $\begin{array}{c}0.189^{* * *} \\
(0.051)\end{array}$ & $\begin{array}{c}0.105 \\
(0.068)\end{array}$ & $\begin{array}{l}-0.354^{*} \\
(0.197)\end{array}$ & $\begin{array}{l}-0.050 \\
(0.253)\end{array}$ & $\begin{array}{c}0.188^{* * *} \\
(0.054)\end{array}$ & $\begin{array}{l}0.114^{*} \\
(0.068)\end{array}$ \\
\hline Hispanic Female & $\begin{array}{c}-0.754^{* * *} \\
(0.145)\end{array}$ & $\begin{array}{c}-0.463^{* *} \\
(0.200)\end{array}$ & $\begin{array}{c}0.180^{* * *} \\
(0.047)\end{array}$ & $\begin{array}{l}0.106 \\
(0.066)\end{array}$ & $\begin{array}{c}-0.652^{* * *} \\
(0.170)\end{array}$ & $\begin{array}{l}-0.317 \\
(0.232)\end{array}$ & $\begin{array}{c}0.212^{* * *} \\
(0.050)\end{array}$ & $\begin{array}{l}0.138^{* *} \\
(0.068)\end{array}$ \\
\hline Constant & $\begin{array}{c}4.625^{* * *} \\
(0.074)\end{array}$ & $\begin{array}{c}4.309^{* * *} \\
(0.236)\end{array}$ & $\begin{array}{c}0.178^{* * *} \\
(0.021)\end{array}$ & $\begin{array}{c}0.260^{* * *} \\
(0.076)\end{array}$ & $\begin{array}{c}4.354^{* * *} \\
(0.084)\end{array}$ & $\begin{array}{c}3.961^{* * *} \\
(0.265)\end{array}$ & $\begin{array}{c}0.262^{* * *} \\
(0.024)\end{array}$ & $\begin{array}{c}0.352^{* * *} \\
(0.077)\end{array}$ \\
\hline Controls & No & Yes & No & Yes & No & Yes & No & Yes \\
\hline Avg. Y & 4.03 & 4.03 & 0.34 & 0.34 & 3.76 & 3.76 & 0.44 & 0.44 \\
\hline $\mathrm{SD} \mathrm{Y}$ & 1.49 & 1.49 & 0.47 & 0.47 & 1.69 & 1.69 & 0.50 & 0.50 \\
\hline Adj. R2 & 0.06 & 0.14 & 0.04 & 0.09 & 0.05 & 0.15 & 0.05 & 0.12 \\
\hline Obs. & 1294 & 1294 & 1294 & 1294 & 1294 & 1294 & 1294 & 1294 \\
\hline
\end{tabular}

Omitted category: White male respondents. Controls in even columns include quadratic function of survey date and dummies for: geographic region, income category, education cat., age cat., employment status, marital status, political leaning, financial literacy score, whether lost job or reduced income since March 2020 , whether state that could not pay for $\$ 400$ emergency expense, whether own primary residence, hold stock, have 401k or similar, whether do groceries, take financial decisions in household, and whether took survey on a mobile device. Robust standard errors in parentheses. ${ }^{*} \mathrm{p}<0.1,{ }^{* *} \mathrm{p}<0.05,{ }^{* * *} \mathrm{p}<0.01$. 


\section{Table 4: Channel 1-Trust in Policy Committees' Action (Post-Intervention)}

A. Distrust that Fed adequately manages unemployment and inflation

\begin{tabular}{|c|c|c|c|c|c|c|c|c|}
\hline & \multicolumn{2}{|c|}{ White } & \multicolumn{2}{|c|}{ Black } & \multicolumn{2}{|c|}{ Hispanic } & \multicolumn{2}{|c|}{ All } \\
\hline & $\mathrm{M}$ & F & M & $\mathrm{F}$ & $\mathrm{M}$ & F & Unw. & Wtd. \\
\hline & (1) & $(2)$ & (3) & (4) & (5) & (6) & (7) & (8) \\
\hline \multirow[t]{2}{*}{ Bostic } & 0.018 & $-0.053^{* *}$ & $-0.078^{* *}$ & $-0.069^{*}$ & 0.053 & 0.017 & $-0.028^{* *}$ & -0.018 \\
\hline & $(0.023)$ & $(0.026)$ & $(0.032)$ & $(0.038)$ & $(0.045)$ & $(0.043)$ & $(0.013)$ & $(0.013)$ \\
\hline \multirow[t]{2}{*}{ Daly } & 0.026 & -0.038 & $-0.077^{* *}$ & $-0.069^{*}$ & $0.113^{* *}$ & 0.010 & -0.019 & -0.007 \\
\hline & $(0.024)$ & $(0.026)$ & $(0.032)$ & (0.037) & $(0.046)$ & (0.043) & $(0.013)$ & $(0.013)$ \\
\hline \multirow[t]{2}{*}{ UR forecast } & -0.020 & -0.020 & $-0.055^{* *}$ & 0.002 & -0.037 & -0.013 & $-0.025^{* *}$ & $-0.024^{* *}$ \\
\hline & $(0.019)$ & $(0.021)$ & $(0.026)$ & $(0.030)$ & $(0.038)$ & $(0.035)$ & $(0.010)$ & $(0.011)$ \\
\hline Controls & Yes & Yes & Yes & Yes & Yes & Yes & Yes & Yes \\
\hline Avg. Y & 0.26 & 0.43 & 0.34 & 0.42 & 0.32 & 0.34 & 0.35 & 0.35 \\
\hline Adj. R2 & 0.07 & 0.05 & 0.05 & 0.02 & 0.06 & 0.06 & 0.06 & 0.07 \\
\hline Obs. & 1980 & 2132 & 1320 & 1068 & 622 & 722 & 7846 & 7846 \\
\hline
\end{tabular}

B. Distrust that Fed cares about economic well-being of all Americans

\begin{tabular}{|c|c|c|c|c|c|c|c|c|}
\hline & \multicolumn{2}{|c|}{ White } & \multicolumn{2}{|c|}{ Black } & \multicolumn{2}{|c|}{ Hispanic } & \multicolumn{2}{|c|}{ All } \\
\hline & M & F & M & F & $\mathrm{M}$ & F & Unw. & Wtd. \\
\hline & (1) & $(2)$ & (3) & (4) & (5) & (6) & (7) & (8) \\
\hline \multirow[t]{2}{*}{ Bostic } & -0.004 & $-0.082^{* * *}$ & -0.017 & $-0.107^{* * *}$ & -0.058 & -0.016 & $-0.044^{* * *}$ & $-0.043^{* * *}$ \\
\hline & $(0.024)$ & $(0.025)$ & $(0.033)$ & $(0.038)$ & $(0.048)$ & $(0.045)$ & $(0.013)$ & $(0.014)$ \\
\hline \multirow[t]{2}{*}{ Daly } & -0.015 & $-0.084^{* * *}$ & $-0.059^{*}$ & $-0.065^{*}$ & 0.003 & -0.030 & $-0.048^{* * *}$ & $-0.045^{* * *}$ \\
\hline & $(0.025)$ & $(0.025)$ & $(0.033)$ & $(0.037)$ & $(0.049)$ & $(0.045)$ & $(0.013)$ & $(0.014)$ \\
\hline \multirow[t]{2}{*}{ UR forecast } & -0.026 & $-0.037^{*}$ & -0.023 & -0.004 & -0.054 & -0.038 & $-0.027^{* *}$ & $-0.031^{* * *}$ \\
\hline & $(0.020)$ & $(0.021)$ & $(0.027)$ & $(0.030)$ & $(0.039)$ & $(0.036)$ & $(0.011)$ & $(0.011)$ \\
\hline Controls & Yes & Yes & Yes & Yes & Yes & Yes & Yes & Yes \\
\hline Avg. Y & 0.32 & 0.55 & 0.42 & 0.52 & 0.37 & 0.40 & 0.44 & 0.43 \\
\hline Adj. R2 & 0.11 & 0.08 & 0.07 & 0.04 & 0.05 & 0.07 & 0.10 & 0.11 \\
\hline Obs. & 1980 & 2132 & 1320 & 1068 & 622 & 722 & 7846 & 7846 \\
\hline
\end{tabular}

Dependent variable: indicator $=1$ if respondent indicates trust $\leq 3$ out of 7 in terms of trusting Fed to adequately manage inflation and unemployment (panel A) or caring about the economic well-being of all Americans (panel B). Omitted categories: Barkin (vs. Bostic and Daly), and inflation information (vs. unemployment information). Column (7) pools all respondents and equal-weights them, while column (8) uses US-population-weights for the different groups. Controls include quadratic function of survey date and dummies for: geographic region, income category, education cat., age cat., employment status, marital status, political leaning, financial literacy score, whether lost job or reduced income since March 2020, whether state that could not pay for $\$ 400$ emergency expense, whether own primary residence, hold stock, have 401k or similar, whether do groceries, take financial decisions in household, and whether took survey on a mobile device. In columns (7) and (8) we also control for respondent race/ethnicity and gender. Robust standard errors in parentheses. ${ }^{*} \mathrm{p}<0.1,{ }^{* *} \mathrm{p}<0.05,{ }^{* * *} \mathrm{p}<0.01$. 


\section{Table 5: Channel 1 - Trust and Expectation Anchoring}

A. Effects of Distrust in Fed Ability on Expectation Anchoring

\begin{tabular}{|c|c|c|c|c|c|c|}
\hline & \multicolumn{3}{|c|}{ Unempl. Expectations } & \multicolumn{3}{|c|}{ Inflation Expectations } \\
\hline & $(1)$ & $(2)$ & $(3)$ & (4) & (5) & (6) \\
\hline Distrust in Fed Ability & $\begin{array}{c}-0.061^{* *} \\
(0.028)\end{array}$ & $\begin{array}{c}-0.098^{* * *} \\
(0.010)\end{array}$ & $\begin{array}{c}-0.084^{* * *} \\
(0.013)\end{array}$ & $\begin{array}{l}-0.005 \\
(0.024)\end{array}$ & $\begin{array}{c}-0.065^{* * *} \\
(0.009)\end{array}$ & $\begin{array}{r}-0.040^{* * *} \\
(0.012)\end{array}$ \\
\hline Distrust in Fed $\times$ UR forecast & & & $\begin{array}{l}-0.034^{*} \\
(0.020)\end{array}$ & & & \\
\hline Distrust in Fed $\times$ Infl. forecast & & & & & & $\begin{array}{c}-0.057^{* * *} \\
(0.019)\end{array}$ \\
\hline Sample & Control & All & All & Control & All & All \\
\hline Controls & Yes & Yes & Yes & Yes & Yes & Yes \\
\hline Avg. Y & 0.39 & 0.47 & 0.47 & 0.22 & 0.28 & 0.28 \\
\hline Adj. R2 & 0.17 & 0.17 & 0.17 & 0.09 & 0.11 & 0.11 \\
\hline Obs. & 1294 & 9140 & 9140 & 1294 & 9140 & 9140 \\
\hline
\end{tabular}

B. Effects of Distrust in Fed Caring for All on Expectation Anchoring

\begin{tabular}{lccccccc}
\hline & \multicolumn{3}{c}{ Unempl. Expectations } & & \multicolumn{3}{c}{ Inflation Expectations } \\
\cline { 2 - 3 } \cline { 7 - 8 } & $(1)$ & $(2)$ & $(3)$ & & $(4)$ & $(5)$ & $(6)$ \\
\hline Distrust in Fed Caring for All & $-0.096^{* * *}$ & $-0.086^{* * *}$ & $-0.087^{* * *}$ & & 0.009 & $-0.053^{* * *}$ & $-0.047^{* * *}$ \\
& $(0.028)$ & $(0.010)$ & $(0.013)$ & & $(0.024)$ & $(0.009)$ & $(0.012)$ \\
Distrust in Fed $\times$ UR forecast & & & 0.004 & & & \\
Distrust in Fed $\times$ Infl. forecast & & & $(0.020)$ & & & \\
& & & & & & \\
& Control & All & All & & Control & All & All \\
Sample & Yes & Yes & Yes & Yes & Yes & Yes \\
Controls & 0.39 & 0.47 & 0.47 & & 0.22 & 0.28 & 0.28 \\
Avg. Y & 0.17 & 0.17 & 0.17 & & 0.09 & 0.11 & 0.11 \\
Adj. R2 & 1294 & 9140 & 9140 & & 1294 & 9140 & 9140 \\
Obs. & & & & & & \\
\hline
\end{tabular}

Dependent variable: indicator $=1$ if modal bin of respondent's posterior contains one of the two FOMC forecast numbers shown for unemployment or inflation. Distrust in Fed $=1$ if respondent indicates trust $\leq 3$ out of 7 in terms of trusting Fed to adequately manage inflation and unemployment (panel A) or caring about the economic well-being of all Americans (panel B). All regressions further control for the treatment (UR or inflation forecast $\times$ policymaker picture, or control), respondent gender and race/ethnicity, as well as a cubic function of the prior point forecast for unemployment, quadratic function of survey date, and dummies for: geographic region, income category, education cat., age cat., employment status, marital status, political leaning, financial literacy score, whether lost job or reduced income since March 2020, whether state that could not pay for $\$ 400$ emergency expense, whether own primary residence, hold stock, have 401k or similar, whether do groceries, take financial decisions in household, and whether took survey on a mobile device. Robust standard errors in parentheses. ${ }^{*} \mathrm{p}<0.1,{ }^{* *} \mathrm{p}<0.05,{ }^{* * *} \mathrm{p}<0.01$. 


\section{Table 6: Channel 2-Information and Knowledge about Policy (Pre- Intervention)}

\begin{tabular}{|c|c|c|c|c|c|c|}
\hline \multirow[t]{2}{*}{ Dep. var. $=0 / 1$ for: } & \multicolumn{2}{|c|}{ Knows FOMC sets rates } & \multicolumn{2}{|c|}{$\pi$-target correct } & \multicolumn{2}{|c|}{$\pi$-target approx. correct } \\
\hline & $(1)$ & $(2)$ & $(3)$ & $(4)$ & $(5)$ & (6) \\
\hline White Female & $\begin{array}{c}-0.233^{* * *} \\
(0.014)\end{array}$ & $\begin{array}{c}-0.066^{* * *} \\
(0.014)\end{array}$ & $\begin{array}{c}-0.133^{* * *} \\
(0.013)\end{array}$ & $\begin{array}{c}-0.033^{* *} \\
(0.014)\end{array}$ & $\begin{array}{c}-0.214^{* * *} \\
(0.014)\end{array}$ & $\begin{array}{c}-0.050^{* * *} \\
(0.014)\end{array}$ \\
\hline Black Male & $\begin{array}{c}-0.204^{* * *} \\
(0.016)\end{array}$ & $\begin{array}{l}-0.012 \\
(0.017)\end{array}$ & $\begin{array}{c}-0.197^{* * *} \\
(0.014)\end{array}$ & $\begin{array}{c}-0.075^{* * *} \\
(0.016)\end{array}$ & $\begin{array}{c}-0.273^{* * *} \\
(0.016)\end{array}$ & $\begin{array}{c}-0.071^{* * *} \\
(0.017)\end{array}$ \\
\hline Black Female & $\begin{array}{c}-0.275^{* * *} \\
(0.017)\end{array}$ & $\begin{array}{c}-0.085^{* * *} \\
(0.018)\end{array}$ & $\begin{array}{c}-0.224^{* * *} \\
(0.014)\end{array}$ & $\begin{array}{c}-0.096^{* * *} \\
(0.016)\end{array}$ & $\begin{array}{c}-0.365^{* * *} \\
(0.016)\end{array}$ & $\begin{array}{c}-0.161^{* * *} \\
(0.018)\end{array}$ \\
\hline Hispanic Male & $\begin{array}{c}-0.086^{* * *} \\
(0.021)\end{array}$ & $\begin{array}{l}-0.011 \\
(0.025)\end{array}$ & $\begin{array}{c}-0.069^{* * *} \\
(0.020)\end{array}$ & $\begin{array}{l}-0.015 \\
(0.024)\end{array}$ & $\begin{array}{c}-0.121^{* * *} \\
(0.021)\end{array}$ & $\begin{array}{c}-0.043^{*} \\
(0.024)\end{array}$ \\
\hline Hispanic Female & $\begin{array}{c}-0.194^{* * *} \\
(0.020)\end{array}$ & $\begin{array}{c}-0.100^{* * *} \\
(0.024)\end{array}$ & $\begin{array}{c}-0.126^{* * *} \\
(0.018)\end{array}$ & $\begin{array}{c}-0.051^{* *} \\
(0.022)\end{array}$ & $\begin{array}{c}-0.189^{* * *} \\
(0.020)\end{array}$ & $\begin{array}{c}-0.087^{* * *} \\
(0.024)\end{array}$ \\
\hline Constant & $\begin{array}{c}0.641^{* * *} \\
(0.010)\end{array}$ & $\begin{array}{c}0.541^{* * * *} \\
(0.027)\end{array}$ & $\begin{array}{c}0.367^{* * *} \\
(0.010)\end{array}$ & $\begin{array}{c}0.287^{* * *} \\
(0.025)\end{array}$ & $\begin{array}{c}0.698^{* * *} \\
(0.010)\end{array}$ & $\begin{array}{c}0.591^{* * *} \\
(0.027)\end{array}$ \\
\hline Controls & No & Yes & No & Yes & No & Yes \\
\hline Avg. Y & 0.48 & 0.48 & 0.25 & 0.25 & 0.52 & 0.52 \\
\hline Adj. R2 & 0.04 & 0.21 & 0.03 & 0.11 & 0.06 & 0.23 \\
\hline Obs. & 9140 & 9140 & 9140 & 9140 & 9140 & 9140 \\
\hline
\end{tabular}

Dependent variables: in columns (1)-(2), indicator $=1$ if respondent chose "The Federal Open Market Committee (part of the Federal Reserve, or Fed)" out of 7 options for question "Eight times a year a group of people meets to set the basic interest rate level in the United States. Who do you think comprises this group?" Columns (3)-(6): respondents were asked for the annual inflation rate the Federal Reserve tries to achieve. " $\pi$-target correct" $=1$ if answered $2 \%$, " $\pi$-target approx. correct" $=1$ if answered in $[1 \%, 3 \%]$. Omitted category: White male respondents. Controls in even columns include quadratic function of survey date and dummies for: geographic region, income category, education cat., age cat., employment status, marital status, political leaning, financial literacy score, whether lost job or reduced income since March 2020 , whether state that could not pay for $\$ 400$ emergency expense, whether own primary residence, hold stock, have 401k or similar, whether do groceries, take financial decisions in household, and whether took survey on a mobile device. Robust standard errors in parentheses. ${ }^{*} \mathrm{p}<0.1,{ }^{* *} \mathrm{p}<0.05,{ }^{* * *} \mathrm{p}<0.01$. 


\section{Table 7: Channel 2-Diversity Salience and Attention Allocation}

\begin{tabular}{|c|c|c|c|c|c|c|}
\hline & \multicolumn{2}{|c|}{ Log(Time) } & \multicolumn{2}{|c|}{ Correct Recall $(0 / 1)$} & \multicolumn{2}{|c|}{ Interesting $(0 / 1)$} \\
\hline & (1) & $(2)$ & $(3)$ & (4) & $(5)$ & $(6)$ \\
\hline$(\mathrm{WF} / \mathrm{BM} / \mathrm{BF}) \times($ Bostic/Daly $)$ & $\begin{array}{c}0.041^{*} \\
(0.023)\end{array}$ & $\begin{array}{c}0.038^{*} \\
(0.023)\end{array}$ & $\begin{array}{c}0.003 \\
(0.018)\end{array}$ & $\begin{array}{l}-0.002 \\
(0.017)\end{array}$ & $\begin{array}{l}0.035^{*} \\
(0.021)\end{array}$ & $\begin{array}{c}0.027 \\
(0.020)\end{array}$ \\
\hline Controls & No & Yes & No & Yes & No & Yes \\
\hline Avg. Y & 3.68 & 3.68 & 0.75 & 0.75 & 0.59 & 0.59 \\
\hline SD Y & 0.55 & 0.55 & 0.43 & 0.43 & 0.49 & 0.49 \\
\hline Adj. R2 & 0.03 & 0.07 & 0.05 & 0.09 & 0.01 & 0.05 \\
\hline Obs. & 9140 & 9140 & 9140 & 9140 & 9140 & 9140 \\
\hline
\end{tabular}

Dependent variables: in columns (1)-(2), $\log$ (time) spent on the treatment screen, winsorized at top/bottom $2.5 \%$; in columns (3)-(4), indicator $=1$ if respondent at the end of the survey correctly recalled Fedrelated picture they saw (multiple choice with 5 options); in columns (5)-(6), indicator $=1$ if at end of the survey, respondent stated that found survey somewhat or very interesting (multiple choice with 5 options). Bostic/Daly $=1$ if the picture seen was of Raphael Bostic or Mary Daly, as opposed to Thomas Barkin. $\mathrm{WF} / \mathrm{BM} / \mathrm{BF}=1$ if respondent is White female, Black male, or Black female. All regressions control for the treatment (UR or inflation forecast $\times$ policymaker picture, or control treatment), respondent gender and race/ethnicity. Even columns additionally control for a quadratic function of survey date and dummies for: geographic region, income category, education cat., age cat., employment status, marital status, political leaning, financial literacy score, whether lost job or reduced income since March 2020, whether state that could not pay for $\$ 400$ emergency expense, whether own primary residence, hold stock, have $401 \mathrm{k}$ or similar, whether do groceries, take financial decisions in household, and whether took survey on a mobile device. Robust standard errors in parentheses. ${ }^{*} \mathrm{p}<0.1,{ }^{* *} \mathrm{p}<0.05,{ }^{* * *} \mathrm{p}<0.01$. 


\section{Table 8: Channel 2-Effect of Diversity Salience on Information Selection}

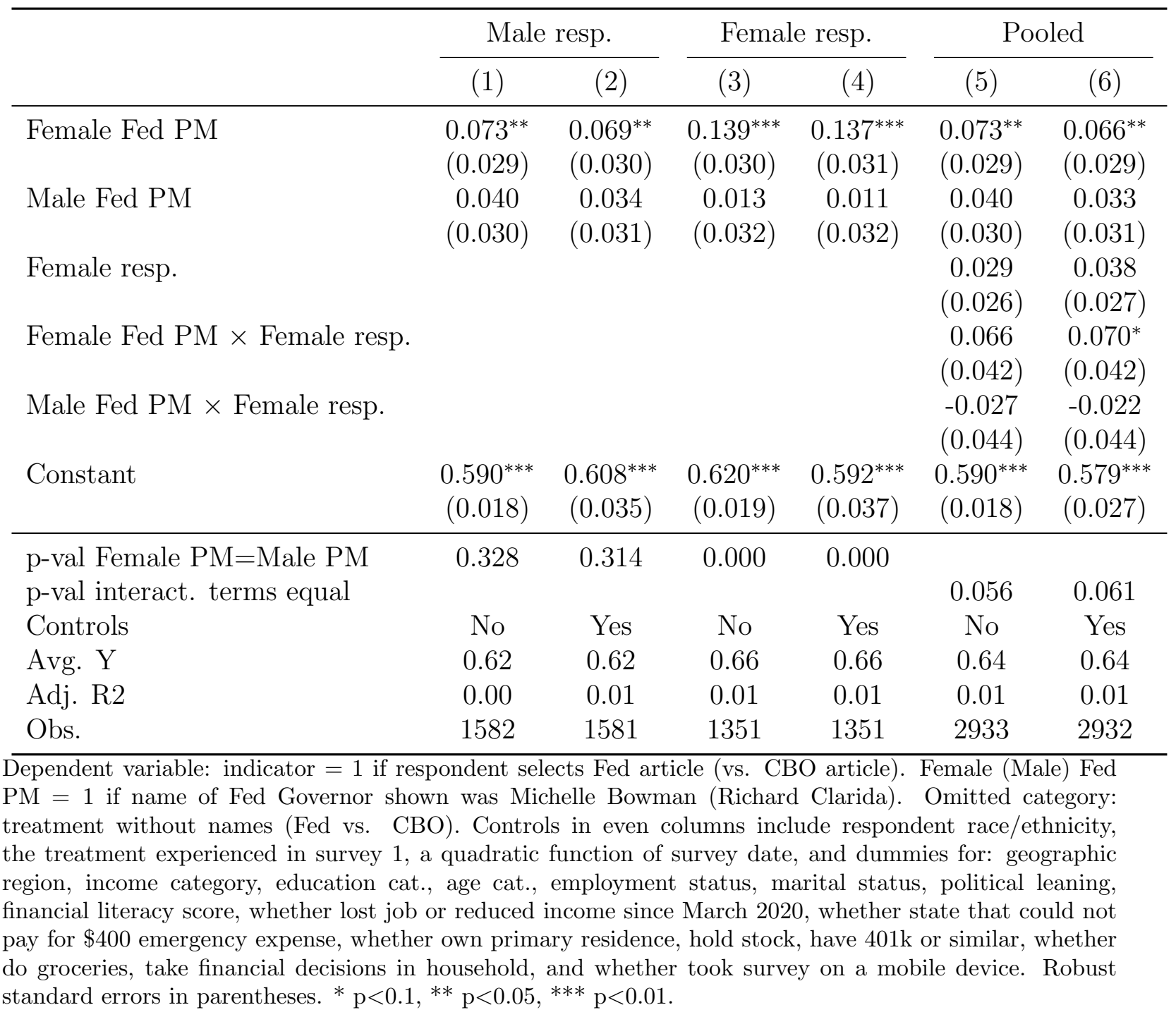


Table 9: Taste for Diversity—Differences Across Groups

\begin{tabular}{lccccccc}
\hline & \multicolumn{3}{c}{ Support for Quotas $(1-7)$} & & \multicolumn{3}{c}{ Diversity Support Score } \\
\cline { 2 - 3 } \cline { 7 - 8 } & $(1)$ & $(2)$ & $(3)$ & & $(4)$ & $(5)$ & $(6)$ \\
\hline White Female & $1.073^{* * *}$ & $0.771^{* * *}$ & $0.702^{* * *}$ & & $0.232^{* * *}$ & $0.185^{* * *}$ & $0.148^{* * *}$ \\
& $(0.098)$ & $(0.102)$ & $(0.093)$ & & $(0.050)$ & $(0.050)$ & $(0.044)$ \\
Black Male & $1.759^{* * *}$ & $0.981^{* * *}$ & $0.726^{* * *}$ & & $0.731^{* * *}$ & $0.483^{* * *}$ & $0.332^{* * *}$ \\
& $(0.107)$ & $(0.123)$ & $(0.115)$ & & $(0.053)$ & $(0.059)$ & $(0.055)$ \\
Black Female & $2.264^{* * *}$ & $1.250^{* * *}$ & $0.916^{* * *}$ & & $0.758^{* * *}$ & $0.444^{* * *}$ & $0.249^{* * *}$ \\
& $(0.101)$ & $(0.124)$ & $(0.114)$ & & $(0.054)$ & $(0.063)$ & $(0.056)$ \\
Hispanic Male & $0.731^{* * *}$ & $0.460^{* * *}$ & $0.471^{* * *}$ & & $0.221^{* * *}$ & $0.127^{*}$ & $0.136^{* *}$ \\
& $(0.141)$ & $(0.133)$ & $(0.117)$ & & $(0.073)$ & $(0.069)$ & $(0.058)$ \\
Hispanic Female & $1.289^{* * *}$ & $0.811^{* * *}$ & $0.751^{* * *}$ & & $0.261^{* * *}$ & $0.133^{* *}$ & $0.101^{*}$ \\
& $(0.133)$ & $(0.130)$ & $(0.117)$ & & $(0.069)$ & $(0.067)$ & $(0.058)$ \\
BLM Support & & & $1.131^{* * *}$ & & & $0.706^{* * *}$ \\
& & & $(0.080)$ & & & $(0.038)$ \\
Women Discr. & & & $0.883^{* * *}$ & & & $0.457^{* * *}$ \\
& & & $(0.078)$ & & & $(0.037)$ \\
Constant & $3.400^{* * *}$ & $3.795^{* * *}$ & $2.654^{* * *}$ & & $-0.303^{* * *}$ & $-0.189^{* * *}$ & $-0.841^{* * *}$ \\
& $(0.065)$ & $(0.095)$ & $(0.097)$ & & $(0.033)$ & $(0.048)$ & $(0.048)$ \\
\hline Controls & No & Yes & Yes & & No & Yes & Yes \\
Avg. Y & 4.39 & 4.39 & 4.39 & & -0.00 & 0.00 & 0.00 \\
St. Dev. Y & 2.03 & 2.03 & 2.03 & & 1.00 & 1.00 & 1.00 \\
Adj. R2 & 0.15 & 0.26 & 0.39 & & 0.08 & 0.22 & 0.40 \\
Obs. & 2933 & 2932 & 2932 & 2933 & 2932 & 2932 \\
\hline
\end{tabular}

Dependent variable in columns (1)-(3) is respondent agreement to statement that organizations such as the Federal Reserve should be required by law to have at least the same share of women and minorities in their top management as in the population overall, measured on 1-7 scale. Dependent variable in columns (4)-(6) is standardized first principal component of agreement to five statements related to diversity (see text for details). Omitted group: White male respondents. BLM Support $=1$ if respondent indicated (in the main survey) support for requests of Black Lives Matter movement $\geq 5$ out of 7 . Women Discr. $=1$ if respondent chose agreement $\geq 5$ out of 7 (in the main survey) that discrimination against women or girls is an important problem in the US. Controls in columns (2), (3), (5) and (6) include the treatment experienced in survey 1 , a quadratic function of survey date, and dummies for: geographic region, income category, education cat., age cat., employment status, marital status, political leaning, financial literacy score, whether lost job or reduced income since March 2020, whether state that could not pay for $\$ 400$ emergency expense, whether own primary residence, hold stock, have $401 \mathrm{k}$ or similar, whether do groceries, take financial decisions in household, and whether took survey on a mobile device. Robust standard errors in parentheses. ${ }^{*} \mathrm{p}<0.1$, $* * \mathrm{p}<0.05, * * * \mathrm{p}<0.01$. 
Table 10: Taste for Diversity \& Effects of Different Policymaker Pictures on Unemployment Expectations Anchoring and Distrust, White Male Respondents

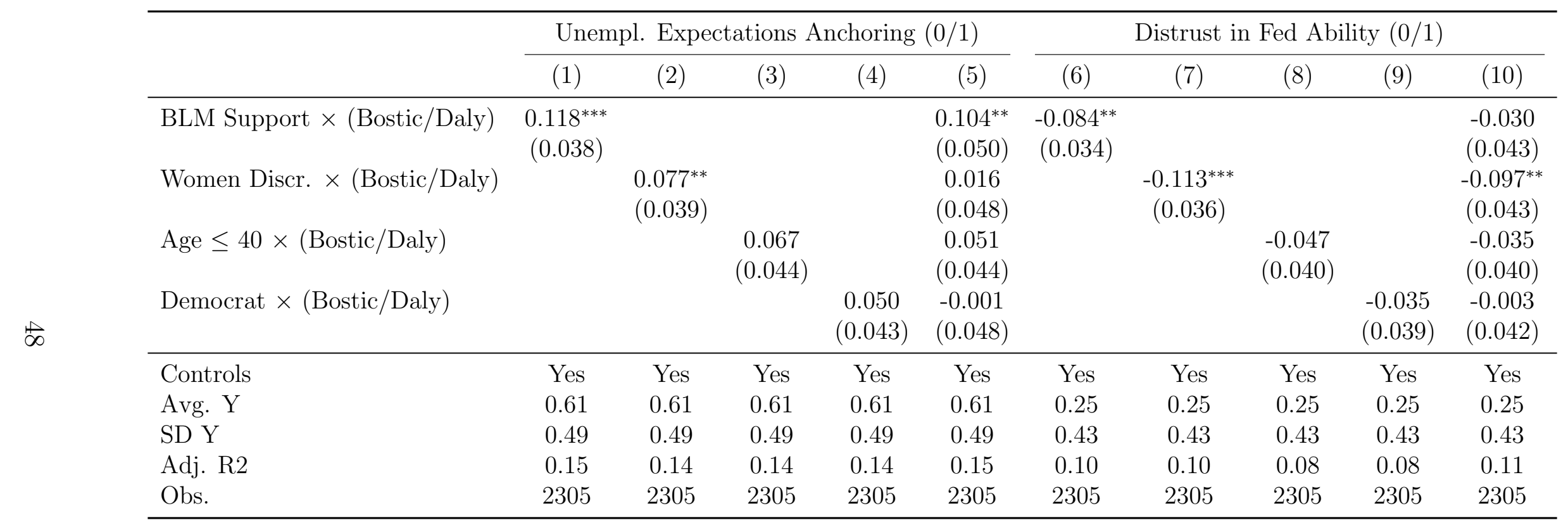

Dependent variable: indicator $=1$ if modal bin of respondent's posterior contains one of the two FOMC forecast numbers shown for unemployment (columns 1-5) or $=1$ if respondent indicates trust $\leq 3$ that Fed adequately manages unemployment and inflation. Bostic/Daly $=1$ if the picture seen was of Raphael Bostic or Mary Daly. BLM Support $=1$ if respondent indicated support for requests of Black Lives Matter movement $\geq 5$ out of 7 . Women Discr. $=1$ if respondent chose agreement $\geq 5$ out of 7 that discrimination against women or girls is an important problem in the US. Interacted terms (BLM Support, Women Discr., Age $\leq 40$, Democrat) also enter regression uninteracted; coefficients not shown. All regressions further control for the treatment (UR or inflation forecast $\times$ policymaker picture, or control), as well as a cubic function of the prior point forecast for unemployment, quadratic function of survey date, and dummies for: geographic region, income category, education cat., age cat., employment status, marital status, political leaning, financial literacy score, whether lost job or reduced income since March 2020, whether state that could not pay for $\$ 400$ emergency expense, whether own primary residence, hold stock, have $401 \mathrm{k}$ or similar, whether do groceries, take financial decisions in household, and whether took survey on a mobile device. Robust standard errors in parentheses. ${ }^{*} \mathrm{p}<0.1,{ }^{* *} \mathrm{p}<0.05,{ }^{* * *} \mathrm{p}<0.01$. 
Online Appendix:

\title{
Diverse Policy Committees Can Reach Underrepresented Groups
}

\author{
Francesco D'Acunto, Andreas Fuster, and Michael Weber
}

Not for Publication

\section{A Additional Figures and Tables}


Figure A.1: Manipulation Check: Perceived Demographic FOMC Composition By Experimental Condition

A. Gender Composition

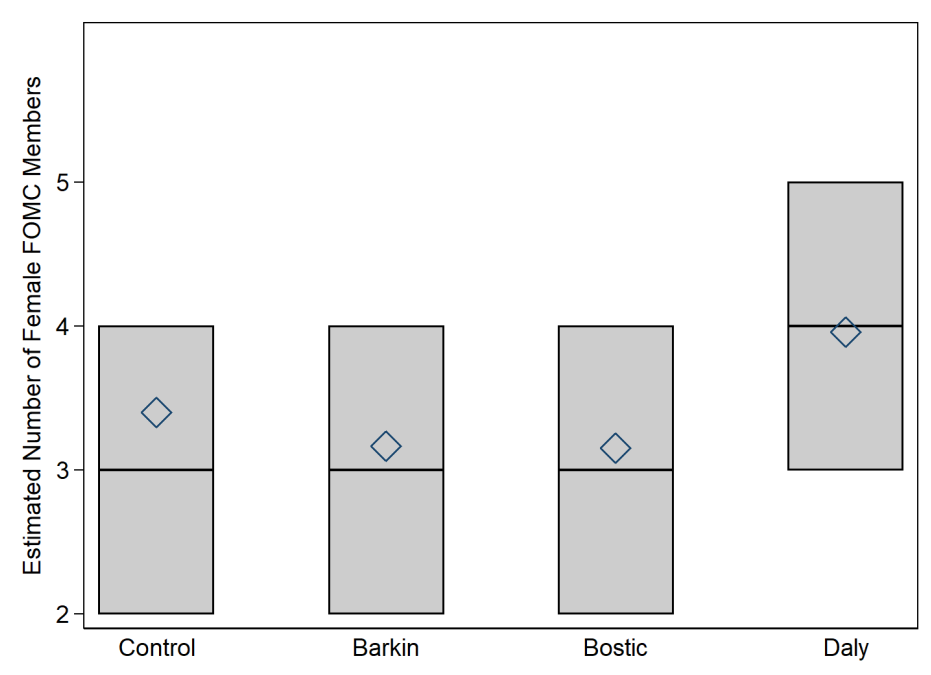

B. Racial/Ethnic Composition

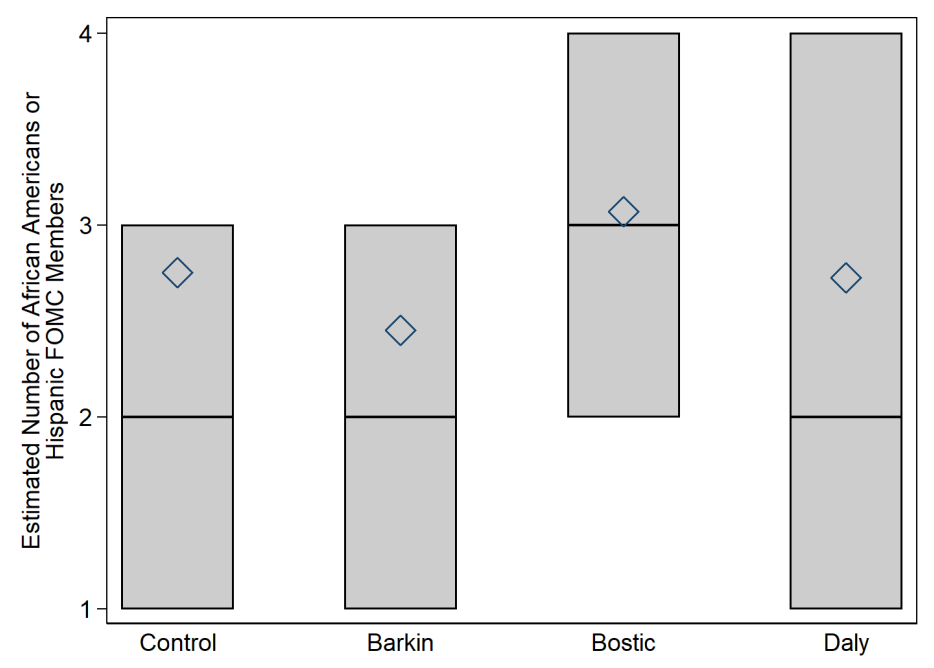

Note: Results from an auxiliary survey run on Amazon Mechanical Turk in which respondents provided their perceived demographic composition of the FOMC after observing the treatment interventions used in the first-wave experiment $(N=1,062)$. Boxes report the $25^{t h}, 50^{t h}$ (median), and $75^{t h}$ percentiles and the diamonds the average reported number of female members (Panel A) and Black or Hispanic members (Panel B) out of the 11 FOMC members after the experimental treatments. Instructions after the treatment screen were: "The Fed committee that sets short-term interest rates in the US is the FOMC, which is currently composed of 11 voting members. Below, we would like to ask you how you think this committee is composed along a few dimensions." (...) "How many committee members do you think are female?" (dropdown menu from 0-11); "And how many do you think are African American or Hispanic?" (dropdown menu from 0-11). 


\title{
Figure A.2: Recognizability of Committee Members' Names and Pictures in the Main Survey
}

\author{
A. Name Recognition
}

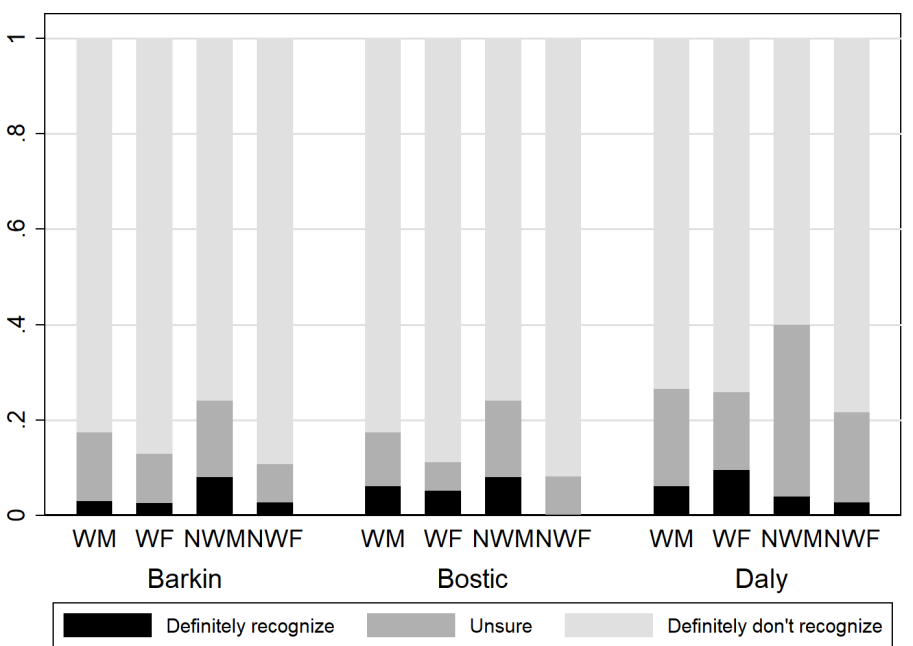

B. Portrait Recognition

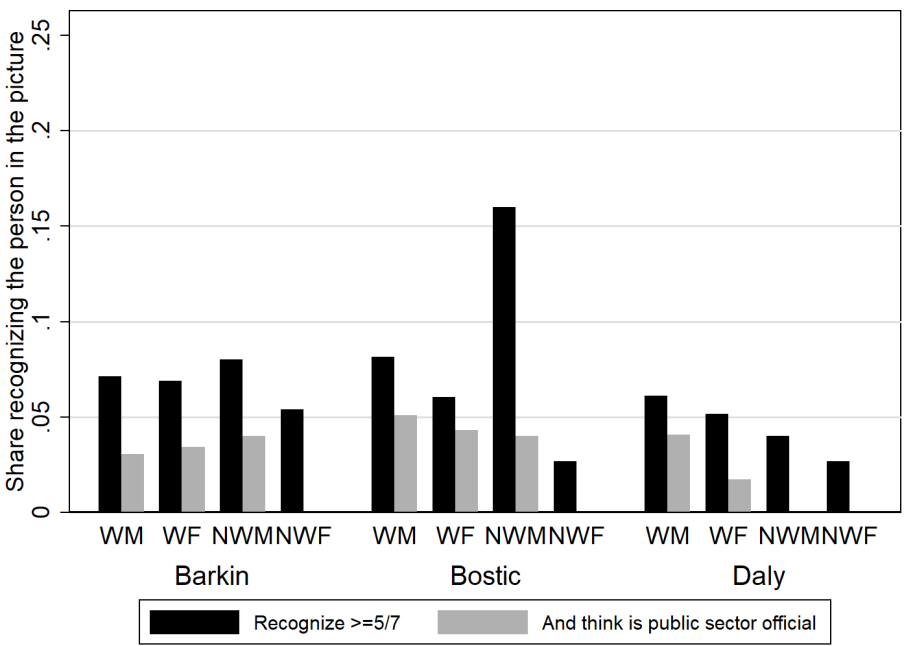

Note: Results from auxiliary surveys run on Amazon Mechanical Turk. For the results in Panel A, respondents were shown the names of each of the three committee members who appeared in the main survey (Thomas Barkin, Raphael Bostic, and Mary Daly). For each name respondents were asked "Do you recognize this name? Do you know who this person is?" Respondents could choose among the following three options: Yes, definitely; Not sure; No, definitely not. Panel A reports the share of respondents who picked each of the options across demographic groups. Panel A reports the shares of respondents who chose each option across demographic groups $[\mathrm{N}=276]$ : White male (WM), White female (WF), Non-White male (NWM), Non-White female (NWF). For the results in Panel B, in a separate task respondents were shown the three portraits of the FOMC members who appeared in the main survey. For each portrait, respondents were asked "At first glance, do you think that you recognize the person portrayed in this picture?" Respondents could rank their answers on a 7-point Likert scale ranging from 0 (I definitely do NOT recognize this person) to 7 (I definitely recognize this person). Black bars in Panel B report the share of respondents who answered values between 5 and 7 on this Likert scale. In a later question, respondents were also asked what they thought about the occupation of the portrayed individuals and could choose among a set of 6 options that included "public sector official." Gray bars report the share of respondents who chose this (correct) option in addition to reporting values between 5 and 7 to the recognition question. $[\mathrm{N}=276]$ 
Figure A.3: Channel 2-Recognizability of Policymakers' Names in Information Acquisition Survey

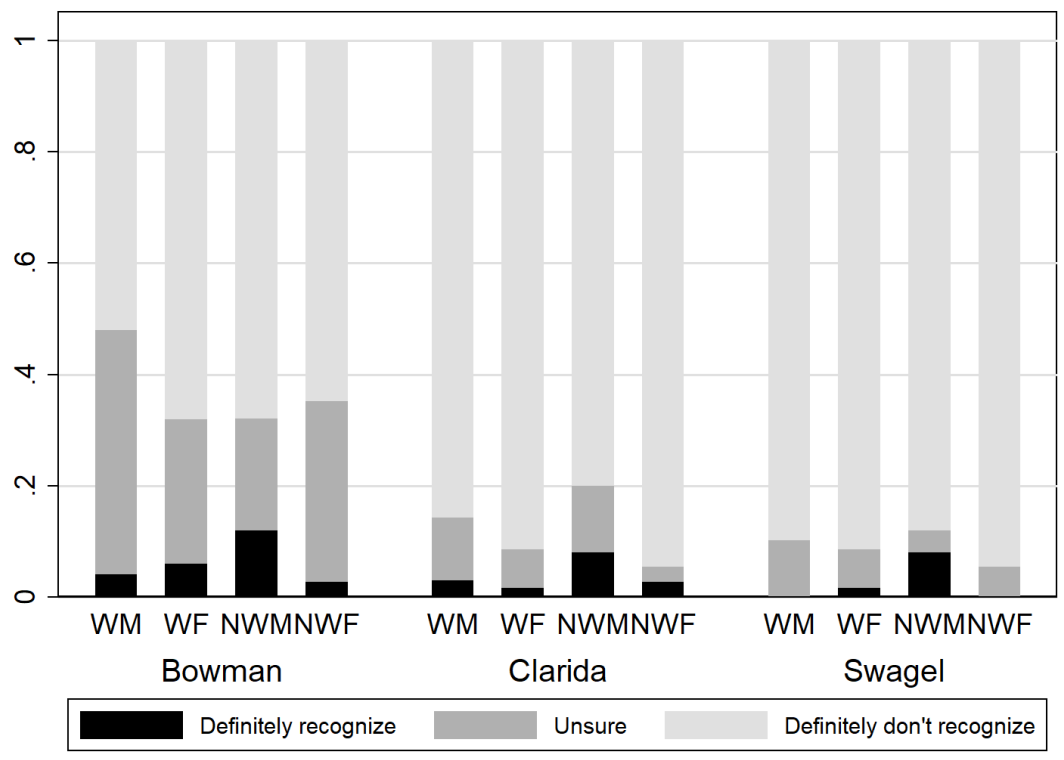

Note: Results from an auxiliary survey run on Amazon Mechanical Turk. Respondents were shown the full names of each of the three policymakers in the information-acquisition task of the second wave of our main survey (Michelle Bowman, Richard Clarida, Phillip Swagel) and for each name they were asked "Do you recognize this name? Do you know who this person is?" Respondents could choose among the following three options: Yes, definitely; Not sure; No, definitely not. We report the share of respondents who picked each of the options across demographic groups [ $\mathrm{N}=276]$ : White male (WM), White female (WF), Non-White male (NWM), Non-White female (NWF). 
Table A.1: Summary Statistics, Follow-up Survey

\begin{tabular}{|c|c|c|c|}
\hline & Mean & Median & St.Dev. \\
\hline \multicolumn{4}{|l|}{ Demographic Characteristics } \\
\hline Female $(0 / 1)$ & 0.46 & 0.00 & 0.50 \\
\hline Black $(0 / 1)$ & 0.28 & 0.00 & 0.45 \\
\hline Hispanic $(0 / 1)$ & 0.20 & 0.00 & 0.40 \\
\hline Age (years) & 51.59 & 53.00 & 15.91 \\
\hline Married $(0 / 1)$ & 0.60 & 1.00 & 0.49 \\
\hline College $(\mathrm{BA}+)(0 / 1)$ & 0.49 & 0.00 & 0.50 \\
\hline Employed $(0 / 1)$ & 0.52 & 1.00 & 0.50 \\
\hline Retired $(0 / 1)$ & 0.27 & 0.00 & 0.44 \\
\hline Unemployed $(0 / 1)$ & 0.10 & 0.00 & 0.30 \\
\hline Household income $\geq 75 \mathrm{k}(0 / 1)$ & 0.44 & 0.00 & 0.50 \\
\hline Income reduction during pandemic $(0 / 1)$ & 0.37 & 0.00 & 0.48 \\
\hline Can’t pay for $\$ 400$ expense $(0 / 1)$ & 0.11 & 0.00 & 0.32 \\
\hline Homeowner $(0 / 1)$ & 0.68 & 1.00 & 0.47 \\
\hline Holds stock $(0 / 1)$ & 0.45 & 0.00 & 0.50 \\
\hline Has 401k $(0 / 1)$ & 0.63 & 1.00 & 0.48 \\
\hline Democrat $(0 / 1)$ & 0.43 & 0.00 & 0.49 \\
\hline Republican $(0 / 1)$ & 0.25 & 0.00 & 0.43 \\
\hline Does most of groceries $(0 / 1)$ & 0.72 & 1.00 & 0.45 \\
\hline Makes all financial decisions $(0 / 1)$ & 0.50 & 0.00 & 0.50 \\
\hline Nr fin. literacy questions correct (0-2) & 1.03 & 1.00 & 0.77 \\
\hline \multicolumn{4}{|c|}{ Perceptions and Expectations (Follow-up Survey) } \\
\hline E(Unemployment) (mean, \%) & 10.80 & 10.40 & 3.55 \\
\hline $\mathrm{E}$ (Inflation) (mean, \%) & 2.66 & 2.47 & 2.94 \\
\hline Trust in Fed Ability (1-7) & 3.97 & 4.00 & 1.57 \\
\hline Trust in Fed Caring for All (1-7) & 3.68 & 4.00 & 1.62 \\
\hline Obs. & 2933 & & \\
\hline
\end{tabular}

This table reports summary statistics for the demographics as well as economic perceptions and expectations of the sample of subjects in the follow-up survey. 
Table A.2: Effects of Diversity Salience and Information Types on Inflation Expectations across Groups

A. Effects on Binary Indicator for Anchored Inflation Expectations

\begin{tabular}{|c|c|c|c|c|c|c|c|c|}
\hline & \multicolumn{2}{|c|}{ White } & \multicolumn{2}{|c|}{ Black } & \multicolumn{2}{|c|}{ Hispanic } & \multicolumn{2}{|c|}{ All } \\
\hline & M & $\mathrm{F}$ & M & $\mathrm{F}$ & $\mathrm{M}$ & F & Unw. & Wtd. \\
\hline & (1) & (2) & (3) & (4) & (5) & (6) & (7) & (8) \\
\hline \multirow[t]{2}{*}{ Bostic } & 0.019 & -0.016 & -0.004 & 0.003 & 0.045 & -0.045 & -0.001 & -0.001 \\
\hline & $(0.025)$ & $(0.023)$ & $(0.029)$ & $(0.030)$ & $(0.044)$ & $(0.039)$ & $(0.012)$ & $(0.013)$ \\
\hline \multirow[t]{2}{*}{ Daly } & 0.012 & -0.012 & -0.008 & 0.022 & 0.022 & -0.038 & -0.003 & -0.002 \\
\hline & $(0.025)$ & $(0.023)$ & $(0.029)$ & $(0.030)$ & $(0.044)$ & $(0.039)$ & $(0.012)$ & $(0.013)$ \\
\hline \multirow[t]{2}{*}{ UR forecast } & 0.006 & -0.001 & 0.009 & 0.047 & 0.014 & 0.028 & 0.015 & 0.011 \\
\hline & $(0.031)$ & $(0.028)$ & $(0.035)$ & $(0.036)$ & $(0.053)$ & $(0.045)$ & $(0.014)$ & $(0.016)$ \\
\hline \multirow[t]{2}{*}{ Infl. forecast } & $0.164^{* * *}$ & $0.140^{* * *}$ & $0.099^{* * *}$ & $0.088^{* *}$ & $0.140^{* *}$ & $0.160^{* * *}$ & $0.136^{* * *}$ & $0.145^{* * *}$ \\
\hline & $(0.032)$ & $(0.028)$ & $(0.036)$ & $(0.037)$ & $(0.055)$ & $(0.047)$ & $(0.015)$ & $(0.016)$ \\
\hline Controls & Yes & Yes & Yes & Yes & Yes & Yes & Yes & Yes \\
\hline Avg. Y & 0.38 & 0.27 & 0.24 & 0.19 & 0.29 & 0.25 & 0.28 & 0.30 \\
\hline Adj. R2 & 0.14 & 0.10 & 0.04 & 0.03 & 0.08 & 0.11 & 0.11 & 0.12 \\
\hline Obs. & 2305 & 2472 & 1540 & 1237 & 731 & 853 & 9140 & 9140 \\
\hline
\end{tabular}

B. Effects on E(inflation)

\begin{tabular}{|c|c|c|c|c|c|c|c|c|}
\hline & \multicolumn{2}{|c|}{ White } & \multicolumn{2}{|c|}{ Black } & \multicolumn{2}{|c|}{ Hispanic } & \multicolumn{2}{|c|}{ All } \\
\hline & M & $\mathrm{F}$ & M & $\mathrm{F}$ & M & $\mathrm{F}$ & Unw. & Wtd. \\
\hline & (1) & $(2)$ & $(3)$ & (4) & (5) & $(6)$ & (7) & (8) \\
\hline \multirow[t]{2}{*}{ Bostic } & 0.060 & -0.234 & -0.338 & 0.260 & -0.305 & 0.114 & -0.111 & -0.103 \\
\hline & $(0.141)$ & $(0.168)$ & $(0.234)$ & $(0.274)$ & $(0.292)$ & $(0.324)$ & $(0.087)$ & $(0.087)$ \\
\hline \multirow[t]{2}{*}{ Daly } & -0.125 & -0.144 & 0.028 & 0.043 & -0.116 & 0.021 & -0.082 & -0.107 \\
\hline & $(0.146)$ & $(0.166)$ & $(0.219)$ & $(0.274)$ & $(0.299)$ & $(0.305)$ & $(0.086)$ & $(0.087)$ \\
\hline \multirow[t]{2}{*}{ UR forecast } & 0.081 & 0.008 & -0.453 & -0.370 & -0.002 & $-0.702^{*}$ & -0.168 & -0.103 \\
\hline & $(0.181)$ & $(0.227)$ & $(0.295)$ & $(0.372)$ & $(0.404)$ & $(0.401)$ & $(0.114)$ & $(0.115)$ \\
\hline \multirow[t]{2}{*}{ Infl. forecast } & $-0.655^{* * *}$ & $-0.388^{*}$ & $-0.820^{* * *}$ & $-0.718^{*}$ & -0.383 & -0.627 & $-0.592^{* * *}$ & $-0.561^{* * *}$ \\
\hline & $(0.181)$ & $(0.227)$ & $(0.300)$ & $(0.367)$ & $(0.394)$ & $(0.405)$ & $(0.114)$ & $(0.114)$ \\
\hline Controls & Yes & Yes & Yes & Yes & Yes & Yes & Yes & Yes \\
\hline Avg. Y & 2.46 & 2.85 & 2.34 & 2.60 & 2.60 & 3.02 & 2.63 & 2.66 \\
\hline Adj. R2 & 0.12 & 0.07 & 0.05 & 0.05 & 0.08 & 0.08 & 0.07 & 0.08 \\
\hline Obs. & 2305 & 2472 & 1540 & 1237 & 731 & 853 & 9140 & 9140 \\
\hline
\end{tabular}

Dependent variable in panel A: indicator $=1$ if modal bin of respondent's posterior contains one of the two FOMC forecast numbers shown for inflation. Dependent variable in panel B: imputed mean of subjective posterior distribution for inflation over coming 12 months. Omitted categories: Barkin (vs. Bostic and Daly), and general Fed info (control treatment). Column (7) pools all respondents and equal-weights them, while column (8) uses US-population-weights for the different groups. Controls include a cubic function of the prior point forecast (unemployment or inflation), quadratic function of survey date, and dummies for: geographic region, income category, education cat., age cat., employment status, marital status, political leaning, financial literacy score, whether lost job or reduced income since March 2020, whether state that could not pay for $\$ 400$ emergency expense, whether own primary residence, hold stock, have 401k or similar, whether do groceries, take financial decisions in household, and whether took survey on a mobile device. In columns (7) and (8) we also control for respondent race/ethnicity and gender. Robust standard errors in parentheses. ${ }^{*} \mathrm{p}<0.1,{ }^{* *} \mathrm{p}<0.05, * * * \mathrm{p}<0.01$. 
Table A.3: Channel 2-Differences in Sources about Economics/Business across Groups

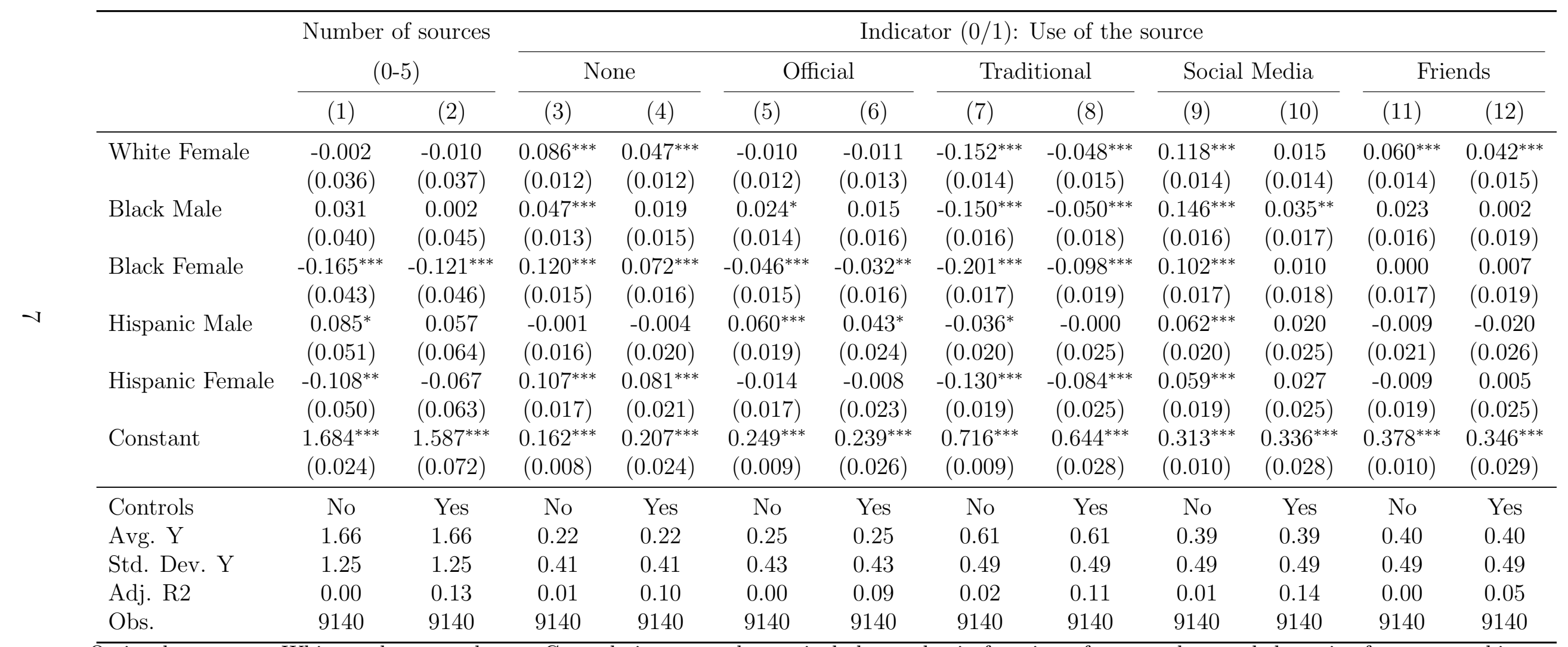

Omitted category: White male respondents. Controls in even columns include quadratic function of survey date and dummies for: geographic region, income category, education cat., age cat., employment status, marital status, political leaning, financial literacy score, whether lost job or reduced income since March 2020, whether state that could not pay for $\$ 400$ emergency expense, whether own primary residence, hold stock, have $401 \mathrm{k}$ or similar, whether do groceries, take financial decisions in household, and whether took survey on a mobile device. Robust standard errors in parentheses. * $\mathrm{p}<0.1,{ }^{*} * \mathrm{p}<0.05, * * * \mathrm{p}<0.01$. 
Table A.4: Channel 2-Effects of Diversity Salience on Information Evaluation

\begin{tabular}{|c|c|c|c|c|c|c|}
\hline & \multicolumn{2}{|c|}{ Article interesting } & \multicolumn{2}{|c|}{ PM competence } & \multicolumn{2}{|c|}{ PM effectiveness } \\
\hline & $(1)$ & $(2)$ & $(3)$ & (4) & $(5)$ & (6) \\
\hline Female Fed PM $\times$ Female resp. & $\begin{array}{c}0.148 \\
(0.225)\end{array}$ & $\begin{array}{c}0.249 \\
(0.226)\end{array}$ & $\begin{array}{l}-0.075 \\
(0.203)\end{array}$ & $\begin{array}{c}0.000 \\
(0.201)\end{array}$ & $\begin{array}{l}-0.124 \\
(0.201)\end{array}$ & $\begin{array}{c}0.009 \\
(0.200)\end{array}$ \\
\hline Female Fed PM article & $\begin{array}{c}-0.258^{*} \\
(0.147)\end{array}$ & $\begin{array}{c}-0.319^{* *} \\
(0.147)\end{array}$ & $\begin{array}{l}-0.023 \\
(0.135)\end{array}$ & $\begin{array}{l}-0.037 \\
(0.136)\end{array}$ & $\begin{array}{c}0.060 \\
(0.137)\end{array}$ & $\begin{array}{l}-0.011 \\
(0.137)\end{array}$ \\
\hline Female resp. & $\begin{array}{c}-0.381^{* *} \\
(0.159)\end{array}$ & $\begin{array}{c}-0.343^{* *} \\
(0.167)\end{array}$ & $\begin{array}{c}-0.418^{* * *} \\
(0.144)\end{array}$ & $\begin{array}{c}-0.329^{* *} \\
(0.150)\end{array}$ & $\begin{array}{c}-0.369^{* * *} \\
(0.141)\end{array}$ & $\begin{array}{l}-0.279^{*} \\
(0.149)\end{array}$ \\
\hline Constant & $\begin{array}{c}4.563^{* * *} \\
(0.099)\end{array}$ & $\begin{array}{c}4.607^{* * *} \\
(0.163)\end{array}$ & $\begin{array}{c}4.492^{* * *} \\
(0.096)\end{array}$ & $\begin{array}{c}4.406^{* * *} \\
(0.152)\end{array}$ & $\begin{array}{c}4.433^{* * *} \\
(0.094)\end{array}$ & $\begin{array}{c}4.416^{* * *} \\
(0.149)\end{array}$ \\
\hline Controls & No & Yes & No & Yes & No & Yes \\
\hline Avg. Y & 4.30 & 4.30 & 4.27 & 4.27 & 4.26 & 4.26 \\
\hline St. Dev. Y & 1.66 & 1.66 & 1.51 & 1.51 & 1.49 & 1.49 \\
\hline Adj. R2 & 0.01 & 0.06 & 0.02 & 0.07 & 0.02 & 0.06 \\
\hline Obs. & 877 & 877 & 877 & 877 & 877 & 877 \\
\hline
\end{tabular}

Dependent variables measured on 1-7 scale; see text for precise questions. Female Fed PM article $=1$ if article shown featured Michelle Bowman (vs. Richard Clarida). Sample restricted to respondents who selected Fed article in treatment where no names were shown at article selection stage (group 1) and who got then randomly allocated either the Bowman or Clarida article. Controls in even columns include respondent race/ethnicity, the treatment experienced in survey 1, a quadratic function of survey date, and dummies for: geographic region, income category, education cat., age cat., employment status, marital status, political leaning, financial literacy score, whether lost job or reduced income since March 2020, whether state that could not pay for $\$ 400$ emergency expense, whether own primary residence, hold stock, have 401k or similar, whether do groceries, take financial decisions in household, and whether took survey on a mobile device. Robust standard errors in parentheses. ${ }^{*} \mathrm{p}<0.1,{ }^{* *} \mathrm{p}<0.05,{ }^{* * *} \mathrm{p}<0.01$. 
Table A.5: Robustness of Differential Effects on Unemployment Expectations Anchoring to Controlling for Taste for Diversity and Policymaker Location

\begin{tabular}{|c|c|c|c|c|c|c|c|}
\hline & (1) & $(2)$ & (3) & (4) & $(5)$ & (6) & (7) \\
\hline$(\mathrm{WF} / \mathrm{BM} / \mathrm{BF}) \times($ Bostic/Daly $)$ & $\begin{array}{l}0.045^{* *} \\
(0.020)\end{array}$ & $\begin{array}{l}0.041^{* *} \\
(0.020)\end{array}$ & $\begin{array}{l}0.044^{* *} \\
(0.020)\end{array}$ & $\begin{array}{c}0.038^{*} \\
(0.020)\end{array}$ & $\begin{array}{l}0.048^{* *} \\
(0.020)\end{array}$ & $\begin{array}{l}0.047^{* *} \\
(0.020)\end{array}$ & $\begin{array}{c}0.039^{*} \\
(0.020)\end{array}$ \\
\hline BLM Support × (Bostic/Daly) & & $\begin{array}{c}0.027 \\
(0.020)\end{array}$ & & & & & $\begin{array}{c}0.030 \\
(0.025)\end{array}$ \\
\hline Women Discr. × (Bostic/Daly) & & & $\begin{array}{c}0.020 \\
(0.021)\end{array}$ & & & & $\begin{array}{c}0.011 \\
(0.025)\end{array}$ \\
\hline Age $\leq 40 \times($ Bostic/Daly $)$ & & & & $\begin{array}{c}0.039^{*} \\
(0.020)\end{array}$ & & & $\begin{array}{c}0.034^{*} \\
(0.020)\end{array}$ \\
\hline Democrat $\times($ Bostic/Daly $)$ & & & & & $\begin{array}{c}-0.019 \\
(0.020)\end{array}$ & & $\begin{array}{c}-0.032 \\
(0.022)\end{array}$ \\
\hline In PM State & & & & & & $\begin{array}{c}0.036 \\
(0.028)\end{array}$ & $\begin{array}{c}0.036 \\
(0.028)\end{array}$ \\
\hline In PM Fed District & & & & & & $\begin{array}{c}0.006 \\
(0.018)\end{array}$ & $\begin{array}{c}0.006 \\
(0.018)\end{array}$ \\
\hline Controls & Yes & Yes & Yes & Yes & Yes & Yes & Yes \\
\hline Avg. Y & 0.47 & 0.47 & 0.47 & 0.47 & 0.47 & 0.47 & 0.47 \\
\hline $\mathrm{SD} \mathrm{Y}$ & 0.50 & 0.50 & 0.50 & 0.50 & 0.50 & 0.50 & 0.50 \\
\hline Adj. R2 & 0.16 & 0.17 & 0.16 & 0.17 & 0.16 & 0.16 & 0.17 \\
\hline Obs. & 9140 & 9140 & 9140 & 9140 & 9140 & 9140 & 9140 \\
\hline
\end{tabular}

Dependent variable: indicator $=1$ if modal bin of respondent's posterior contains one of the two FOMC forecast numbers shown for unemployment. Bostic/Daly $=1$ if the picture seen was of Raphael Bostic or Mary Daly. WF/BM/BF $=1$ if respondent is White female, Black male, or Black female. BLM Support $=1$ if respondent indicated support for requests of Black Lives Matter movement $\geq 5$ out of 7 . Women Discr. $=1$ if respondent chose agreement $\geq 5$ out of 7 that discrimination against women or girls is an important problem in the US. In PM State (Fed District) $=1$ if respondent lives in state (Fed district) where the displayed policymaker is regional Fed president. Interacted terms (BLM Support, Women Discr., Age $\leq 40$, Democrat) also enter regression uninteracted; coefficients not shown. All regressions further control for the treatment (UR or inflation forecast $\times$ policymaker picture, or control), respondent gender and race/ethnicity, as well as a cubic function of the prior point forecast for unemployment, quadratic function of survey date, and dummies for: geographic region, income category, education cat., age cat., employment status, marital status, political leaning, financial literacy score, whether lost job or reduced income since March 2020 , whether state that could not pay for $\$ 400$ emergency expense, whether own primary residence, hold stock, have $401 \mathrm{k}$ or similar, whether do groceries, take financial decisions in household, and whether took survey on a mobile device. Robust standard errors in parentheses. ${ }^{*} \mathrm{p}<0.1,{ }^{* *} \mathrm{p}<0.05,{ }^{* * *} \mathrm{p}<0.01$. 
Table A.6: Channel 1-Trust in Policy Committees' Action (Post-Intervention): Robustness to Controlling for Taste for Diversity and Policymaker Location

\begin{tabular}{|c|c|c|c|c|c|c|c|c|c|c|c|c|c|c|}
\hline & \multicolumn{7}{|c|}{ A. Adequately manages inflation and unemployment } & \multicolumn{7}{|c|}{ B. Cares about economic well-being of all Americans } \\
\hline & $(1)$ & $(2)$ & $(3)$ & $(4)$ & $(5)$ & $(6)$ & $(7)$ & $(8)$ & $(9)$ & $(10)$ & $(11)$ & $(12)$ & (13) & $(14)$ \\
\hline$(\mathrm{WF} / \mathrm{BM} / \mathrm{BF}) \times($ Bostic/Daly $)$ & $\begin{array}{c}-0.088^{* * *} \\
(0.022)\end{array}$ & $\begin{array}{c}-0.081^{* * *} \\
(0.023)\end{array}$ & $\begin{array}{c}-0.079^{* * *} \\
(0.022)\end{array}$ & $\begin{array}{c}-0.085^{* * *} \\
(0.022)\end{array}$ & $\begin{array}{c}-0.081^{* * *} \\
(0.022)\end{array}$ & $\begin{array}{c}-0.089^{* * *} \\
(0.022)\end{array}$ & $\begin{array}{c}-0.072^{* * *} \\
(0.023)\end{array}$ & $\begin{array}{c}-0.049^{* *} \\
(0.023)\end{array}$ & $\begin{array}{l}-0.040^{*} \\
(0.023)\end{array}$ & $\begin{array}{l}-0.040^{*} \\
(0.023)\end{array}$ & $\begin{array}{c}-0.045^{* *} \\
(0.023)\end{array}$ & $\begin{array}{l}-0.044^{*} \\
(0.023)\end{array}$ & $\begin{array}{c}-0.049^{* *} \\
(0.023)\end{array}$ & $\begin{array}{l}-0.031 \\
(0.024)\end{array}$ \\
\hline Age $\leq 40 \times($ Bostic/Daly $)$ & & $\begin{array}{l}-0.033 \\
(0.023)\end{array}$ & & & & & $\begin{array}{l}-0.030 \\
(0.023)\end{array}$ & & $\begin{array}{c}-0.047^{* *} \\
(0.023)\end{array}$ & & & & & $\begin{array}{l}-0.046^{*} \\
(0.024)\end{array}$ \\
\hline Democrat $\times($ Bostic/Daly $)$ & & & $\begin{array}{c}-0.058^{* *} \\
(0.023)\end{array}$ & & & & $\begin{array}{c}-0.050^{* *} \\
(0.025)\end{array}$ & & & $\begin{array}{c}-0.057^{* *} \\
(0.023)\end{array}$ & & & & $\begin{aligned}-0.054^{* *} \\
(0.025)\end{aligned}$ \\
\hline Women Discr. $\times($ Bostic/Daly $)$ & & & & $\begin{array}{l}-0.030 \\
(0.024)\end{array}$ & & & $\begin{array}{l}-0.011 \\
(0.028)\end{array}$ & & & & $\begin{array}{l}-0.037 \\
(0.025)\end{array}$ & & & $\begin{array}{l}-0.027 \\
(0.029)\end{array}$ \\
\hline BLM Support × (Bostic/Daly) & & & & & $\begin{array}{l}-0.039^{*} \\
(0.023)\end{array}$ & & $\begin{array}{l}-0.013 \\
(0.029)\end{array}$ & & & & & $\begin{array}{l}-0.030 \\
(0.023)\end{array}$ & & $\begin{array}{c}0.008 \\
(0.029)\end{array}$ \\
\hline In PM State & & & & & & $\begin{array}{l}-0.038 \\
(0.028)\end{array}$ & $\begin{array}{l}-0.036 \\
(0.028)\end{array}$ & & & & & & $\begin{array}{l}-0.041 \\
(0.029)\end{array}$ & $\begin{array}{l}-0.039 \\
(0.029)\end{array}$ \\
\hline In PM Fed District & & & & & & $\begin{array}{c}0.004 \\
(0.018)\end{array}$ & $\begin{array}{c}0.004 \\
(0.018)\end{array}$ & & & & & & $\begin{array}{c}0.015 \\
(0.018)\end{array}$ & $\begin{array}{c}0.015 \\
(0.018)\end{array}$ \\
\hline Controls & Yes & Yes & Yes & Yes & Yes & Yes & Yes & Yes & Yes & Yes & Yes & Yes & Yes & Yes \\
\hline Avg. Y & 0.35 & 0.35 & 0.35 & 0.35 & 0.35 & 0.35 & 0.35 & 0.44 & 0.44 & 0.44 & 0.44 & 0.44 & 0.44 & 0.44 \\
\hline SD Y & 0.48 & 0.48 & 0.48 & 0.48 & 0.48 & 0.48 & 0.48 & 0.50 & 0.50 & 0.50 & 0.50 & 0.50 & 0.50 & 0.50 \\
\hline Adj. R2 & 0.06 & 0.06 & 0.06 & 0.07 & 0.07 & 0.06 & 0.07 & 0.10 & 0.10 & 0.10 & 0.10 & 0.10 & 0.10 & 0.10 \\
\hline Obs. & 7846 & 7846 & 7846 & 7846 & 7846 & 7846 & 7846 & 7846 & 7846 & 7846 & 7846 & 7846 & 7846 & 7846 \\
\hline
\end{tabular}

Dependent variable: Distrust in Fed $=1$ if respondent indicates trust $\leq 3$ out of 7 in terms of trusting Fed to adequately manage inflation and unemployment (panel A) or caring about the economic well-being of all Americans (panel B). Bostic/Daly = 1 if the picture seen was of Raphael Bostic or Mary Daly, as opposed to Thomas Barkin. WF/BM/BF $=1$ if respondent is White female, Black male, or Black female. BLM Support $=1$ if respondent indicated support for requests of Black Lives Matter movement $\geq 5$ out of 7 . Women Discr. $=1$ if respondent chose agreement $\geq 5$ out of 7 that discrimination against women or girls is an important problem in the US. In PM State (Fed District) $=1$ if respondent lives in state (Fed district) where the displayed policymaker is regional Fed president. Interacted terms (BLM Support, Women Discr., Age $\leq 40$, Democrat) also enter regression uninteracted; coefficients not shown. All regressions further control for the treatment (UR or inflation forecast $\times$ policymaker picture, or control), respondent gender and race/ethnicity, as well as a quadratic time trend and dummies for: geographic region, income category, education cat., age cat., employment status, marital status, political leaning, whether lost job or reduced income since March 2020, whether state that could not pay for $\$ 400$ emergency expense, whether own primary residence, hold stock, have 401k or similar, whether do groceries, take financial decisions in household, responded correctly to each of two financial literacy questions, and whether took survey on a mobile device. Robust standard errors in parentheses. ${ }^{*} \mathrm{p}<0.1,{ }^{* *} \mathrm{p}<0.05,{ }^{* * *} \mathrm{p}<0.01$. 
Table A.7: Effects of Diversity Salience on Expectations and Trust: Persistence?

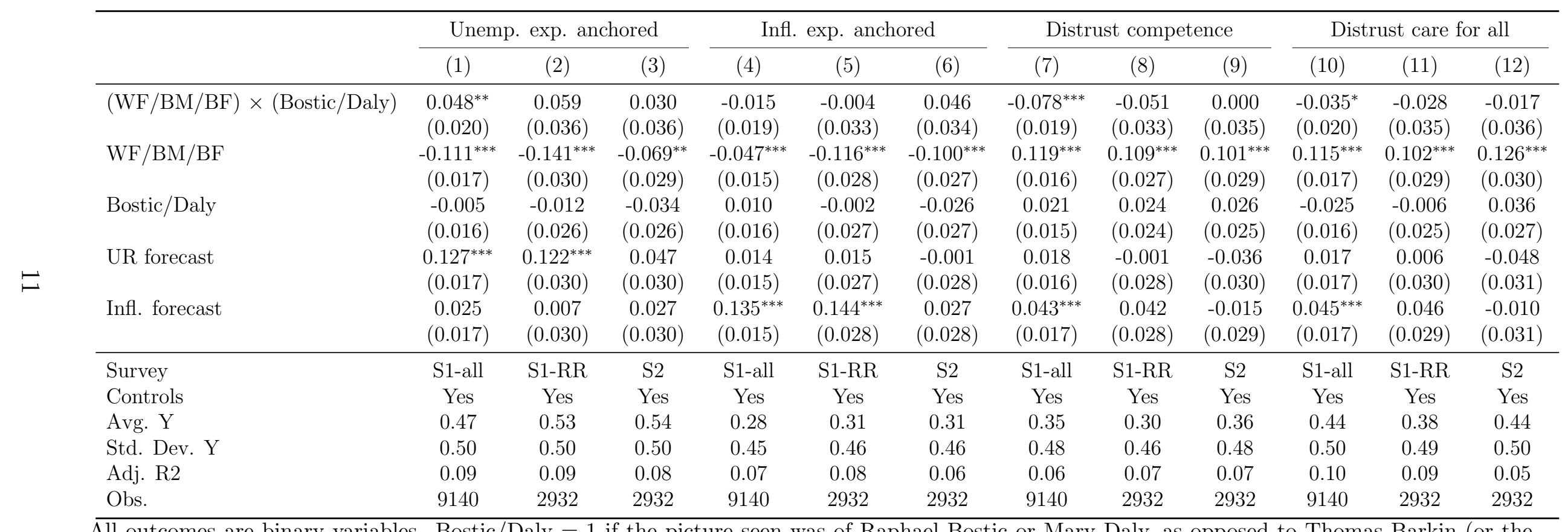

All outcomes are binary variables. Bostic/Daly $=1$ if the picture seen was of Raphael Bostic or Mary Daly, as opposed to Thomas Barkin (or the control group). WF/BM/BF $=1$ if respondent is White female, Black male, or Black female. Controls include a quadratic function of survey date, and dummies for: geographic region, income category, education cat., age cat., employment status, marital status, political leaning, financial literacy score, whether lost job or reduced income since March 2020 , whether state that could not pay for $\$ 400$ emergency expense, whether own primary residence, hold stock, have 401k or similar, whether do groceries, take financial decisions in household, and whether took survey on a mobile device. Samples: S1-all is the main (first) survey. S2 is the second survey. S1-RR are the respondents in the main survey who later participated in the follow-up. Robust standard errors in parentheses. ${ }^{*} \mathrm{p}<0.1,{ }^{* *} \mathrm{p}<0.05,{ }^{* * *} \mathrm{p}<0.01$. 


\section{B Survey Wording and Screenshots}

\section{B.1 Questions in Main Survey (August 2020)}

Thank you very much for your interest in our survey, which involves academic research. The purpose of the research is to ask your opinions and views about the current and future state of the US economy, as well as how your household is doing and will do going forward.

In addition to today's survey, you may be contacted again in about 4 weeks to complete a second survey.

While you participate in the survey, we will provide you with information about the economy, which we hope you will find interesting and useful. Whether this information influences your views depends fully on your opinion. There is no right or wrong answer. Answers are only right if they truly reflect your own views and opinions, as opposed to those of somebody else.

We do not foresee any type of risk or discomfort from this survey. Participation is entirely voluntary, and you will be able to leave the survey at any time you want if you faced unknown risks. Withdrawal from participation will not hinder you from learning about the economy and provide your opinions about the economy.

Your answers will be analyzed in aggregation with the answers of all other respondents to create general, average trends about views of the US economy. This information will be important to US policy makers and regulators, in order to improve the way in which they think about individuals' priorities.

All your answers will be confidential. The researchers who will elaborate the data will have no access to any identifiable information about you. They will receive anonymized information including your answers associated with an ID code, which the researchers cannot link back to your identity. If you have any concerns, you can contact K. M. Green at kmgreen999@gmail.com.

If you agree with these conditions, and are willing to participate in the survey, please check the box below:

Box: I consent to the conditions to participate in the survey 
Question 1 What year were you born?

[DROPDOWN BOX] Year: 1916, 1917.. 2005

Question 2 What is the highest level of school you have completed, or the highest degree you have received?

- High school or less

- Some college but no degree (including academic, vocational, or occupational programs)

- Associate/Junior College degree (including academic, vocational, or occupational programs)

- Bachelor's Degree (For example: BA, BS)

- Postgraduate Degree (For example: MA, MBA, MS, PhD, JD, MD)

- Other (please specify)

Question 3 What is the state of your primary residence?

[DROPDOWN BOX]

Question 4 During the last month, have you consulted any of the following sources of information on economics and business conditions in the U.S.? Please select all that apply.

- Official sources (like the webpages of the Government, statistical agencies or the Fed)

- Traditional media (television, radio, newspapers -in print or online)

- Social media (for example, blogs, discussion forums Facebook, Twitter, Instagram, etc.)

- Friends, relatives, and colleagues

- I did not come across any information on economic and business conditions

- Other sources of information (please specify)

Question 5 Eight times a year a group of people meets to set the basic interest rate level in the United States. Who do you think comprises this group?

- The President of the United States and his advisors

- The U.S. Treasury 
- The Federal Open Market Committee (part of the Federal Reserve, or Fed)

- The U.S. Senate and House of Representatives

- The CEOs of the largest U.S. banks

- Other

- Don’t know

Question $6{ }^{1}$ Suppose that you have an emergency expense that costs \$400. Based on your current financial situation, how would you pay for this expense? If you would use more than one method to cover this expense, please select all that apply.

- Put it on my credit card and pay it off in full at the next statement

- Put it on my credit card and pay it off over time

- With the money currently in my checking/savings account or with cash

- Using money from a bank loan or line of credit

- By borrowing from a friend or family member

- Using a payday loan, deposit advance, or overdraft

- By selling something

- I wouldn't be able to pay for the expense right now

- Other (please specify):

Question 7 Did you, or anybody in your household, lose your job(s) or close your business during the COVID-19 pandemic?

- Yes

- No

Question 8 Did your monthly household income decline during the COVID-19 pandemic?

- Yes

- No

\footnotetext{
${ }^{1}$ This question is taken from the Federal Reserve Board's Survey of Household Economics and Decisionmaking (SHED).
} 
The next question is about the following problem. In questionnaires like ours, sometimes there are participants who do not carefully read the questions and just quickly click through the survey. This means that there are a lot of random answers which compromise the results of research studies. To show that you read our questions carefully, please choose "Very strongly interested" as your answer in the next question.

Question 9 How interested are you in sports?

Slider from 1 to 5 ( 1 = "not at all interested"; 5 = "very strongly interested")

Now please answer "Not at all interested" to the following question:

Question 10 How interested are you in music?

Slider from 1 to 5 ( 1 = "not at all interested"; 5 = "very strongly interested")

We now would like to ask you about the unemployment rate.

The unemployment rate is defined as the number of unemployed people as a percentage of the labor force (which includes people who are either working or actively seeking work).

Question 11 What do you think is the current official unemployment rate in the U.S.?

- ___ percent [allow for 1 decimal]

Question 12 What do you think the official unemployment rate will be 12 months from now (in August 2021)?

- ___ percent [allow for 1 decimal]

Question 13 How confident are you in this answer?

Slider from 1 to 7 ( 1 = "not confident at all"; 7 = "completely confident")

Next, we would like to ask you about the rate of inflation/deflation in the U.S. economy.

(Note: inflation is the percentage rise in prices of goods and services in the economy, most commonly measured by the Consumer Price Index. Deflation means prices are falling, and hence is the opposite of inflation. For instance, if a price moves from \$2 to \$2.12 the rate of inflation is (2.12-2)/2 $=6 \%$. If a price moves from \$3 to \$2.91 the rate of deflation is $(2.91-3) / 3=-3 \%$.) 
Question 14 The Federal Reserve is responsible for monetary policy in the U.S., which includes, among other things, achieving a stable target for inflation over longer time periods. What is your best guess about the annual inflation rate that the Federal Reserve tries to achieve on average over longer time periods?

- _ $\%$ per year [RANGE: -100-100 allow 2 decimal points]

Question 15 How confident are you in this answer?

Slider from 1 to 7 (1 = "not confident at all"; 7 = "completely confident")

Question 16 By how much do you think prices of goods and services in the U.S. changed over the past 12 months (as measured by the Consumer Price Index)?

Please enter a number in the box below. If you do not think there was any inflation/deflation in the last 12 months, please enter a "0". If you think there was deflation (=negative inflation, i.e. prices decreased), enter a negative value. If you think there was inflation, enter a positive value.

Over the last 12 months, my best guess is that the rate of inflation/deflation was

- _ $\%$ per year [RANGE: -100-100 allow 2 decimal points]

Question 17 And by how much do you expect prices of goods and services in the U.S. to change over the next 12 months? Please provide an answer as a percentage change from current prices.

Over the next 12 months, my best guess is that the rate of inflation/deflation will be

- $\%$ per year [RANGE: -100-100 allow 2 decimal points]

Question 18 How confident are you in this answer?

Slider from 1 to 7 ( $1=$ "not confident at all"; $7=$ "completely confident")

[INFORMATION TREATMENTS.

EACH SURVEY PARTICIPANT IS RANDOMLY ASSIGNED INTO EITHER THE "CONTROL GROUP" OR GROUPS $1-6$. 


\section{[SHOW TO EVERYONE ]}

We would now like to provide you with some information about monetary policy in the United States, and then ask you some more questions.

[Control Group]

The Federal Reserve, or Fed, conducts the nation's monetary policy by influencing money and credit conditions in the economy in pursuit of full employment and stable prices.

The Federal Reserve System includes three key entities: the Board of Governors, 12 Federal Reserve Banks, and the Federal Open Market Committee (FOMC). The FOMC is the monetary policymaking body of the Federal Reserve System, and sets short-term interest rates. The FOMC is composed of 12 members-the seven members of the Board of Governors and five of the 12 Reserve Bank

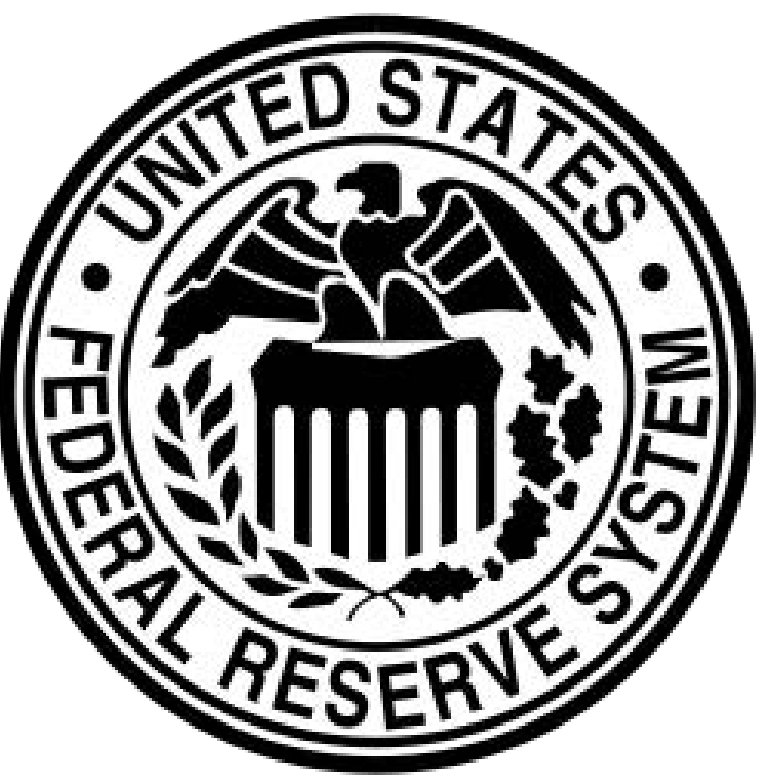
presidents. 
[Treatment Group 1]

The Federal Reserve, or Fed, conducts the nation's monetary policy by influencing money and credit conditions in the economy in pursuit of full employment and stable prices.

At their meeting in June 2020, the Federal Reserve Bank Presidents and Federal Reserve Board Governors forecasted (on average)

- a $0.8 \%$ inflation rate in 2020

- a $1.6 \%$ inflation rate in 2021

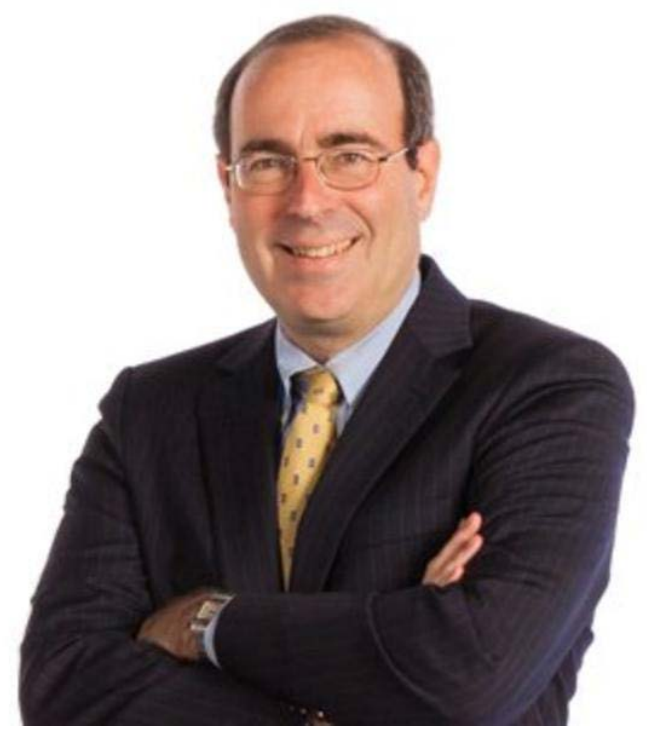

Thomas Barkin, President of the Federal Reserve Bank of Richmond, who participated in the June 2020 Fed meeting. 
[Treatment Group 2]

The Federal Reserve, or Fed, conducts the nation's monetary policy by influencing money and credit conditions in the economy in pursuit of full employment and stable prices.

At their meeting in June 2020, the Federal Reserve Bank Presidents and Federal Reserve Board Governors forecasted (on average)

- a $9.3 \%$ unemployment rate in the fourth quarter of 2020

- a $6.5 \%$ unemployment rate in the fourth quarter of 2021

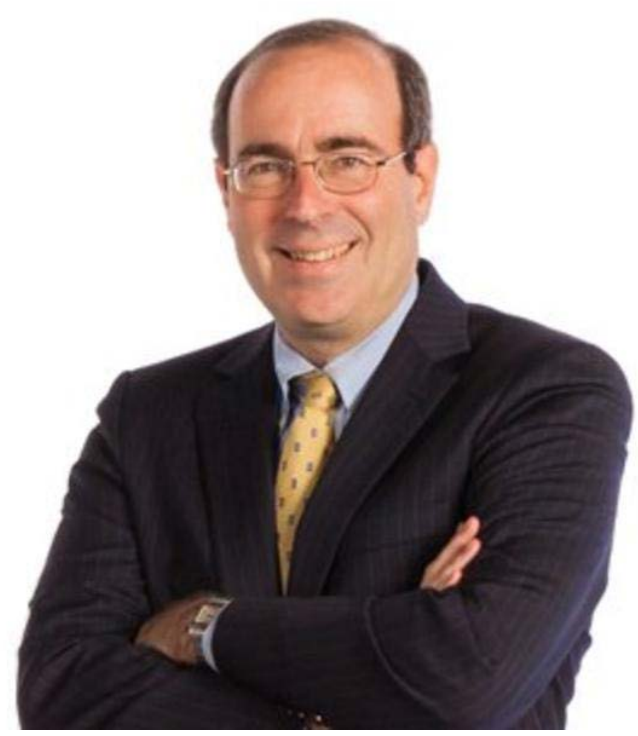

Thomas Barkin, President of the Federal Reserve Bank of Richmond, who participated in the June 2020 Fed meeting. 
[Treatment Group 3]

The Federal Reserve, or Fed, conducts the nation's monetary policy by influencing money and credit conditions in the economy in pursuit of full employment and stable prices.

At their meeting in June 2020, the Federal Reserve Bank Presidents and Federal Reserve Board Governors forecasted (on average)

- a $0.8 \%$ inflation rate in 2020

- a $1.6 \%$ inflation rate in 2021

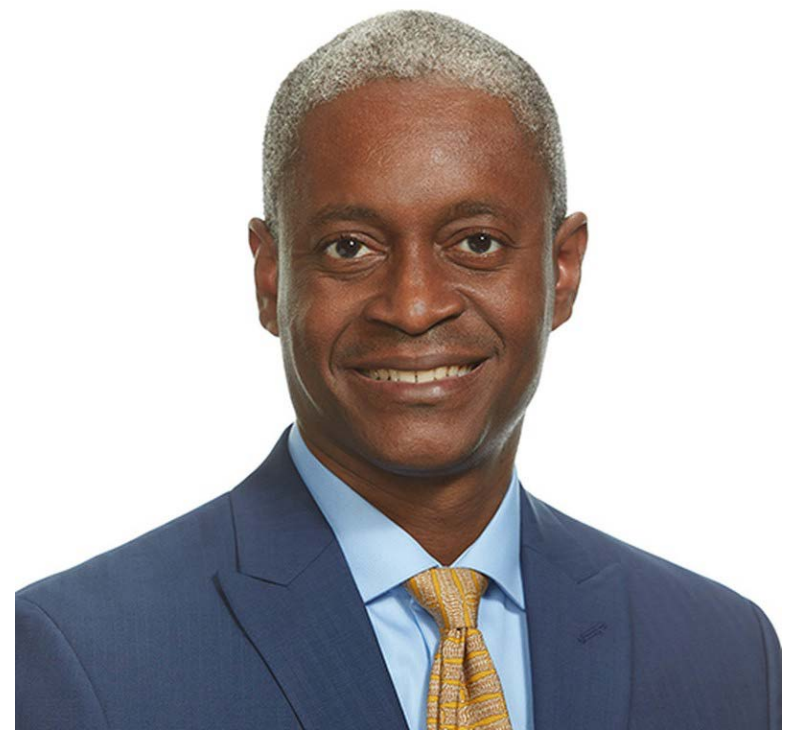

Raphael Bostic, President of the Federal Reserve Bank of Atlanta, who participated in the June 2020 Fed meeting. 
[Treatment Group 4]

The Federal Reserve, or Fed, conducts the nation's monetary policy by influencing money and credit conditions in the economy in pursuit of full employment and stable prices.

At their meeting in June 2020, the Federal Reserve Bank Presidents and Federal Reserve Board Governors forecasted (on average)

- a $9.3 \%$ unemployment rate in the fourth quarter of 2020

- a $6.5 \%$ unemployment rate in the fourth quarter of 2021

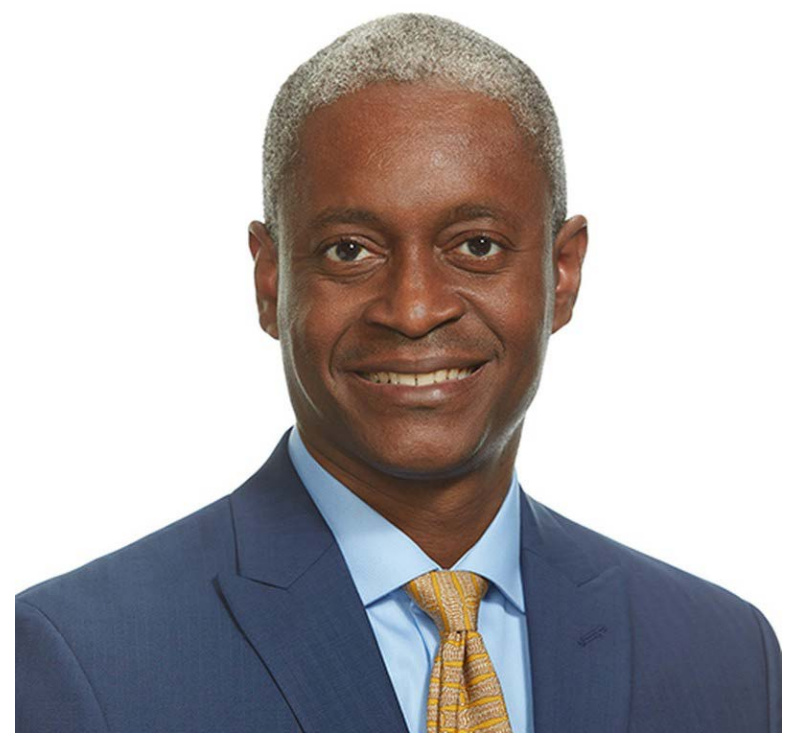

Raphael Bostic, President of the Federal Reserve Bank of Atlanta, who participated in the June 2020 Fed meeting. 
[Treatment Group 5]

The Federal Reserve, or Fed, conducts the nation's monetary policy by influencing money and credit conditions in the economy in pursuit of full employment and stable prices.

At their meeting in June 2020, the Federal Reserve Bank Presidents and Federal Reserve Board Governors forecasted (on average)

- a $0.8 \%$ inflation rate in 2020

- a $1.6 \%$ inflation rate in 2021

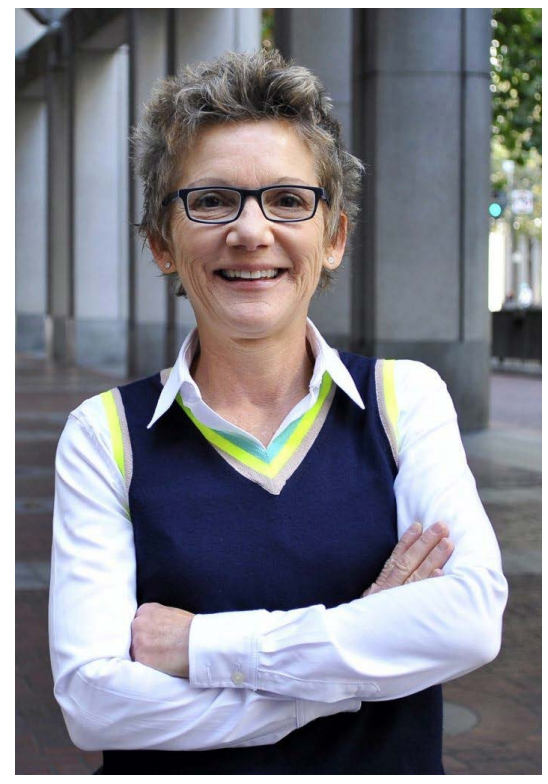

Mary Daly, President of the Federal Reserve Bank of San Francisco, who participated in the June 2020 Fed meeting. 
[Treatment Group 6]

The Federal Reserve, or Fed, conducts the nation's monetary policy by influencing money and credit conditions in the economy in pursuit of full employment and stable prices.

At their meeting in June 2020, the Federal Reserve Bank Presidents and Federal Reserve Board Governors forecasted (on average)

- a $9.3 \%$ unemployment rate in the fourth quarter of 2020

- a $6.5 \%$ unemployment rate in the fourth quarter of 2021

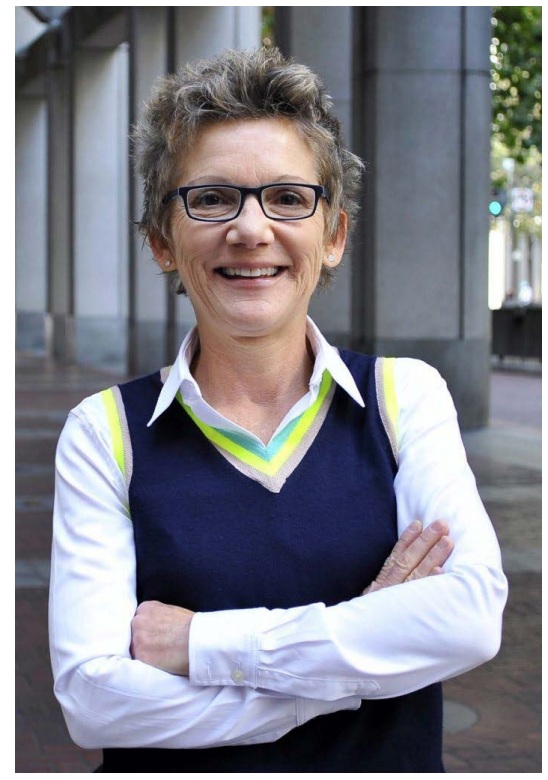

Mary Daly, President of the Federal Reserve Bank of San Francisco, who participated in the June 2020 Fed meeting. 
Question 19 How much do you trust the Fed to adequately manage inflation and unemployment?

Slider from 1 to 7 ( 1 = "no trust at all"; 7 = "completely trust")

Question 20 And how much do you trust the Fed to care about the economic well-being of all Americans, including people like yourself?

Slider from 1 to 7 ( $1=$ "no trust at all"; 7 = "completely trust")

In the next two questions, you will be asked about the PERCENT CHANCE of something happening. The percent chance must be a number between 0 and 100 .

For example, numbers like:

2 and 5 percent may indicate "almost no chance"

18 percent or so may mean "not much chance"

47 or 52 percent chance may be a "pretty even chance"

83 percent or so may mean a "very good chance"

95 or 98 percent chance may be "almost certain"

When we ask you about the percent chance of different options, the sum of your answers must add up to 100 . We realize that these questions may take a little more effort.

Question 21 First, we would like you to think about the different things that may happen to the official unemployment over the next 12 months.

What do you think is that percent chance that, 12 months from now $\cdots$

(Please note: The numbers need to add up to 100.)

\section{[RANGE OF EACH OPTION BELOW: 0-100 Do Not ALLOW FOR DECIMAL POINTS]}

- the unemployment rate will be $17 \%$ or higher

- the unemployment rate will be between $14 \%$ and $17 \%$

- the unemployment rate will be between $11 \%$ and $14 \%$

- the unemployment rate will be between $8 \%$ and $11 \%$

- the unemployment rate will be between $5 \%$ and $8 \%$ 
- the unemployment rate will be $5 \%$ or lower

Question 22 Now we would like you to think about the different things that may happen to inflation over the next 12 months.

(Note: inflation is the percentage rise in prices of goods and services in the economy, most commonly measured by the Consumer Price Index. Deflation means prices are falling, and hence is the opposite of inflation.)

What do you think is the percent chance that, over the next 12 months ..

(Please note: The numbers need to add up to 100.)

\section{[RANGE OF EACH OPTION BELOW: 0-100 Do Not ALLOW FOR DECIMAL POINTS]}

- the rate of inflation will be $8 \%$ or more

- the rate of inflation will be between $4 \%$ and $8 \%$

- the rate of inflation will be between $2 \%$ and $4 \%$

- the rate of inflation will be between $0 \%$ and $2 \%$

- the rate of deflation (opposite of inflation) will be between $0 \%$ and $2 \%$

- the rate of deflation (opposite of inflation) will be between $2 \%$ and $4 \%$

- the rate of deflation (opposite of inflation) will be between $4 \%$ and $8 \%$

- the rate of deflation (opposite of inflation) will be $8 \%$ or more

In the next two questions, we would like you to think about the value of money over time.

Question 23 Let's say you have \$200 in a bank account. The account earns ten per cent interest per year. Interest accrues at the end of each year. If you never withdraw money or interest payments, how much do you think you will have in the account at the end of two years?

- USD

Question 24 Imagine that the interest rate on your bank account is 1\% per year and inflation is $2 \%$ per year. After one year, how much would you be able to buy with the money in this account? 
- More than today

- Exactly the same as today

- Less than today

You are almost done with the survey. Just a few more questions about yourself and your household:

Question 25 What is your gender?

- Male

- Female

Question 26 How do you identify yourself?

Please select all that apply.

- American Indian or Alaska Native

- Asian

- Black or Black

- Native Hawaiian or Other Pacific Islander

- White

- Other (please specify)

Question 27 What is your current employment situation?

- Working full-time (for someone or self-employed)

- Working part-time (for someone or self-employed)

- Not working, but would like to work

- Not actively looking for work

- Student, at school or in training

- Other (please specify)

Question 28 Which of the following describes you best in terms of your political views? 
- Republican

- Independent

- Democrat

- Libertarian

Question 29 Are you currently married or living as a partner with someone?

- Yes

- No

Question 30 What is the ZIP code of your primary residence (the place where you usually live)?

Question 31 Do you own your current primary residence?

- Yes

- No

[Only ask Question 32 if answered YES to Question 31]

Question 32 Do you have any outstanding loans against the value of your home (including all mortgages, home equity loans and home equity lines of credit) at this time?

- Yes

- No

Question 33 Do you hold any stock or other equity investments at this time?

- Yes

- No

Question 34 Do you have a retirement fund, such as $401(k)$ or other types of retirement funds?

- Yes

- No 
Question 35 Which category represents the total combined pre-tax income of all members of your household (including you) during the past 12 months?

Please include money from all jobs, net income from business, farm or rent, pensions, interest on savings or bonds, dividends, social security income, unemployment benefits, Food Stamps, workers compensation or disability benefits, child support, alimony, scholarships, fellowships, grants, inheritances and gifts, and any other money income received by members of your household who are 15 years of age or older.

- Less than $\$ 10,000$

- $\$ 10,000$ to $\$ 19,999$

- $\$ 20,000$ to $\$ 29,999$

- $\$ 30,000$ to $\$ 39,999$

- $\$ 40,000$ to $\$ 49,999$

- $\$ 50,000$ to $\$ 59,999$

- $\$ 60,000$ to $\$ 74,999$

- $\$ 75,000$ to $\$ 99,999$

- $\$ 100,000$ to $\$ 149,999$

- $\$ 150,000$ to $\$ 199,999$

- $\$ 200,000$ or more

Question 36 Approximately, how many times per month do you go to a gas station to buy gasoline or for other reasons? (Please enter a number)

- _ times

Question 37 Who does the grocery shopping for yourself/your household?

- I do most of the groceries

- I do only some of the groceries

- Somebody else does most of the groceries

Question 38 Which of the following best describes how financial decisions are made in your household?

- Someone else in my household makes all financial decisions 
- I share financial decisions equally with someone else in my household

- I make all financial decisions myself

Question 39 How much do you agree with the following statement:

"Discrimination against women or girls is an important problem in the US."

Slider from 1 to 7 ( 1 = "do not agree at all"; $7=$ "completely agree")

Question 40 The recent events have reopened the debate about social justice in the United States, with a primary role for the Black Lives Matter (BLM) movement.

To what extent do you support the requests of the BLM movement?

Slider from 1 to 7 ( $1=$ "do not support at all"; 7 = "support wholeheartedly")

Question 41 Earlier in the survey, we showed you a picture related to the Federal Reserve. Do you remember who/what was in the picture?

- Raphael Bostic, President of the Federal Reserve Bank of Atlanta

- Thomas Barkin, President of the Federal Reserve Bank of Richmond

- Mary Daly, President of the Federal Reserve Bank of San Francisco

- Neel Kashkari, President of the Federal Reserve Bank of Minneapolis

- The symbol of the Federal Reserve

Question 42 Could you tell us how interesting or uninteresting you found the questions in this survey?

- Very uninteresting

- Somewhat uninteresting

- Neither interesting or uninteresting

- Somewhat interesting

- Very interesting

Question 43 Do you have any comments about the survey or the survey experience?

Please type these in the box below. 


\section{B.2 Questions in Follow-Up Survey (September 2020)}

Thank you very much for your interest in our survey, which involves academic research. The purpose of the research is to ask your opinions and views about the current and future state of the US economy, as well as how your household is doing and will do going forward.

While you participate in the survey, we will provide you with information about the economy, which we hope you will find interesting and useful. Whether this information influences your views depends fully on your opinion. There is no right or wrong answer. Answers are only right if they truly reflect your own views and opinions, as opposed to those of somebody else.

We do not foresee any type of risk or discomfort from this survey. Participation is entirely voluntary, and you will be able to leave the survey at any time you want if you faced unknown risks. Withdrawal from participation will not hinder you from learning about the economy and provide your opinions about the economy.

Your answers will be analyzed in aggregation with the answers of all other respondents to create general, average trends about views of the US economy. This information will be important to US policy makers and regulators, in order to improve the way in which they think about individuals' priorities.

All your answers will be confidential. The researchers who will elaborate the data will have no access to any identifiable information about you. They will receive anonymized information including your answers associated with an ID code, which the researchers cannot link back to your identity. If you have any concerns, you can contact K. M. Green at kmgreen999@gmail.com.

If you agree with these conditions, and are willing to participate in the survey, please check the box below:

Box: I consent to the conditions to participate in the survey

In the next two questions, you will be asked about the PERCENT CHANCE of something happening. The percent chance must be a number between 0 and 100 .

For example, numbers like:

2 and 5 percent may indicate "almost no chance" 18 percent or so may mean "not much chance" 47 or 52 percent chance may be a "pretty even chance" 83 percent or so may mean a "very good chance" 95 or 98 percent chance may be "almost certain"

When we ask you about the percent chance of different options, the sum of your answers must add up to 100 . We realize that these questions may take a little more effort. 
Question 1 First, we would like you to think about the different things that may happen to the official unemployment in the U.S. over the next 12 months.

What do you think is that percent chance that, 12 months from now $\ldots$

(Please note: The numbers need to add up to 100.)

[RANGE OF EACH OPTION BELOW: 0-100 Do Not ALLOW FOR DECIMAL POINTS]

- the unemployment rate will be $17 \%$ or higher

- the unemployment rate will be between $14 \%$ and $17 \%$

- the unemployment rate will be between $11 \%$ and $14 \%$

- the unemployment rate will be between $8 \%$ and $11 \%$

- the unemployment rate will be between $5 \%$ and $8 \%$

- the unemployment rate will be $5 \%$ or lower

Question 2 Now we would like you to think about the different things that may happen to inflation over the next 12 months.

(Note: inflation is the percentage rise in prices of goods and services in the economy, most commonly measured by the Consumer Price Index. Deflation means prices are falling, and hence is the opposite of inflation.)

What do you think is the percent chance that, over the next 12 months ...

(Please note: The numbers need to add up to 100.)

[RANGE OF EACH OPTION BELOW: 0-100 Do Not ALLOW FOR DECIMAL POINTS]

- the rate of inflation will be $8 \%$ or more

- the rate of inflation will be between $4 \%$ and $8 \%$

- the rate of inflation will be between $2 \%$ and $4 \%$

- the rate of inflation will be between $0 \%$ and $2 \%$ 
- the rate of deflation (opposite of inflation) will be between $0 \%$ and $2 \%$

- the rate of deflation (opposite of inflation) will be between $2 \%$ and $4 \%$

- the rate of deflation (opposite of inflation) will be between $4 \%$ and $8 \%$

- the rate of deflation (opposite of inflation) will be $8 \%$ or more

Question 3 During the last two weeks, did you read any newspaper articles (or online articles etc.) about the Federal Reserve (Fed) or monetary policy in the U.S.?

- No, I did not read any such articles

- Yes, I read one such article

- Yes, I read two or more such articles

Question 4 During the last four weeks, did the Federal Reserve make any changes to the level of short-term interest rates in the U.S.?

- Yes

- No

- Don’t know

Question 5 The Federal Reserve is responsible for monetary policy in the U.S., which includes, among other things, achieving a stable target for inflation over longer time periods. What is your best guess about the annual inflation rate that the Federal Reserve tries to achieve on average over longer time periods?

- _ $\%$ per year [RANGE: -100-100 allow 2 decimal points]

Question 6 How confident are you in this answer?

Slider from 1 to 7 ( $1=$ "not confident at all"; $7=$ "completely confident")

Question 7 How much do you trust the Fed to adequately manage inflation and unemployment?

Slider from 1 to 7 ( $1=$ "no trust at all"; 7 = "completely trust") 
Question 8 And how much do you trust the Fed to care about the economic well-being of all Americans, including people like yourself?

Slider from 1 to 7 ( $1=$ "no trust at all"; $7=$ "completely trust")

[INFORMATION SELECTION MODULE.

EACH SURVEY PARTICIPANT IS RANDOMLY ASSIGNED INTO ONE OF THE GROUPS $1-4$.

Groups 1 and 2:]

On the next page, you will be shown a short article that features a statement about the future of the U.S. economy from a high-ranked official from ONE of the following TWO policy-making agencies. Then you will be asked some questions about the article you were shown.

1. Congressional Budget Office (CBO)

2. Federal Reserve

Note: The Congressional Budget Office (CBO) is a federal agency that provides economic forecasts and budget information to the Congress.

The Federal Reserve (Fed) conducts the nation's monetary policy by influencing money and credit conditions in the economy in pursuit of full employment and stable prices.

Question 9 Please choose which article you would like to see:

I would prefer to see the article that features a statement from an official from the

- Congressional Budget Office

- Federal Reserve

[Programmer Instruction:

- If select Congressional Budget Office $\rightarrow$ get article 1 (CBO, Philipp Swagel)

- If select Federal Reserve and in Group $1 \rightarrow$ get article 2 (Fed, Richard Clarida)

- If select Federal Reserve and in Group $2 \rightarrow$ get article 3 (Fed, Michelle Bowman)] 
[Group 3:]

On the next page, you will be shown a short article that features a statement about the future of the U.S. economy from ONE of the following TWO policy makers. Then you will be asked some questions about the article you were shown.

1. Mr. Philipp Swagel, Director of the Congressional Budget Office (CBO)

2. Mr. Richard Clarida, Governor, Federal Reserve Board

Note: The Congressional Budget Office (CBO) is a federal agency that provides economic forecasts and budget information to the Congress.

The Federal Reserve (Fed) conducts the nation's monetary policy by influencing money and credit conditions in the economy in pursuit of full employment and stable prices.

Question 9 Please choose which article you would like to see:

I would prefer to see the article that features a statement from

- Mr. Swagel, CBO

- Mr. Clarida, Federal Reserve Board

[Programmer Instruction:

- If select Swagel $\rightarrow$ get article 1 (CBO, Philipp Swagel)

- If select Clarida $\rightarrow$ get article 2 (Fed, Richard Clarida)]

[Group 4:]

On the next page, you will be shown a short article that features a statement about the future of the U.S. economy from ONE of the following TWO policy makers. Then you will be asked some questions about the article you were shown.

1. Mr. Philipp Swagel, Director of the Congressional Budget Office (CBO)

2. Ms. Michelle Bowman,, Governor, Federal Reserve Board 
Note: The Congressional Budget Office (CBO) is a federal agency that provides economic forecasts and budget information to the Congress.

The Federal Reserve (Fed) conducts the nation's monetary policy by influencing money and credit conditions in the economy in pursuit of full employment and stable prices.

Question 9 Please choose which article you would like to see:

I would prefer to see the article that features a statement from

- Mr. Swagel, CBO

- Ms. Bowman, Federal Reserve Board

[Programmer Instruction:

- If select Swagel $\rightarrow$ get article 1 (CBO, Philipp Swagel)

- If select Bowman $\rightarrow$ get article 3 (Fed, Michelle Bowman)]

[Articles that were then shown:

ARTICLE 1 (CBO/SWAGEL)]

Congress mounted a $\$ 3$ trillion response to the pandemic but any boost in economic activity will be "tempered" as long as some social distancing continues, the director of the Congressional Budget Office, Phillip Swagel, said in early June.

Mr. Swagel also said that additional emergency aid for state and local governments would increase the federal deficit, but help reduce the size of tax hikes and budget cuts that governors and local officials will be forced to consider.

"Continued business closures and the reduction in hours worked mean that the supply of certain goods and services will remain suppressed," the head of the independent budget agency wrote. "At the same time, as people limit their social interactions, household and business demand for many goods and services will be subdued."

"Therefore, CBO estimates that as long as some degree of social distancing remains in place, the economic boost that might be expected from recent legislation will be smaller than it would be during a period of economic weakness without social distancing," he said.

(Note: original article edited for brevity and clarity.)

Source (not displayed): Politico

[ARTICLE 2 (FED/CLARIDA)] 
Federal Reserve Vice Chair Richard Clarida said on Wednesday that policymakers "are not even going to begin thinking" about raising interest rates until inflation hits $2 \%$, comments aimed at cementing the public's understanding of the U.S. central bank's new approach to monetary policy.

The Fed cut rates to near zero in March and took other steps to combat a recession that took hold as businesses shut down and consumers stayed home to fight the spread of the coronavirus.

Mr. Clarida said that with further government aid from Congress and the steps the Fed has already taken, the U.S. economy could return from the current "deep hole" of joblessness and weak demand in perhaps three years.

To aid that process, the Fed in late August revised its approach to monetary policy to commit to lower rates for longer periods of time, allowing the risk of higher inflation to try to encourage a stronger economic recovery and more job gains for workers.

(Note: original article edited for brevity and clarity.)

Source (not displayed): Reuters

\section{[ARTICLE 3 (FED/BOWMAN)]}

The U.S. economy has bounced back "noticeably" from the depths of the coronavirus recession, Federal Reserve Governor Michelle Bowman said on Wednesday, but it is still far from back to normal and will take some time to get there.

"Progress toward a full recovery in economic activity may well be slow and uneven," Ms. Bowman said in remarks prepared for delivery to the Kansas Bankers Association. "The Federal Reserve will continue to monitor progress and respond promptly and flexibly to support the recovery."

To help shape her understanding of the outlook, Bowman said she is in the process of speaking individually with every CEO of 650 Fed-supervised community banks across the country.

The pandemic "continues to weigh heavily on our national economy," she said, and community banks remained well-positioned to help support the recovery.

(Note: original article edited for brevity and clarity.)

Source (not displayed): Reuters

\section{Question 10 How interesting did you find the article?}

Slider from 1 to 7 ( $1=$ "not interesting at all"; 7 = "very interesting")

Question 11 How much do you trust in the competence of the policy maker cited in the article in understanding the economy and proposing effective policy measures to counteract the COVID-19 crisis? 
Slider from 1 to 7 ( $1=$ "no trust at all"; $7=$ "complete trust")

Question 12 Do you think policy makers like the one from the article are effective at helping the economy in the current situation?

Slider from 1 to 7 ( 1 = "not effective at all"; 7 = "extremely effective")

We will now show you a few recent statements by policy makers, economists, and journalists. For each statement, we would like you to tell us to what extent you agree or disagree with the statement.

[NOTE: STATEMENTS SHOWN IN RANDOM ORDER. ALL STATEMENTS SHOWN TO ALL SUBJECTS]

Question 13 "Diversity makes the [Federal Reserve] Board stronger by providing different talents and perspectives that help make us more effective." Jerome Powell, Chairman, Federal Reserve Board

Slider from 1 to 7 ( 1 = "completely disagree"; $7=$ "completely agree")

Question 14 "Diverse organizations are also better able to relate to and talk to many different communities."

Jerome Powell, Chairman, Federal Reserve Board

Slider from 1 to 7 ( 1 = "completely disagree"; 7 = "completely agree")

Question 15 "The Federal Reserve has a chronic white male problem that is going to make it harder for the institution to help lead the country at a historic moment of crisis."

Pedro Nicolaci da Costa, Economic journalist for leading US newspapers

Slider from 1 to 7 ( $1=$ "completely disagree"; $7=$ "completely agree")

Question 16 "Economists of color missing from the [Federal Reserve Board] means that race has largely been missing from its policy deliberations." Claudia Sahm, Director, non-profit research organization

Slider from 1 to 7 ( $1=$ "completely disagree"; $7=$ "completely agree") 
Question 17 "The demand for diversity has steadily weakened the norms of objectivity and truth and substituted for them a culture of grievance and group loyalty."

Anthony Kronman, former dean of Yale Law School

Slider from 1 to 7 ( 1 = "completely disagree"; 7 = "completely agree" $)$

Finally, please indicate your level of agreement with the following statement:

Question 18 "Public organizations such as the Federal Reserve should be required by law to have at least the same share of women and minorities in their top management as in the population overall."

Slider from 1 to 7 ( $1=$ "completely disagree"; 7 = "completely agree" $)$ 